Running head: GENRE ANALYSIS OF SCHOOL SHOOTERS' NOTES

\author{
"I'm NOT A MONSTER": \\ A Corpus-Based Genre Analysis of School Shooter Notes
}

By

\title{
Kathryn Carreau
}

A thesis submitted to the Faculty of Graduate and Postdoctoral Affairs in partial fulfillment of the requirements for the degree of

Master

In

Applied Linguistics and Discourse Studies

\section{Carleton University \\ Ottawa Ontario}

(C) 2019

Kathryn Carreau 


\section{Glossary}

Communicative Event: "an event in which language...plays both a significant and an indispensable role.” (Swales, 1990. p. 45)

Communicative Purpose: The main goal fulfilled by a text (Swales, 1990).

Contagion: The notion that perpetrators of a crime draw influence from previous perpetrators of the same crime.

Discourse Community: A community linked by shared goals and values, sharing a common mode of communication (Swales, 1990).

Focal discourse community: Discourse communities with a wider reach (i.e., across a region, nation, or internationally) (Swales, 2016).

Genre: a community-driven, goal-oriented text type (Swales, 1990).

Key Word in Context (KWIC) search: A query performed in corpus linguistics software which provides a word in its immediate context (i.e., in this case, seven words to the left and right).

Lemma: The dictionary form of a word.

Move: A functional segment of a text (Swales, 1990).

Semantic Field: Groupings of words linked by a common semantic value

Silential relations: The unsaid, tacitly understood, components of a text (Becker 1995, as cited by Swales, 2016).

Stem: The underived and uninflected component of a word.

Step: A constituent part of a move.

Tokens (in corpus linguistics): Words in a corpus.

Types (in corpus linguistics): Unique spelling forms in a corpus. 


\begin{abstract}
The increasing incidence of school shootings in the United States has prompted researchers and policy-makers alike to pose questions about the intentions and actions of school shooters (e.g., Lankford, 2016). The scope of previous work has been limited due to a lack of access to perpetrators (i.e., due to their being incarcerated or deceased). This study seeks to access perpetrators' perspectives via an analysis of their written notes. A mixed methods design (Creswell, 2014) combining the methods of Forensic Corpus Linguistics (Coulthard, Johnson, \& Wright, 2017; Baker, 2006) and the English for Specific Purposes (ESP) approach to Genre analysis (Swales, 1981) probes the salient linguistic and discursive features represented within school shooters' written notes. Findings indicate the recurrence of generic structures and lexical selections suggesting that school shooters may have shared communicative goals. This study contributes new directions for multidisciplinary work in the study of texts written by violent offenders.
\end{abstract}

Keywords: corpus linguistics, corpus-driven, genre analysis, move-step, school shooters 


\section{Acknowledgements}

I want to extend my sincerest gratitude to those individuals without whom this thesis would have been impossible. To those who have provided me with help and support throughout the completion of this thesis, thank you. In particular, I would like to mention: my supervisors, Dr. Natasha Artemeva and Dr. Craig Bennell, to whom I am ever-grateful. Natasha Artemeva's consistent guidance throughout this project has been invaluable; she has provided me with prompt and thorough feedback at every step of this process, and spent many hours discussing with me to expand and build upon my ideas. Craig Bennell has shared with me his insights from the perspective of forensic psychology, which have allowed me to fully contextualize my research in a multi-disciplinary research area. The suggestions and resources he has provided have helped me to navigate unfamiliar concepts from his field of expertise. I would also like to thank Dr. Geoff Pinchbeck, who consulted with me on matters pertaining to corpus linguistics; with his guidance, this method has greatly contributed to the findings of this study. Additionally, I want to thank Professor Betty Samraj for serving as external examiner and for providing me with useful feedback. I also extend my gratitude to Dr. Michael Rogers, who served as the internal examiner, whose comments have also been greatly informative and useful.

Further, I express my gratitude to Ana Tavares Monteiro, who volunteered her time and effort to act as a second coder for this study. Her willingness to contribute to this study allowed for the completion of a test of inter-coder reliability ensuring the empirical strength of this work.

Finally, I wish to thank my parents, to whom this thesis is dedicated. Their encouragement has carried me through many moments of stress and self-doubt. They have supported me, not only throughout the completion of this thesis, but throughout my lifetime. 


\section{Table of Contents}

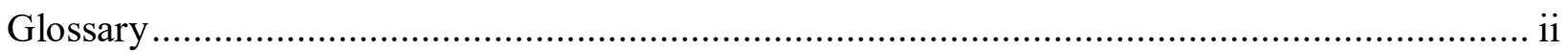

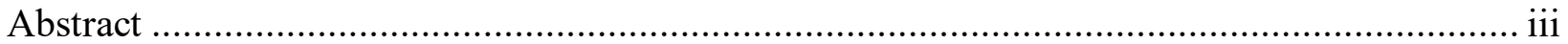

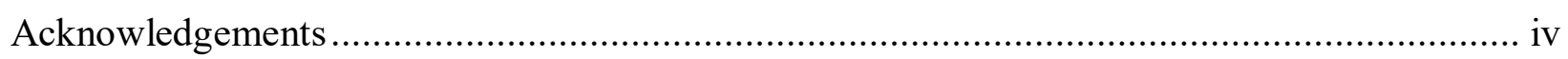

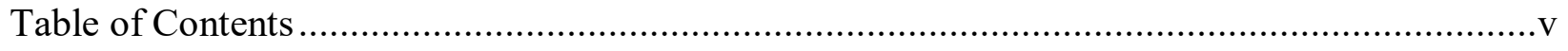

List of Tables ................................................................................................................ viii

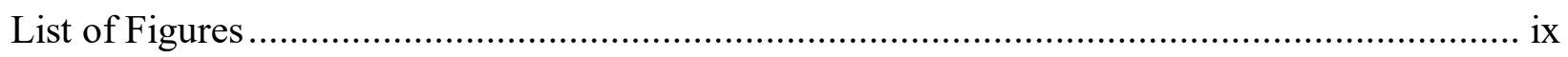

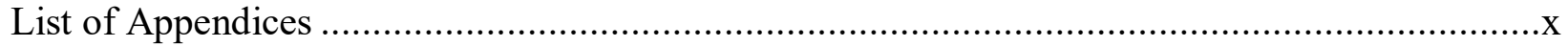

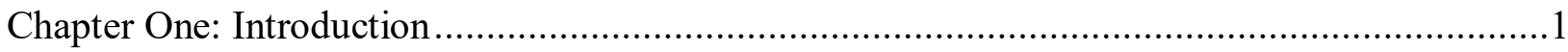

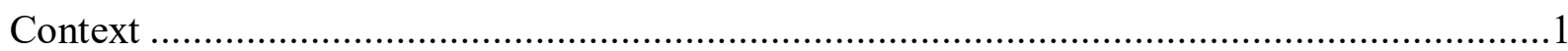

This study: Research purpose and questions .............................................................

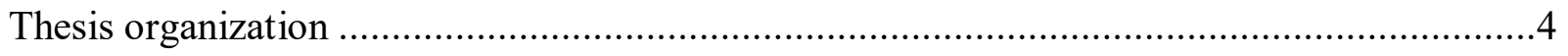

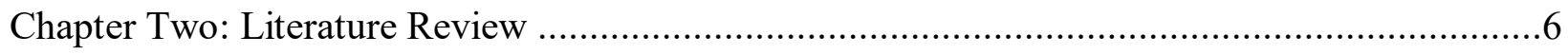

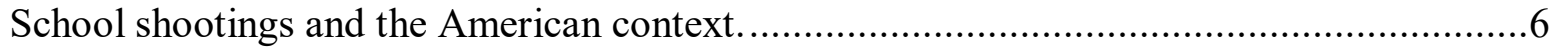

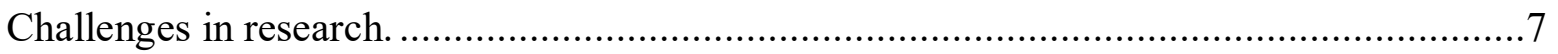

School shooters: a demographic description .......................................................

A popular myth: school shooters are mentally ill. ............................................... 9

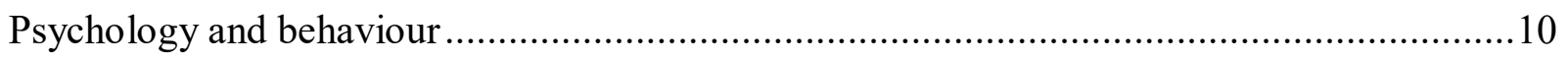

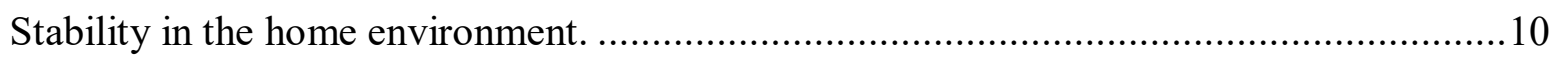

Bullying and the social environment....................................................................... 11

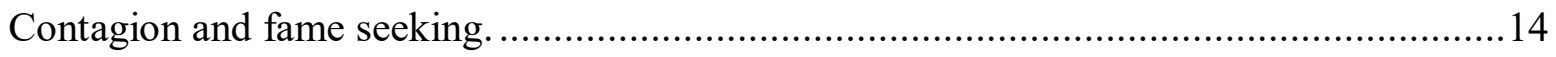

The written discourse of school shooters: why analyze language? ..................................... 14

Applied Linguistics and Discourse Studies: preliminary work. .................................. 15

Looking forward: solutions in progress. ......................................................... 18

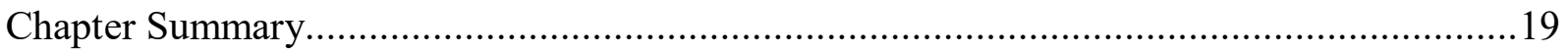

Chapter Three: Analytical and Theoretical Framework.................................................21

The ESP approach to genre - Key terms ..................................................................22

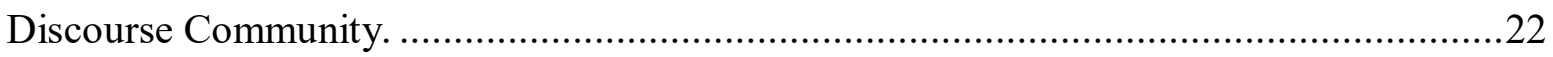

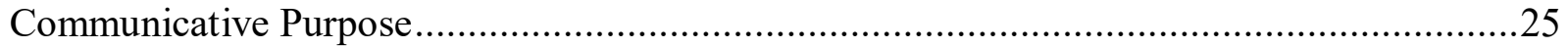

Defining Genre within the ESP approach .............................................................26

Theory in the analytical frame: Rhetorical Move-Step Analysis.....................................28 


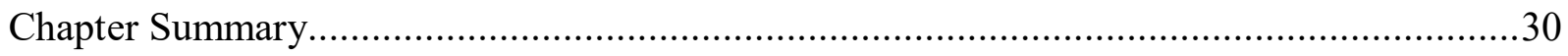

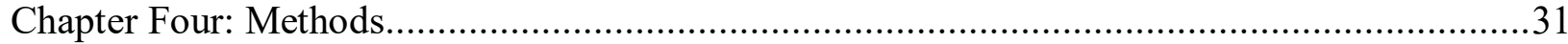

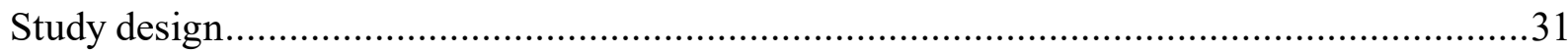

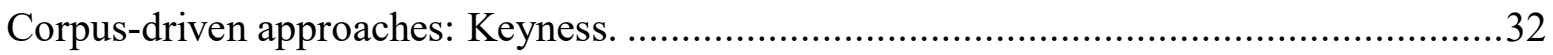

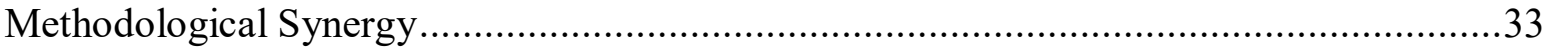

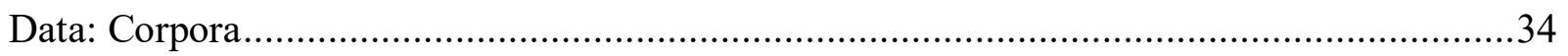

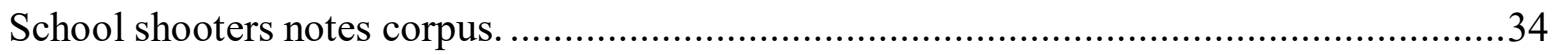

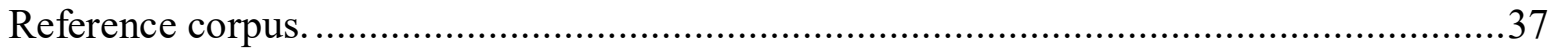

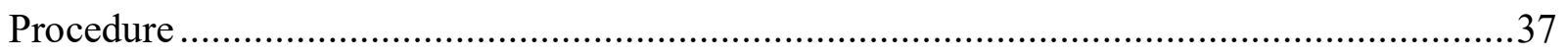

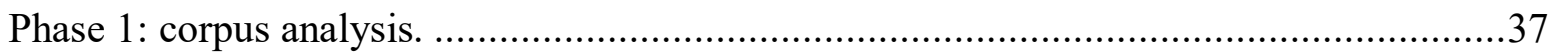

Phase 2: rhetorical move-step genre analysis. ................................................................ 39

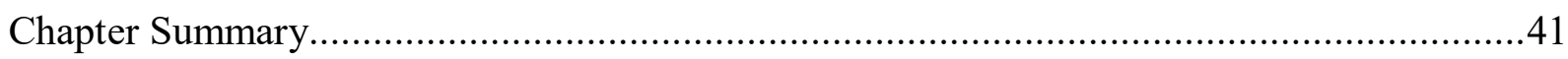

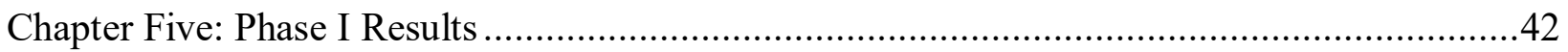

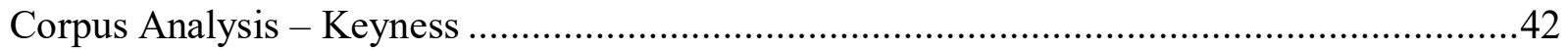

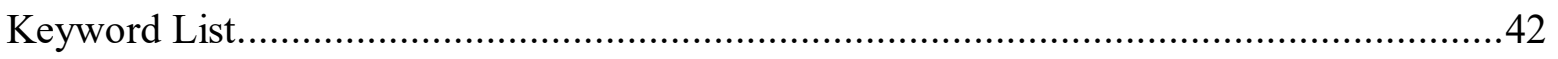

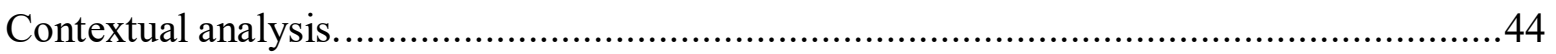

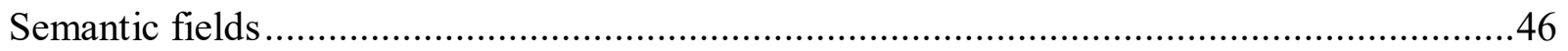

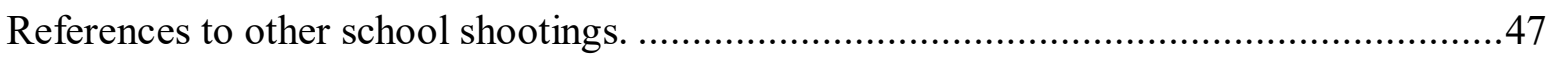

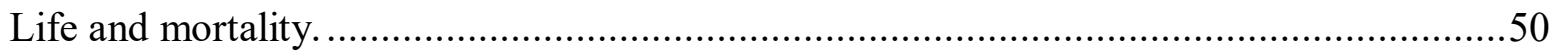

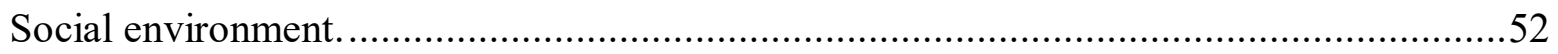

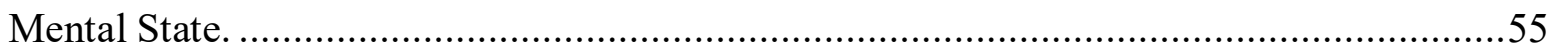

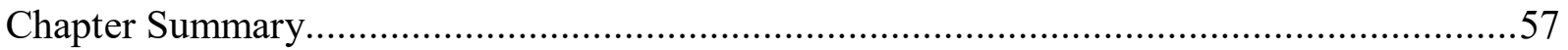

Chapter Six: Phase II Findings and Discussion ......................................................................

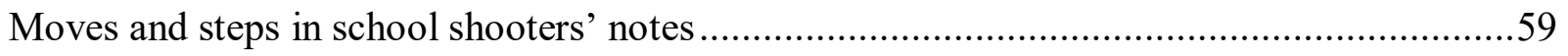

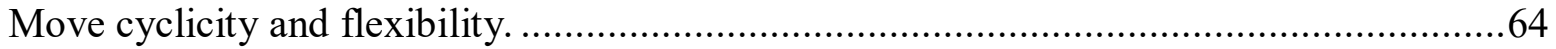

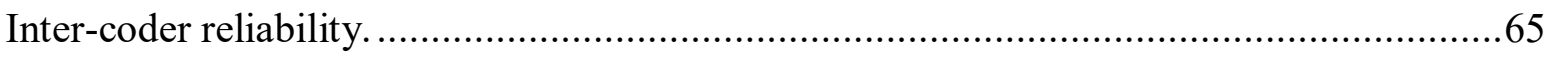

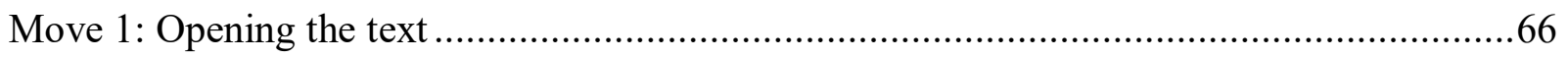

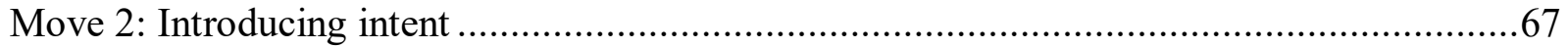

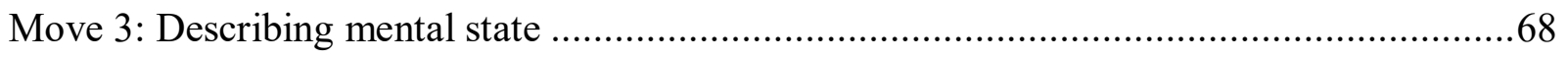

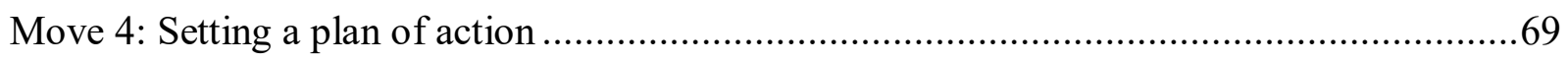

Move 5: Addressing friends and/or family ...................................................................... 


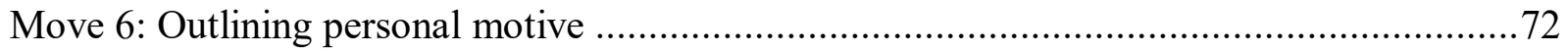

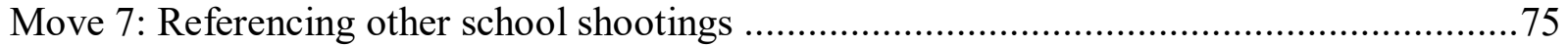

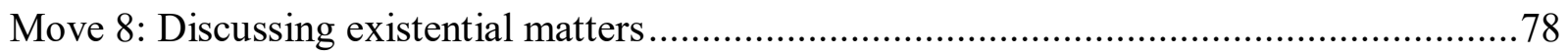

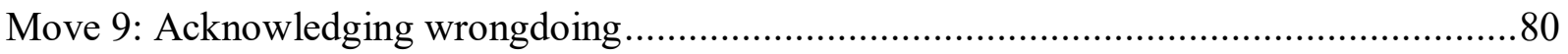

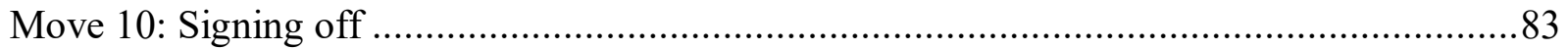

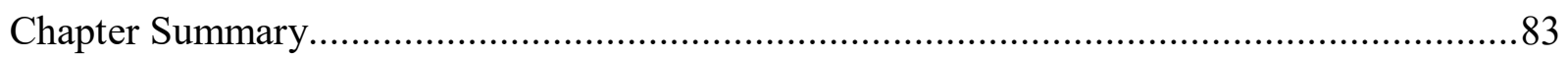

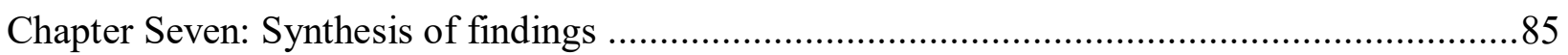

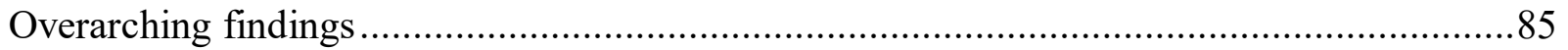

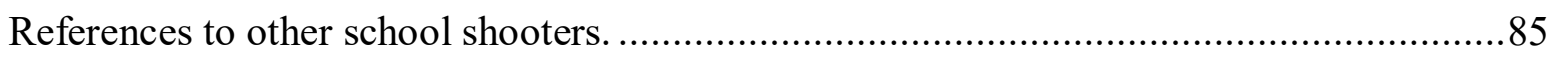

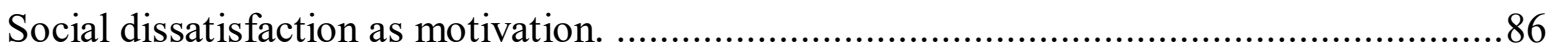

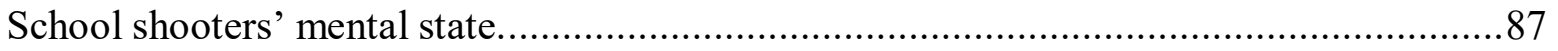

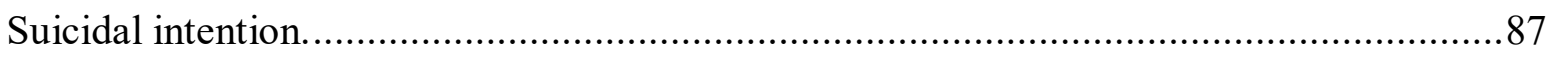

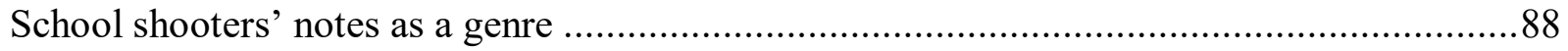

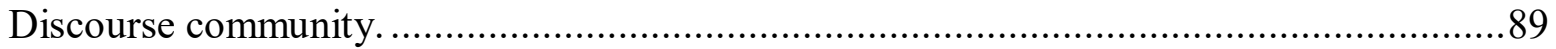

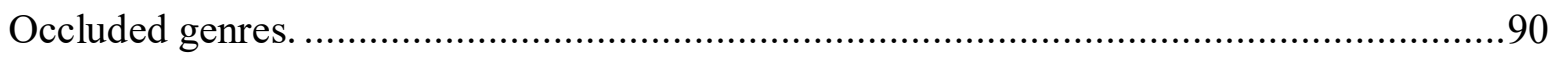

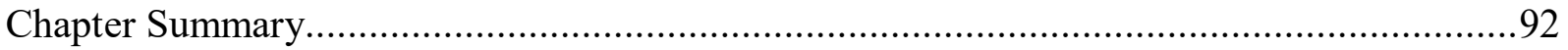

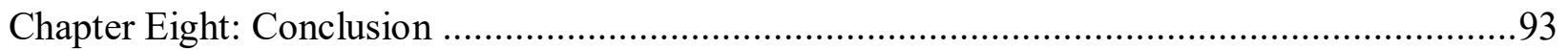

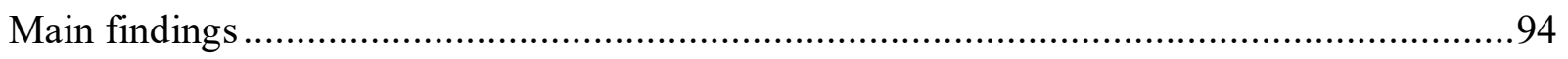

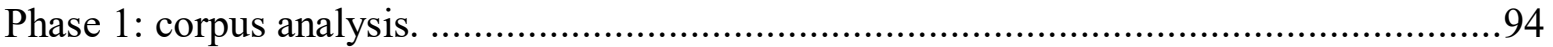

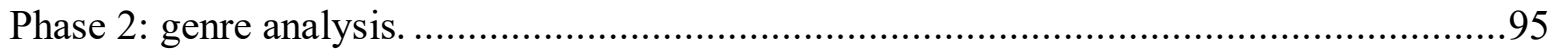

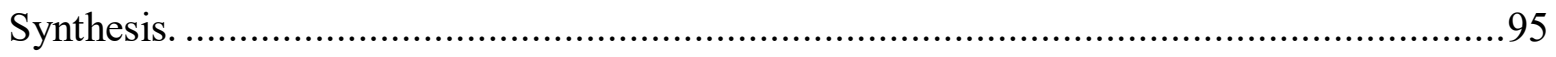

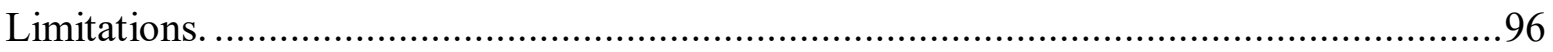

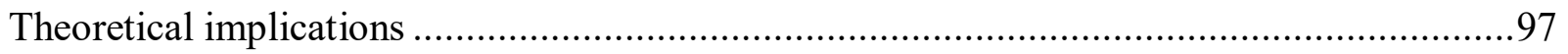

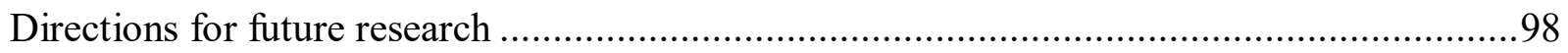

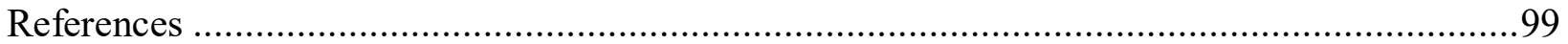




\section{List of Tables}

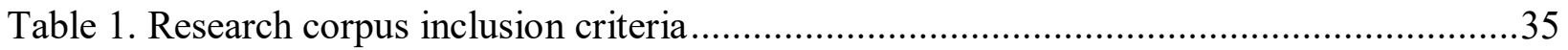

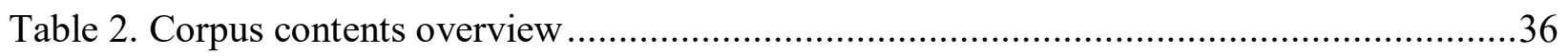

Table 3: Upper ten keywords in the school shooters' notes corpus....................................44

Table 4. Keywords: references to other school shootings ................................................48

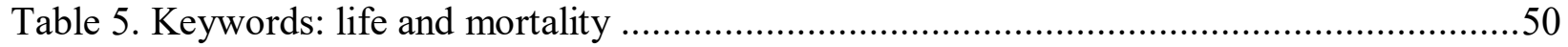

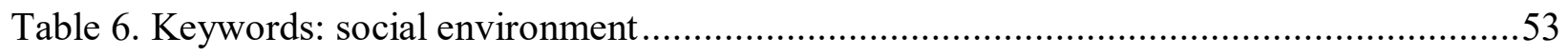

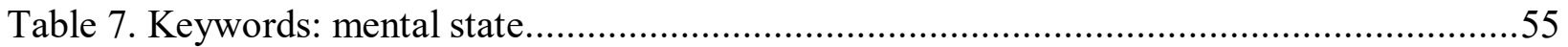




\section{List of Figures}

Figure 1. A schematic view of genre ...............................................................................28

Figure 2. CARS moves and steps example ....................................................................29

Figure 3. Explanatory sequential design - illustrated (Creswell, 2014) ...............................31

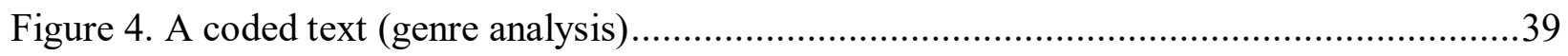

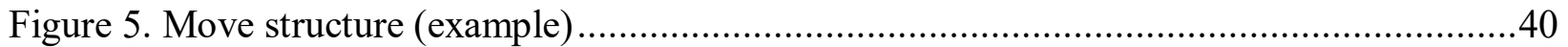

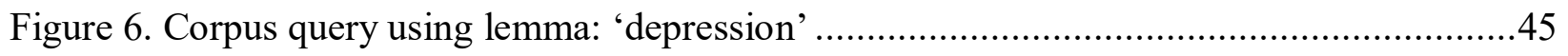

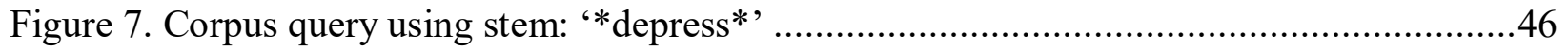

Figure 8. Corpus query: 'school' .....................................................................................53

Figure 9: A preliminary segmentation (Appendix A, note 3) ...........................................59

Figure 10:A fully segmented note (Appendix A, note 1) ......................................................60

Figure 11: Coded steps (Appendix A, note 3) ................................................................61

Figure 12: Move-step model of school shooters' notes $(* *$ obligatory, *conventional) .............63 


\section{List of Appendices}

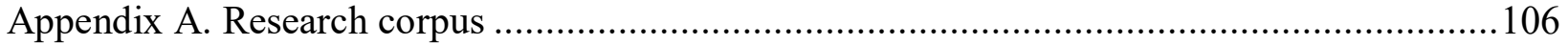

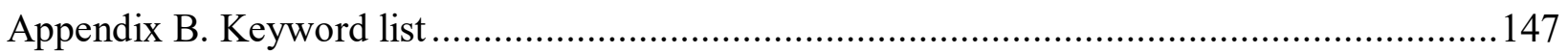

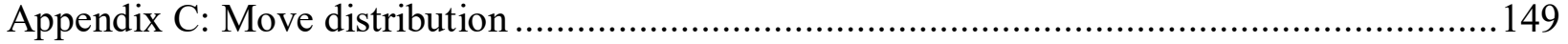




\section{Chapter One: Introduction}

This chapter serves to introduce the context surrounding the central issue considered by this study: school shootings. Further, a brief overview of the literature and theory of particular relevance to this study are presented. The chapter concludes with a summary of the organization of the eight component chapters of this thesis.

\section{Context}

Recent reports indicate that there have been approximately 500 firearm related incidents in United States schools in 2018 (The Gun Violence Archive, 2018). The rate of school shootings continues to increase, and the emergent consequences have been made apparent: such incidents have resulted in 81 victims in 2018, 29 of whom were killed (The Gun Violence Archive, 2018). This statistic excludes the plight of those who have lost teachers, peers, friends, and family. It also excludes the countless students who have experienced posttraumatic distress and subsequent academic decline as a result of their experiences (Beland \& Kim, 2014; Suomalainen, Haravuori, Berg, Kiviruus, \& Marttunen, 2011).

In early 2018, a shooting at Stoneman Douglas High School in Parkland, Florida, catapulted the issue of school shootings to the forefront of public discussion (Chuck, Johnson, \& Siemaszko, 2018; Reilly, 2018; Slater, 2018). The incident prompted students to organize March for Our Lives, a demonstration drawing crowds of approximately 800,000 to Washington D.C. (Reilly, 2018). Edna Chávez, a seventeen-year-old student who experienced the loss of her brother to gun violence, spoke of the public's desensitization to school shootings: "This is normal" she said, "normal to the point that I learned to duck from bullets before I learned how to read" (Epstein \& Amenabar, 2018, para. 16-18). 
The majority of literature on school shootings, which typically investigates the common factors among school shooters, has emerged from the field of psychology. It bears mentioning, however, that challenges in research (e.g., the inaccessibility of perpetrators due to suicide) have limited the findings that have emerged thus far. Some (e.g., Henry, 2009) have pointed out that a multidisciplinary effort in research is needed to identify effective means of reducing the prevalence of school shootings. Recently, approaches from Applied Linguistics and Discourse Studies (ALDS) have begun to be used with a similar aim (e.g., Turybury, 2016; Wing, 2017). Linguistic evidence is particularly useful for the study of school shooters as it can provide information from the shooter's perspective without elicitation from the researcher. For this reason, it is important to consider ALDS research on this topic in conjunction with the work that has been completed in psychology. By studying writing produced by school shooters, researchers may develop a better understanding of shooters' intentions. One of the key questions in such an analysis is if there are any commonalities or patterns in the written notes left by school shooters, and, if so, what information such patterns can provide to researchers.

The approach of particular interest to this study, because it allows researchers to focus on the purpose of discourse, is Swales' (1981) English for Specific Purposes (ESP) approach to genre. Genre, in this context, refers to a community-driven, goal-oriented text type. Genres allow discourse communities - that is, communities tied by common goals, assumptions, and valuesto fulfill their communicative goals. These communicative goals, termed by Swales as communicative purposes, are carried out linguistically. It is these linguistic pursuits of a discourse communities shared goals that make up genre. Swales' analytical approach to genrerhetorical move-step analysis_-investigates a text's rhetorical moves (i.e., the functional segments of a text) and steps (i.e., the segments which make up moves, and perform 
communicative actions). Move-step analysis has been applied by some researchers (e.g., Samraj and Gawron, 2015) in the investigation of forensic texts, such as suicide notes (e.g., Samraj \& Gawron, 2015). The analysis of suicide notes has revealed a complex structure of this genre, which may assist forensic researchers in uncovering the writer's reasons for, and justifications of, suicide (e.g., Abaalkhail, 2014; Samraj \& Gawron, 2015).

\section{This study: Research purpose and questions}

This study follows the investigations of suicide notes by Samraj and Gawron (2015) and responds to the call for multidisciplinary research (e.g., Henry, 2008), contributing to the areas of psychology, ALDS, and forensic linguistics. Given that linguistic evidence left by school shooters is accessible to researchers and can be analyzed from a genre perspective, the present research study investigates the notes written by school shooters prior to committing their crimes. The ESP approach to genre provides the theoretical and analytical frame through which the following research questions are considered:

1. What are the key, or most salient, lexical features occurring in the notes of school shooters?

2. How do school shooters discursively construct the reasons for and causes of their actions in notes they have written before the shooting?

3. Do school shooters' notes share a common goal and address similar audiences; that is, can they be viewed as a genre?

A mixed-methods design (Creswell, 2014) incorporating the quantitative approaches of corpus linguistics and qualitative genre analysis (Swales, 1990) is used for the purposes of this analysis. 
This study responds to the call for multi-disciplinary research, contributing to the areas of psychology, ALDS and forensic linguistics.

\section{Thesis organization}

This thesis consists of eight chapters, including the current introductory chapter. Each of the subsequent chapters provides and in-depth view of the key features of this study. Chapter two summarizes current literature on the topic of school shooters emerging from the fields of psychology and ALDS; in particular, this chapter touches on school shooters' behaviours, social environments, and writing. Chapter three lays out the theoretical and analytical framework underpinning this study_-Swales' (1981) ESP approach to genre — and further unpacks the definitions of key terms associated with this framework (e.g., discourse community, communicative purpose, and genre). Chapter four describes the methods applied in this study, which involve a mixed-methods (Creswell, 2014) design combining the quantitative approach of corpus linguistics and the qualitative approach of Swales' (1990) genre analysis. An analysis of school shooters' notes was conducted in two phases, the findings of which are presented and discussed in two respective chapters. More specifically, chapter five addresses the quantitative, corpus linguistics phase of analysis which identified keywords within a corpus of school shooters' notes, and chapter six explicates the findings of the second phase of analysis, which was informed by the results of the previous phase in order to conduct an analysis of the rhetorical moves and steps of school shooters' notes. Chapter seven considers these phases in tandem in order to synthesize the findings of the present research study; as such, this chapter points to the overall findings of the analysis. The final, eighth chapter of this thesis briefly summarizes the findings of the analyses of school shooters' notes, and goes on to describe the implications of such findings. This chapter also discusses some of the limitations presented throughout the 
thesis. Finally, the chapter concludes by providing directions for future research which might address some of these limitations, further elaborating upon the findings of this research. 


\section{Chapter Two: Literature Review}

A wide breadth of research has sought to make sense of school shooters' actions and motivations. These investigations are complicated by a unique set of challenges (e.g., difficulties gaining access to perpetrators) which, in many cases, require special consideration on the part of the researcher in choosing an appropriate methodology. In order to appropriately contextualize the present study, it is first necessary to touch on: (1) the background and contexts of existing research, (2) the study of psychology and the behaviour of school shooters, and (3) the study of the written discourse of school shooters. The literature discussed below is not meant to be comprehensive; rather, it is included based on its relevance to this study.

\section{Background and context}

School shootings and the American context. In a cross-national study of 171 countries, Lankford (2016) found that the US had an exceptionally large incidence of public massshootings. Approximately $31 \%$ of mass shootings had occurred on US soil, while Americans accounted for less than $5 \%$ of the global population. While school shootings have been known to occur worldwide, the disproportionate occurrence of such events in the US is noteworthy. The discussions presented herein primarily function with the American context in mind. This focus is not intended to minimize the significance of violent events in other nations; rather, it seeks to delve deeper into the high incidence of US school shootings. In a previous study (Lankford, 2015), mass shooters from the US were found to be significantly more likely to attack a school or workplace than perpetrators from other nations. American perpetrators were also found to be more likely to carry several weapons. It was theorized that American society's culture surrounding firearms is conducive to these trends, and consequently, the US has a higher 
incidence of school shootings. This combination of factors is indicative of a uniquely American problem that warrants consideration in its own right.

Challenges in research. There have been many attempts at formalizing our understanding of school shootings and their perpetrators. To date, psychology researchers have generally sought to investigate recurring variables in school shooters' environment, social lives, and personalities. The identified commonalities among perpetrators (i.e., pertaining to their social environments and personalities) — sometimes referred to as risk factors — are viewed as a means of understanding and preventing school shootings (O'Toole, 2000; Verlinden, Hersen, \& Thomas, 2000). This section provides a summary of current literature as a means of framing this study within the larger research context. That said, the completion of research on the subject of school shooters is not without its own set of challenges. As such, it is also necessary to briefly touch on some of the common difficulties arising in the study of school shootings.

As Langman (2014) points out, it is difficult to pursue research on this topic for a variety of reasons; the problem of a small research population, for example, is exacerbated by ongoing legal proceedings. Needless to say, cases in which school shooters commit suicide also leave limited information from which to draw findings. Problems have also been known to emerge from the realities of research in and of itself; the definition of a school shooting, for instance, is not agreed upon. As a result, chosen research populations may differ or overlap in a number of significant ways, ultimately varying researchers' findings and making meta-analyses less feasible. Another issue lies in insufficiently focused results: O’Toole (2000), for example, identified 47 descriptors that shooters had in common. Though informative, similarly broad results can limit our capacity for intervention with at-risk individuals, making the prevention of school shooting incidents an insurmountable task. Suffice it to say, the identification of risk 
factors has as of yet yielded little in terms of practical solutions for law enforcement and educational institutions, and continues to present researchers with significant methodological challenges. These difficulties point to a need for novel approaches at researching this topic.

The development of an established typology or model to organize the current literature on school shooters could be helpful in some respects, but may also come with its own limitations. Langman (2014), for example, developed a typology of school shooters' personality types with the aim of facilitating more focused research. Ten school shooters were evaluated and grouped into three types (1) traumatized (i.e, emerging from unstable and abusive home environments), (2) psychopathic (i.e., narcissistic and lacking in empathy), and (3) psychotic (i.e., suffering from schizophrenia or schizotypal disorders). However, as Langman (2014) points out, this typology leaves room for contradiction and overlap on a case by case basis.

\section{School shooters: a demographic description}

There are a number of demographic factors that seem to overwhelmingly account for the population of school shooters. First, it should be acknowledged that use of the term school shooter varies within academic literature. As some have pointed out, this can be problematic when searching for patterns observable across research (Langman, 2009). In some cases, school shooters are included within the overall population of mass killers (i.e., who prioritize killing large numbers of people in a single event). While it is true that these groups may in some cases overlap, the conflation of these groups fails to account for aspects specific to school shooters (e.g., choice of venue). However, the demographic factors presented in the following subsections — some which have emerged from research on mass killers or active shooters — are consistent with the literature on the subject of school shooters specifically. In consideration of these findings, it is justifiable that this study places its focus on a sample of perpetrators aligned 
with the most commonly represented demographics. The exclusion of anomalous cases is intended to allow for the investigation of overall trends while minimizing outliers. Further detail on the demographic criteria for inclusion within this study is provided in Chapter 4: Methods.

A study conducted by the Federal Bureau of Investigation (2013) identified several demographic criteria for school shooters. Of the studied school shooter cases, all the perpetrators had acted alone. In the case of High School and Middle School shootings, the majority of perpetrators were current students at the targeted institutions between the ages of 12 and 19 . Furthermore, a wide discrepancy between male and female shooters was identified; of 160 active shooting incidents between 2000 and 2013, only six had been completed by female perpetrators, and all but 2 had acted alone (Federal Bureau of Investigation, 2013). This trend holds true for shootings in educational contexts, of which only two shooters (of 39) were female. It is worth mentioning that both female perpetrators had carried out their acts in institutions of higher education, and that one of the female perpetrators was an employee of the institution, rather than a student. Findings such as these indicate that female school shooters may behave somewhat differently than male shooters. The disproportionate representation of male school shooters is not well understood. While several authors have speculated that threatened masculinity could be a contributing factor, there is little concrete evidence confirming or denying their claims (Kimmel \& Mahler, 2003; Larkin, 2010; Tonso, 2009). The role of gender and masculinity in school shootings, while apparent, is one that requires much further investigation.

A popular myth: school shooters are mentally ill. In considering the demographics represented in the population of school shooters, there is a final point that should be addressed; a commonly held belief that has perpetuated itself in the media is that the majority of school shooters are mentally ill. Based on current research, this is not necessarily untrue (Lankford, 
2017; Newman \& Fox, 2009; Verlinden et al., 2000). However, according to some researchers, although mental illness may be a factor in some school shootings, the instinct to portray school shooters as mentally ill may do more harm than good. Doing so may minimize the plight of victims of violence, perpetuate existing stigma against the mentally ill, and waste prevention resources (e.g., police efforts) on low-risk individuals (Knoll \& Annas, 2016). The link between mental illness and mass shootings is decidedly uncertain at this time. However, it is worth keeping in mind that only about $5 \%$ of violent crime is perpetrated by mentally ill individuals (Fazel \& Grann, 2006). As Knoll and Annas (2016) point out, there are factors which hold significantly more promise for the prevention of school shootings and intervention with at-risk individuals; social and fame-seeking behaviours, for example, are discussed further in this text. So, while mental illness may be a contributing factor, it may not necessarily be the most pressing topic for discussion.

That being said, the connection between school shooters and suicide is fairly clear-cut. It appears that mass shooters commit suicide at a rate higher than any other premeditated crime (Lankford, 2017). The likelihood of a school shooter being killed by his own hand, or by police, is exceptionally high (Lankford, 2017). Furthermore, in a study conducted by the United States Secret Service, $78 \%$ of school shooters had a history of prior suicide attempts or suicidal ideation (Vossekuil, Fein, Reddy, Borum, \& Modzeleski, 2004). A disregard for life and suicidal tendency, then, seem to be commonly observable in perpetrators of school shootings.

\section{Psychology and behaviour}

Stability in the home environment. Another common misconception is that school shooters have relatively stable home lives. It is not uncommon to hear acquaintances claiming disbelief because the shooter came from an ordinary family In many cases, however, this seems 
to be inaccurate. Dysfunctional upbringing seems to be another predictor of school violence, based on the results of various studies (Heitmeyer, 2013; Verlinden et al., 2000). Langman (2016), for example, compiled several indicators of unstable home life (e.g., parental absence, parental alcoholism or drug addiction, and abuse), and tabulated those that affected school shooters. Of the 56 school shooters included in the sample, only 10 were deemed to have stable home lives.

Bullying and the social environment. Perhaps one the most prevalent discussion on the subject of school shootings is in regard to its ties with bullying and social rejection. The report published by the United States Secret Service (mentioned above), for example, claimed that approximately two thirds of school shooters had expressed having been "bullied, persecuted, or injured by others prior to the attack" (Vossekuil, et al., p. 12). Further, several had experienced bullying long-term, which seemed to have contributed significantly to their actions (Vossekuil et al., 2004).

While the evidence may appear convincing at face value, some argue that the link between school shootings and bullying is oversimplified. A meta-analysis conducted by Sommer, Leuschner and Scheithauer (2014) demonstrated that in approximately 88 percent of school shooting cases, social dynamics seemed to have been a contributing factor. However, Sommer et al. point out that the issue is more complex than the binary question: was the perpetrator bullied? A minority of perpetrators had experience physical bullying $(\sim 30 \%)$ and romantic rejection ( $\sim 30 \%)$. Peer rejection $(53.7 \%)$ and conflict with teachers $(43.3 \%)$ appeared to have played a more significant role. Based on these analyses, it seems that certain aspects of the social environment may carry more influence on the outcomes of school shootings than bullying alone. Sommer et al. note that research should aim to gather detailed information on the 
perpetrator's social environment. Mears, Moon and Thielo (2017) came to a similar conclusion, claiming that the link between bullying and school shootings is not well supported by current scientific research. Although in some cases school shooters were found to have been bullied, the reverse was true in a number of cases as well (i.e., school shooters were found not to have been bullied). Perhaps Mears, Moon and Thielo's most compelling argument, however, is that the overwhelming majority of bullied youth never participate in a school shooting. Attempting to decrease the incidence of bullying, they claim, may not be likely to prevent future shootings. Mears et al. also point out that there is a need to "invest in a diverse set of approaches" (p. 952) in future research, to identify a more diverse set of factors contributing to school shootings.

To complicate matters further, there is counter-evidence to the claim that bullying causes school shootings. Langman (2014) highlights two important points reflecting on his investigation of 48 school shooter cases. First, despite the suggestion that school shootings occur in retaliation to bullying, only one shooter had actively sought out and killed his bully. Secondly, Langman notes that, in many cases, perpetrators have often been identified as being bullies themselves. The role of bullying as a motivation for school shootings is far from clear cut. That said, there does seem to be a link between social rejection, feelings of persecution, and violence (Heitmeyer, Bockler, \& Seeger, 2013; Langman, 2014).

As these findings indicate, there is a pressing need to investigate school shootings with attention to specific aspects of the social environment, which have to date been considered under the blanket concept 'bullying'. For instance, Heitmeyer et al. (2013) propose that experiencing a loss of control may be a decisive factor in school-based violence. The absence of recognition from parents, peers, and teachers seems a likely reason young people may experience a loss of control. In other words, when they find themselves losing control of their lives (i.e., through 
social, familial, or academic troubles), they may be prompted to seek control over others through violence. These observations are similar to those of a recent case study indicating that large student populations may exacerbate students' stress levels, and may be a predictor of school shootings. This was especially true in cases where the students had previously attended a smaller school with more supportive resources (Baird, Roellke, \& Zeifman, 2017). A possible conclusion to be drawn from this research is that the link between bullying and school shootings may be a misinterpretation of the perpetrators' broader social problems. It is plausible that shooters' described feelings of rejection and isolation may stem from the shooters' own behaviour (e.g., anti-social behaviour, and combative attitudes towards peers) and academic failings (e.g., skipping school, or failing classes) (Heitmeyer, et al., 2013; Langman, 2014; Langman, 2017b).

In a similar vein, some have speculated that a distorted perception of victimization, with an inability to acknowledge one's own fault, may be the result of narcissistic tendencies. According to Lankford (2017), whether school shooters' perceptions of victimization are accurate (i.e., the person has actually been put through hardship) or entirely fabricated varies by case. Although it may be unintuitive to describe school shooters - who are so often painted as bullied social outcasts, with low self-worth—as being narcissistic, some claim that it is exactly this quality that leads to their feelings of victimhood in some instances (Bushman, 2018; Lankford, 2017). Lankford (2017) summarizes this phenomenon as follows: "[narcissistic tendencies] can make them hypersensitive to perceived insults and ego threats, and more likely to respond with aggression" (p. 6). As such, it is worth investigating whether school shooters' perceived victimhood is caused by external factors (i.e., bullying, mistreatment by others, or academic failings) or internal factors linked to personality (i.e., narcissism, and poor social skills). 
Contagion and fame seeking. Bearing in mind the discussion of narcissism from the previous section, it seems a natural extension to discuss school shooters' attention and fame seeking tendencies. Past research has identified ties between media reporting and violence; specifically, research on homicide and suicide rates has indicated that media reporting seems to produce an increase in subsequent incidents. This phenomenon, referred to as contagion, has since been linked to the prevalence of mass killings, including school shootings (Towers, Gomez-Lievano, Khan, Mubayi, \& Castillo-Chavez, 2015). Lankford and Madfis (2017) suggest that media reporting practices may be partly responsible for inciting the violent behaviour of school shooters, who are seeking to gain attention by committing violence. It is also speculated that this may contribute to an increase in the severity of school shootings (i.e., by breeding competition between offenders, leading to higher death tolls).

That said, there are a lot of unknowns about the effect of contagion on school shootings beyond the causal relationship between killings and the media's reporting practices. For instance, rather than focusing only on the ways in which contagion influences the incidence and outcomes of school shootings, it may additionally be important to examine why this is the case. Langman (2017), for example, attempted to outline some of the motivations for copycat killings. Based on his findings, it seems that copycat killings may be motivated by a desire for fame and attention. Langman (2017) emphasizes that killers rarely imitated attack methodology (e.g., weapons used, planning process, etc.). Rather, it seems more likely that killers are drawn to imitate or deify those with whom they sympathize and relate.

\section{The written discourse of school shooters: why analyze language?}

The previous sections, which summarize a wide breadth of literature, have served to highlight, albeit indirectly, a key problem in research on school shooters. While there exists a 
wealth of information on school shooters and their motivations, there is a marked absence of tangible solutions for the prevention of school violence. The dearth of applicable research findings may be remedied in part by the introduction of new approaches to research. The analysis of language use is particularly relevant for the study of school shooters, given that linguistic evidence is plentiful. As Lankford (2017) describes, school shooters often make their intentions and motivations known via suicide notes, journals, manifestos, videos, and online posts. Although research has occasionally drawn insights from school shooters' written language (e.g., Dutton, White, \& Fogarty, 2013), it has rarely been investigated beyond its explicit content. As such, it is reasonable to suggest that further conclusions may be made with more in-depth analyses conducted from ALDS perspectives. Some research has attempted to make progress in this direction (e.g., Pfeifer \& Ganzevoort, 2016; Turybury, 2016; Wing, 2017). The methods and outcomes of this research, alongside their shortcomings and challenges, are discussed in the following sections.

\section{Applied Linguistics and Discourse Studies: preliminary work. As was mentioned} above, a criticism of previous analyses of school shooters' language lies in its sole focus on content. In a study conducted by Dutton, White, and Fogarty (2013), this type of approach is deemed an oversimplification, in that influencing factors (e.g., bullying, or mental illness) are being considered independently of one another. Dutton et al.'s analysis examined school shooters' writings (e.g., journals, manifestos) as a means of determining a score of negative emotionality (NEM). The traits measured by NEM — alienation, vengefulness, and aggressionare typically measured using a multidimensional questionnaire. In this case, however, the traits measured by NEM were considered based on their expression in the school shooters' writing. Dutton et al. indicated that the emotions expressed in the writings of school shooters were 
consistent with paranoia, as opposed to the low emotionality exhibited by psychopaths.

Furthermore, the authors pointed to the possibility that paranoia may cause personality changes over time. This is not dissimilar to the conclusions of psychologists regarding school shooters' unwarranted perceptions of victimization, presented above (Lankford, 2017). The viewing of one's self as persecuted bears some similarity to what Dutton et al. describe as paranoia (Heitmeyer, et al., 2013; Langman, 2014, 2017b).

In a similar study, Pfeifer and Ganzevoort (2016) investigated the prevalence of existential concerns (i.e., concerns pertaining to mortal existence) in school shooters' writing. The writings of seven school shooters were codified using the following subcategories: death, isolation, identity, freedom, and meaning. Findings indicated that expressions of death and isolation were the most common, and occurred in all of the texts. Pfeifer and Ganzevoort also noted that perpetrators described themselves in an excessively positive light (i.e., emphasizing that they view themselves as superior to others), hinting at possible narcissism. The combination of narcissistic traits with isolation and rejection, they claim, may contribute to a sense of having been supremely wronged, allowing them to justify their actions as killing "inferiors". This, again, resembles the conclusions presented in the previous sections above (Heitmeyer et al., 2013; Langman, 2014; Lankford, 2017).

The studies presented above provide a needed expansion of the existing literature in psychology. However, there are some points of which to be cautiously aware. In both cases, the authors' used several genres of texts in their analyses. This may be problematic, given that the content of the texts may rely heavily on the genre selected by the writer. For instance, the content of a short story would likely be in stark contrast to the content of a suicide note. It may be preferable that future studies of this kind consider a single genre for analysis or, at the very least, 
select texts that somewhat resemble one another. Nevertheless, the similarities in findings between the fields of psychology and ALDS demonstrate the potential for these fields to work in concert with one another. The congruence of findings from these fields is not a unique occurrence. Two other studies, conducted by Turybury (2016) and Wing (2017) demonstrated similarities as well: Turybury's (2016) work involved the case study of two school shooters' writings. The study made use of Critical Discourse Analysis - an approach viewing discourse as a vehicle for the propagation of ideology and power relations - as a means of studying the shooters' discursive expressions of power (Turybury, 2016; Van Dijk, 2001). The most important finding, Turybury claims, is a discursive commonality between the shooters: their selfdescriptions portrayed them as struggling for power and painted them in a superior light. They equated themselves to gods or martyrs, while their victims were reduced to animals, hedonists, or snobs. Again, the repeated trend of narcissism is made evident by Turybury's findings, alongside a described "struggle for power" which calls to memory the notion of "loss of control" (Heitmeyer et al. 2013).

Wing's (2017) research used a sample of writing from six perpetrators to conduct a discourse analysis of school shooters' use of attitudinal markers (i.e., linguistic markers which reveal the shooters' interpersonal perceptions). The shooters' self-perception, perception of others, and perception of others' opinions were examined diachronically via their attitudinal markers as a means of identifying attitudinal changes over time. Findings indicated that appraisals became gradually more self-focused, and were increasingly negative over time. Wing makes the connection between the self-focused texts and narcissism, noting that a negative selfimage is somewhat contradictory to the notion that school shooters are narcissistic. This is not unlike the Bushman (2018) and Lankford's (2018) assertions, which stipulate that despite feeling 
bullied and isolated, school shooters sometimes view themselves in an overly positive (i.e., superior) light. Similarly to Langman's (2014) claim that shooters rarely target those who have wronged them, Wing's study notes that appraisals of others are increasingly positive over time, shedding doubt on previous assumptions that school shooters are seeking vengeance on those who have done them wrong. In considering contradictions in the literature-such as the ones touched on here-it is not necessary to outright reject some of the hypotheses that have been previously suggested. Rather, these contradictions demonstrate a need for the refinement of current hypotheses that better account for variation and inconsistency within the population of school shooters.

Looking forward: solutions in progress. As was previously mentioned, the overall goal of researching school shooters' language use lies in the development of tools for the prevention of future incidents. There have, however, been modest successes in this pursuit. Neuman, Assaf, Cohen, and Knoll (2015), for example, propose the use of automatic text analysis. Their method is based in a vector space model of semantics, which posits that the meanings of words can best be determined by their common collocates (i.e., words with which they frequently co-occur). The authors provide the example of the word 'depressed', suggesting that in quantifying its common collocates (e.g., anxious, angry, or suicidal), it is possible to "measure the degree to which the feeling of being depressed is expressed within a text" (p. 2). As a means of testing this hypothesis, six texts written by school shooters were compared to blogs written by males of the same age (15-25 years). Findings indicated that shooters' texts scored significantly higher than the bloggers' in the dimensions of vengefulness, narcissism, and humiliation. These dimensions, the authors claim, could be used in the task of threat assessment. This method is meant to 
introduce increased efficiency to the process of investigating reports of threatening language, making better use of police resources.

Other research that could also be used for the purposes of prevention is represented by a study conducted by Lindberg, Oksanen, Sailas, and Kaltiala-Heino (2012), which identified a connection between the mode of communication (i.e., online posting) and the threat-risk (i.e., the likelihood that the writer would commit an act of violence). Their study of 77 adolescents — each of whom had threatened to carry out a school massacre - indicated that those who had expressed their threats online appeared to present a greater risk of actually committing a crime (i.e., they had clearer intentions, and had made preparations to act) (Lindberg et al., 2012). Although the functionality these types of tools — as described by Neuman, Assaf, Cohen, and Knoll(2015) as well as Oksanen, Sailas, and Kaltiala-Heino — are still in their preliminary stages, it seems that there may be a promising future for the development of preventative measures in ALDS research.

\section{Chapter Summary}

This chapter served to summarize current research on the topic of school shooters, by presenting a sample of work that is particularly relevant to the aims of this study. As this chapter demonstrates, there are many facts to consider when conducting this type of research. In particular, bearing in mind the specific challenges involved in such work - that is, dealing with the lack of access to perpetrators - is of primary concern when developing new plans for research. It is also noteworthy that research findings to date have shed light on a wide array of information on school shooters, pertaining to their psychology and writing. However, as was pointed out above, there is still much work to be done, particularly in the investigation of school shooters' written discourse. In sum, the literature covered in this chapter provides the foundation 
for the study presented in this thesis, and serves as a guide for the procedures and discussion of the remaining chapters. 


\section{Chapter Three: Analytical and Theoretical Framework}

This chapter describes the theoretical underpinnings of this study, which are situated within a school of genre developed in the ESP pedagogical approach. To date, the teaching of specialized varieties of English to non-native speakers has been the primary focus of ESP research; research touching on English usage in the workplace, academic contexts, and specialized fields (e.g., medicine, agriculture) is also quite common as it feeds into the development of relevant pedagogies. The ESP approach to genre - the chosen analytical and theoretical framework guiding this study_-was originally developed by Swales (1981) and was further expanded in his work Genre Analysis: English in Academic and Research Settings (1990). Swales' work is largely responsible for the rise in popularity of genre analysis in the frame of ESP research (Bawarshi \& Reiff, 2010). The constituent parts and rhetorical organization of a genre are demystified by this approach, allowing the researcher to better understand the role of texts as social actions (Cooper, 1989). Swales' analytical method facilitates the bulk of the analysis presented herein and, as such, is described alongside its associated theoretical frames.

Further in this chapter, in clarification of the theoretical considerations of this study, key terms in the ESP method are introduced and defined. Furthermore, the applicability of the ESP genre analysis to the study of specialized texts — specifically, forensic texts — alongside additional considerations of the method's fit to the study of forensic texts, is discussed in the latter portion of this chapter. This chapter serves to make explicit those aspects of the ESP genre analysis method which are applied in this study, with particular focus on those that require more careful consideration to suit the analysis of a specialized corpus (i.e., of school shooters' notes). 
As such, this chapter is intended not only to describe the ESP approach to genre analysis but to situate it within a new context of research.

\section{The ESP approach to genre - Key terms}

Properly describing the ESP approach to genre requires, first and foremost, the careful definition and unpacking of two key terms: discourse community and communicative purpose. These concepts inform Swales' (1990) definition of genre which, as mentioned above, functions as the theoretical underpinning of this study. The following subsections describe these concepts in detail, and clarify their usage in the definition of genre to be presented in the section to follow.

Discourse Community. Swales (1990), defines discourse community by contrasting it with another concept: speech community (i.e., a group of individuals with a shared set of linguistic norms) (Labov, 1966). According to Swales, speech communities share socially determined linguistic norms. The behaviours of discourse communities, on the other hand, are primarily guided by function. Further, he points out a difference in community membership: speech communities gain members by immersion within the speaking context, whilst discourse community members are linked by some manner of thinking, education, or qualification. The formal definition of discourse community provided by Swales in 1990 involves 6 defining characteristics:

1. "A discourse community has a broadly agreed set of common public goals." (p. 24)

2. "A discourse community has mechanisms of intercommunication among its members." (p. 25) 
3. "A discourse community uses its participatory mechanisms primarily to provide information and feedback." (p. 26)

4. "A discourse community utilizes and hence possesses one or more genres in the communicative furtherance of its aims." (p. 26)

5. "In addition to owning genres, a discourse community has acquired some specific lexis." (p. 26)

6. "A discourse community has a threshold level of members with a suitable degree of relevant content and discoursal expertise.” (p. 27)

In evaluating these characteristics in reference to the population of school shooters - and, more specifically, the population of school shooters who leave behind notes - it quickly becomes apparent that the concept of discourse community defined above is not well suited to describing this particular group. After all, school shooters do not have mechanisms of intercommunication among members or allow for participation and feedback. The latter three characteristics are not so evident either, although confirming whether they are applicable would require further investigation.

It would seem that the incongruence of these characteristics with the population at hand might be a fair point of criticism for the use of the ESP genre analysis approach in the study of school shooters' notes. It may be useful instead, however, to consider Swales' original definition of discourse community with some scrutiny. Note that, in revising these characteristics more recently, Swales (2016) has acknowledged that this definition is somewhat overly deterministic; he concedes that the actual manifestation of genres can be subject to some degree of flexibility in terms of discourse community. As Swales himself points out, an increasingly globalized world has changed the way we communicate. In particular, technological advancement has given rise to 
a number of influencing factors, for instance: family dispersion, modern modes of communication, and international trade. Communication and by extension, the production of discourse, do not require a shared local context as they once did. Swales proposes modifications to his earlier definition, considering first this issue of proximity: discourse community members may not be situated within a single, immediate context. Discourse communities with a wider reach (across a region, nation, or internationally), which he refers to as focal discourse communities, are linked by their central point(s) of interest. Further, Swales revisits the six characteristics discussed above, introducing some level of flexibility in the definition of discourse community:

1. A discourse community has a "potentially discoverable" set of goals. (para. 22)

2. A discourse community has mechanisms of intercommunicating among members, which may include digital modes of communication (e.g., texting, blogs, etc.) (para. 23).

3. A discourse community uses its participatory mechanisms to "initiate actions and activities" (para. 24)

4. A discourse community uses an "evolving set of genres" which are continuously "performed, re-performed, and refined" (para. 25).

5. A discourse community has "acquired and continues to refine" a specific lexis (para. 26).

6. A discourse community has an "explicit or implicit hierarchy or structure" determining community membership (para. 27).

As can be extrapolated from these modified criteria, Swales (2016) presents a changeable view of discourse community that is applicable to a wider scope of modern genres. He also goes on to 
add two additional criteria. First, he describes the use of what is termed "silential relations" (para. 29), borrowed from Becker (1995), within discourse communities. Silential relations are represented by the information contained within a text that is understood without explicit mention. In other words, discourse communities define themselves not only by what they say but by what they omit (i.e., information that does not require being spelled out explicitly). Swales' second addition is that discourse communities develop "horizons of expectation" (para. 31). A discourse community's roots - that is, in terms of its history and values - help to determine these expectations. In essence, discourse communities' expectations may vary widely on the basis of factors that are ultimately arbitrary. According to Swales, the meeting of these expectations helps to distinguish work that the discourse community deems good from that which it views as subpar.

From the perspective of Swales' (2016) modified definition of discourse community, the feasibility of considering school shooters' notes in the frame of the ESP approach to genre appears far less grim. In fact, the revised characteristics laid out by Swales help to open channels of enquiry within this study which provide a new view of school shooters, not as individuals, but as an imagined collective. As will be touched on in the later chapters of this thesis, school shooters notes - while composed in isolation - incorporate some aspects of communication (e.g., by quoting one another, or referring to each other by name). In reflection of this, it is interesting to probe, for example, the ways in which school shooters notes initiate actions within the discourse community.

\section{Communicative Purpose}

Swales (1990) describes communicative purpose as being the primary driving force of a genre, helping to direct the social action of a text in fulfillment of a discourse community's 
goals. Communicative purpose is exposed via the actions that are performed by a text's structural components. This subtle quality situates communicative purpose at the center of the ESP genre theory; Swales describes communicative purpose as privileged, in so much as it underlies a text's communicative actions.

The analysis of communicative purpose, however, is not in itself unchallenging. As Askehave and Swales (2001) discuss, it is challenging to identify a text's communicative purpose at the outset. In reflection of this difficulty, Swales (2004) clarifies his stance on communicative purpose: "It is sensible to abandon social purpose as an immediate or quick method for sorting discourses into generic categories while retaining it as a valuable long-term outcome of analysis"(p. 72). This clarification highlights the status of communicative purpose as being an outcome of genre analysis — a result to be pursued by the researcher in order to gain further insight as to a genre's communicative action. To briefly summarize: a genre's communicative purpose is centered within a text's social actions; in other words, it is by performing actions through discourse that texts' communicative purposes are fulfilled. As such, inquiries as to these actions allow the subtle aspects of communicative purpose and discourse community to reveal themselves more clearly.

\section{Defining Genre within the ESP approach}

In advance of discussing the ESP definition of genre, it is necessary to first consider the concept of the communicative event. According to Swales (1990), a communicative event is "one in which language ... plays both a significant and an indispensable role" (p. 45). Activities inherently involving linguistic communication — such as a conversation with a neighbour, or a post on social media — can be considered communicative events. Activities which may incidentally involve the use of language (e.g., a game of football), in contrast, do not constitute 
communicative events, according to Swales. The concept of communicative event - as well as the concepts of discourse community and communicative purpose-help to make up the definition of genre, described as follows by Swales (1990):

A genre comprises a class of communicative events, the members of which share some set of communicative purposes. These purposes are recognized by the expert members of the parent discourse community and thereby constitute the rationale for the genre. This rationale shapes the schematic structure of the discourse and influences and constrains choice of content and style. (p. 58)

In other words, a collection of communicative events is considered a genre provided it meets certain criteria; that is, it is produced within a discourse community sharing a central communicative purpose. The reverse, then - that a collection of communicative events will always constitute a genre - is inaccurate. It cannot be said that a collection of communicative events constitutes a genre in the absence of a discourse community.

Swales goes on to explain that genres may be totally indistinct based on form and content alone. Satire, for instance, is identifiably separate from the genre it mocks - not due to differences in content and form—-but due to its distinct communicative purpose (Swales, 1990). Communicative purpose, it seems, functions in such a way that is less overt, pointing to its "considerable heuristic value" (p.46). As such, the ESP approach to genre prioritizes purposes and community above form or content, classifying texts on the basis of structures that lie beneath the surface. As such, the definition of genre is framed by its interconnection with a discourse community; genres are, necessarily, produced in the pursuit of a discourse community's communicative goals. In essence, it is a discourse community's shared goals (i.e., their 
communicative purposes) that form their discourse, thereby facilitating the achievement of those goals. Figure 1 (below) presents a diagram that depicts the definition of genre as a chain of contact. The discourse community can be described as a base-level, foundational component of a genre, whilst communicative events are representative of its outward appearance.

Communicative purpose is situated at the center of the diagram, binding these concepts together and allowing for the construction of a systematically goal-driven product (i.e., a genre).

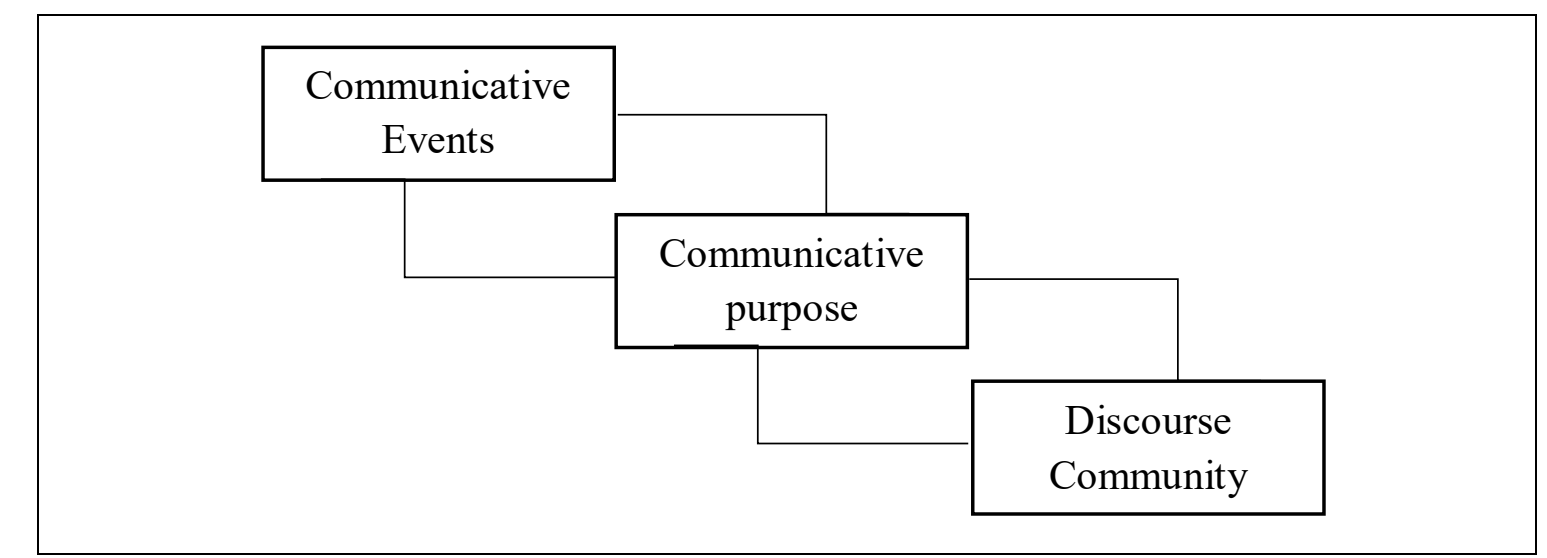

Figure 1. A schematic view of genre

Finally, in considering the definition of genre, it is important to reiterate that Swales (2004) has since revisited this definition, opting for a more flexible approach to the concept. He cautions that the strict adherence to such static definitions as his original one "can prevent us from seeing newly explored or newly emergent genres for what they really are" (p. 61). It is with this notion of possible flexibility in genre that this study addresses a unique collection of forensic texts.

\section{Theory in the analytical frame: Rhetorical Move-Step Analysis}

The ESP approach to genre makes use of an analytical method referred to as Rhetorical Move/Step analysis. This method serves to describe discourse genres in terms of their communicative function. Swales (2004) defines moves as "functional, not formal, unit(s)" (p. 229). That is, moves supersede grammatical or syntactic boundaries; they are classified based on 
their communicative force (Swales, 1990; 2004). As such, sentence, clause, and paragraph structure are irrelevant to the identification of moves. The identification of moves requires the consideration of a separate unit—-the step — which, in simple terms, helps to fulfill the move's function. Steps can be described as communicative actions, constructing moves which are themselves serving the text's overarching communicative purpose (Swales, 1990). In essence, it is the units of a text achieving a particular communicative function (i.e., moves and steps) that make up the structure of a text. In conducting a Rhetorical Move/Step analysis, the researcher typically produces a model illustrating the moves and steps present within a genre. Consider, for example, Swales' (1990) Create a Research Space (CARS) model of research article introductions. The figure below shows Move 1 of this model: Establishing a territory (p. 141).

\section{Move 1 - Establishing a territory}

Step 1 Claiming centrality

Step 2 Making topic generalization(s)

Step 3 Reviewing items of previous research

Figure 2. CARS moves and steps example

Moves and Steps within this model are headed with verbs (i.e., 'establishing', 'claiming', 'making', and 'reviewing'), helping to frame them as communicative actions, as opposed to features of form or content. The move-step model serves as a portion of the analytical framework of this study which, in Chapter 4: Methods, is described in full. The current subsection serves to explicate the place of move-step analysis' within the ESP approach to genre. The previous sections have emphasized the importance of texts as social action, and the role these play within discourse communities. Fundamentally, move-step analysis provides a means of representing 
these concepts through a formalized model. Furthermore, analyzing the moves and steps of a text then allows for the text to be compared with other, similar texts. A collection of texts that share a communicative purpose developed within a discourse community and sharing highly similar move-step structures can be classified as a genre (Swales, 1990).

\section{Chapter Summary}

This chapter laid out the theoretical foundations of this study, with particular attention to the key concepts underpinning the ESP approach to genre: discourse community, communicative purpose, and communicative event. The definitions of these concepts, and the changes they have undergone over time, have been described in a manner of clarifying the theoretical context within which this study's research corpus is considered. The concept of genre itself has also been defined, bringing together the key terms mentioned above. Finally, a description of move-step analysis (i.e., the analytical method which allows genres to be deconstructed and constructed) has been provided. Going forward, this information helps to frame the methods and findings discussed in the chapters to come. 


\section{Chapter Four: Methods}

This chapter provides an overview of this mixed-methods study. The design of this study — alongside its advantages in this particular research context - is discussed. This is followed by an in-depth discussion of the corpora used in this research, with particular attention to the inclusion criteria leading to their selection for analysis. In addition, illustrative examples and descriptions of the research tools, procedures, and data coding applied within this research are provided. Lastly, measures of inter-coder reliability underpinning the reliability of this study are also discussed.

\section{Study design}

This study makes use of a mixed-methods explanatory-sequential design. As described by Creswell (2014) "the intent of the explanatory sequential design is to begin with a quantitative strand and then conduct a second qualitative strand to explain the quantitative results" (p. 38) As such, this study was conducted in two phases: (1) a quantitative corpus analysis, which subsequently guided (2) a qualitative analysis of the texts. The results of both phases were then synthesized in order to draw wider conclusions which address the questions posed in this study. The application of explanatory-sequential design to this study is illustrated in Figure 3.

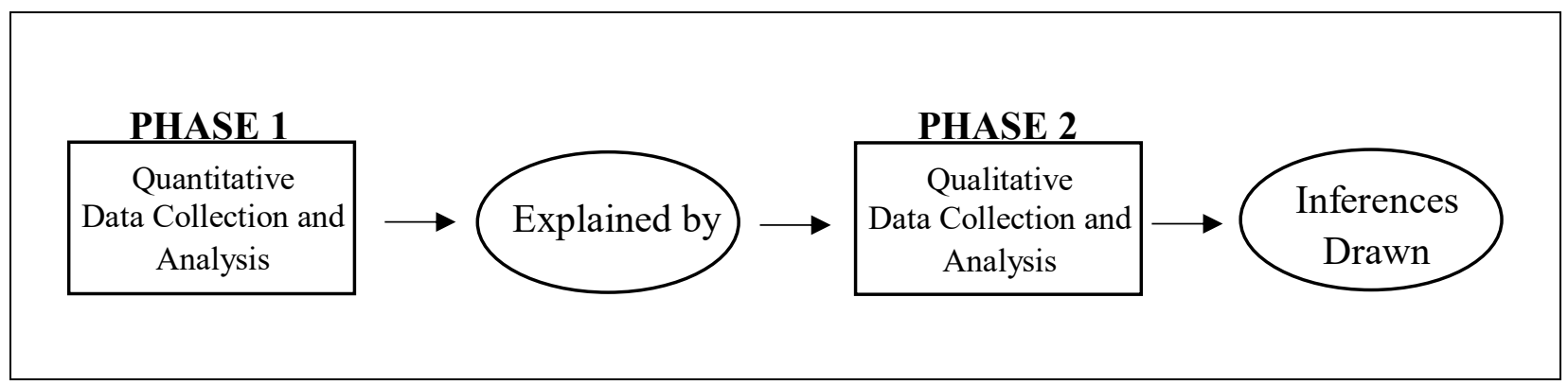

Figure 3. Explanatory sequential design - illustrated (Creswell, 2014) 
In the previous section, it was explained that the ESP approach to genre analysis places its focus on texts' context and purpose (Swales 1990). As such, the approach lends itself well to qualitative analyses of language. However, the application of a mixed-methods design which integrates corpus methods into the qualitative methods of rhetorical move-step analysis aims to introduce a multi-faceted approach which combines the strengths of quantitative and qualitative work.

Corpus-driven approaches: Keyness. In considering potential corpus-based approaches for the study of school shooters' notes, it became apparent that analyses based on frequency were not well suited to the data under study because the research corpus (i.e., of school shooters' notes) investigated in this study is relatively small, limiting the potential for statistical analyses based on frequency.

While the identification of high frequency words is useful in identifying trends in language usage, it may be ill-fitted in seeking those parts of a text that are particularly salient. As Scott (1997) points out, frequency measures may afford unwarranted significance to the overall occurrence of a given word. It is possible, for example, that high-frequency words serve a functional purpose (i.e., contributing to the grammar or formatting of a text) rather than contributing to a text's content (i.e., relaying the authors' intention or purpose in writing). Scott goes on to explain that it is the occurrence of words with unusual frequency-as opposed to high frequency — that is predictive of their salience. Unusually frequent words (i.e., key words), he claims, can be identified by comparison of the research corpus with a reference corpus (i.e., a large, general corpus). This approach, termed Keyness analysis, serves as the basis of the first phase of this study. 


\section{Methodological Synergy}

The application of a corpus-driven approach to the study of genre is not entirely new. A recent study conducted by Omidian, Siyanova-Chanturia, and Shahriari (2018) made use of a similar approach which used corpus methods to identify frequent multi-word expressions in research article abstracts. These multi-word expressions were then investigated within the scope of their communicative function, shedding light on the intricacies of the research article abstract as a genre. Although the analysis of Keyness has not been applied to the area of genre specifically, it has proven useful to other areas of research in the study of discourse. Lukac (2011), for example, compared 19 pro-anorexia blogs with a 140-million-word corpus of weblogs to facilitate an analysis in the frame of Critical Discourse Analysis (CDA) ${ }^{1}$. Key words were then organized semantically, helping to illustrate the ways in which ideology is constructed in the semantic field.

Though scarce in number, previous studies such as these point to the potential for a strong synergy between corpus methods and the study of written discourse. Genre studies has thus far placed a focus on academic writing (Bawarshi \& Reiff, 2010), allowing for the analysis of texts in tandem with the populations that produce them. Conversely, the investigation of specialized corpora — and of forensic texts in particular — requires an altered approach that is sensitive to the challenges of researching the writing of less accessible (or inaccessible) populations. Earlier in this text, I mentioned that accessing school shooters' perspectives has been particularly challenging, given that they are in many cases difficult to access (i.e., because

\footnotetext{
${ }^{1}$ An interdisciplinary approach to the study of discourse as a manifestation of social power relations (Fairclough, 1989).
} 
they are deceased or incarcerated). As such, the researcher must take special care to minimize the risk of misconstruing or obfuscating the texts' communicative purpose(s).

It is with this in mind that the synergy of Keyness analysis and Genre analysis comes to light. The application of Keyness analysis, in this case, generates key words independently of the researcher by use of software, thereby limiting the influence of the researcher's preconceptions at this state of analysis. However, it is worth noting that purely quantitative work would, in this case, omit some contextual information provided by the texts' overall discursive construction. For this reason, a subsequent genre analysis serves to address those features of a text which are not expressed by its constituent parts, but by its entire construction. In a sense, Keyness analysis reveals the foundational building-blocks of a communicative purpose, while Genre analysis assesses their function and role within a text's larger structure. The pairing of these analytical approaches — which function to complement each other-provides an empirically sturdy ground from which to draw findings. The use of a mixed-methods approach, then, provides a multifaceted view of communicative purpose.

\section{Data: Corpora}

The corpus-driven approach applied in this study required the use of two corpora: (1) a research corpus (i.e., of school shooters' notes) and (2) a reference corpus of general English (i.e., SUBTLEXus). Each of these corpora is described below:

School shooters notes corpus. This corpus is drawn from an open-access source: an online library compiled by Dr. Peter Langman (2019), which contains a wide variety of writings produced by school shooters. Documents included within the library are freely accessible to the public — via the website schoolshooters.info-for the purposes of education and research. Texts 
from this library were selected for inclusion in the research corpus based on their fit to the criteria presented in Table 1.

Table 1. Research corpus inclusion criteria

Note-like structure

Date of composition

Demographic Considerations
Texts included in the corpus shared a similar note-like

structure

Texts were written shortly before the crime

In order to minimize the influence of confounding variables, specific demographic criteria were selected for the inclusion of texts based on authorship. These criteria were selected on the basis of statistical likelihood, as described in the Literature Review above (O’Toole, 2000). As such, the texts' authors were required to meet the following demographic criteria:

- Age range: 12-30 years old

- Gender: male

- Language: Native or Native-like English proficiency

- Nationality: United States (Citizen)

As per the criteria presented in Table 1, 14 texts - authored by 12 individuals - were selected for the purposes of analysis, resulting in a 10,076 word (tokens) corpus of school shooters' notes. In two instances, authors had produced more than one text. In these cases, each text was included within the corpus and analyzed independently of the other. An overview of the corpus contents can be seen in Table 2. 
Table 2. Corpus contents overview

\begin{tabular}{lll}
\hline $\begin{array}{l}\text { Name } \\
\text { (Surname, First initial) }\end{array}$ & $\begin{array}{l}\text { Texts } \\
\text { (No.) }\end{array}$ & $\begin{array}{l}\text { Words } \\
\text { (tokens) }\end{array}$ \\
\hline Atchison, W. & 1 & 93 \\
Bartley, K. & 1 & 130 \\
Butler, R. & 1 & 67 \\
Castillo, A. & 1 & 777 \\
Cho, S. & 1 & 1,864 \\
Harper-Mercer, C. & 1 & 1,591 \\
Hribal, A. & 1 & 953 \\
Ramsey, E. & 2 & 355 \\
Reyes, J. & 2 & 317 \\
Romano, J. & 1 & 985 \\
Stair, R. & 1 & 2,944 \\
Ybarra, A. & 1 & 1,032 \\
\hline & Total: & Total: \\
\hline & $\mathbf{1 4}$ & $\mathbf{1 1 , 1 0 8}$ \\
\hline
\end{tabular}

It bears mentioning that the research corpus was subject to certain limitations which limit the scope of this study. Texts included in the research corpus (i.e., of school shooters' notes), for example, had occasionally been redacted in the process of transcription and, as such, some information cannot be accounted for within the scope of this study. For example, instances of profanity (i.e., swearing), in addition to multimodal information (i.e., drawings, images, formatting, etc.) had been redacted and, therefore, could not be taken into account as part of the analysis presented below. As a consequence, considerations of multimodality (i.e., communication practices across various non-textual visual modes [e.g., Kress, 2009]) were omitted from the analytical phases described below. Additionally, notes selected for inclusion within the research corpus were transcribed or converted from various formats (e.g., images, pdf) to a single, text-readable format (i.e., UTF-8) allowing for the analysis using corpus software. 
Reference corpus. The reference corpus serves as the basis for comparison of the research corpus. In order to properly identify salient language in the corpus of American school shooters' notes, it was necessary to identify a corpus that provided a diverse and representative sample of general American English usage. The SUBTLEXus corpus, compiled by Brysbaert and New (2009), is a 51 million word corpus of American English subtitles stemming from television series (16.1 million words) and films (34.9 million words). The SUBTLEXus corpus was selected as the reference corpus for this study as it serves as a strong baseline measure for American English word frequency. Given that the corpus consists of American English samples, it was well suited to comparison with the school shooter notes corpus. Furthermore, it was important that the reference corpus represent a range of formality. For instance, the corpus could not solely consist of workplace writing. It is likely that subtitles provide good representation of both colloquial and formal registers of language, making the SUBTLEXus corpus well suited in this respect as well.

\section{Procedure}

As was mentioned in the previous section, this study was conducted in two sequential phases: (1) a quantitative corpus analysis using the Keyness method (Scott, 1997), followed by (2) a qualitative analysis based in the ESP approach to Genre (Swales, 1981). Upon completion of both phases, the ensuing results were synthesized through the creation of a Move/Step model and a tabulation of key words. The following subsections provide a detailed summary of the component procedures of each phase, as well as the subsequent synthesis of results.

Phase 1: corpus analysis. This analysis was primarily conducted using an open-source software, Keyworder (Milička, 2012), which measures a word's salience by assessing its distribution within a research corpus and comparing it with its distribution in a reference corpus 
(Scott, 1997). Case sensitivity was set to 'off' to ensure that upper and lowercase usage (e.g., for reasons of grammatical prescription or emphasis) did not influence words' inclusion within the keyword list. Given that semantic content was the primary interest in assessing the corpus for Keyness, evaluating the use of capitalization (e.g., for reasons of emphasis) was unnecessary. The keyword list discussed herein was generated using Keyworder (Milička, 2012). The two corpora described in the previous section (i.e., the research corpus of school shooters' notes and the reference corpus, SUBTLEXus) were compared using this software, which was set to identify words with positive Minimal Ratio (MR) scores (i.e., words occurring at an equal or higher rate in the research corpus, as compared with the reference corpus). A positive MR score signals that a word occurs at a higher rate within the research corpus in comparison with the reference corpus. As such, this analysis primarily focuses on those aspects of writing that are deemed salient due to their unusually frequent usage in the research corpus as compared to the reference corpus. For this reason, Negative MR scores (i.e., words occurring at a lower rate in the research corpus, as compared to the reference corpus) were not considered for the purposes of this study. However, these aspects of writing may be useful for future projects of this kind, particularly in investigating silential relations (Becker, 1995), as discussed by Swales (2016).

The generated keywords are subsequently subject to a Key Word in Context (KWIC) search using LancBox (i.e., an open-source corpus analysis software developed at Lancaster University [Brezina, McEnery, \& Wattam, 2015]). This accounts for the contextual usage of key words in order to verify their semantic value within the research corpus. The wordlist is then coded based on individual words' semantic value, after which point they may be grouped into broader semantic fields (i.e., groupings of words linked by a common semantic value). For instance, words like 'friend', 'grandfather', or 'Lucy' (e.g., in reference to the writer's sister) 
might fall into the semantic field of social relationships, while 'love', 'hate', and 'sadness' would fall under the semantic field of emotional status. Words were assigned to a semantic field based on their semantic value in context (i.e., in the research corpus), so as to account for unusual word usages (e.g., metaphorical usage).

Phase 2: rhetorical move-step genre analysis. Following the completion of the keyword analysis, the corpus was modified in order to indicate key words and their respective semantic fields. In other words, key words were made distinct within the texts (i.e., highlighted), ensuring that a particular focus was afforded to the salient words within the corpus. The surrounding text of these highlighted words served as the preliminary segments from which the analysis was drawn; these blocks of text served as the starting point for the subsequent move and step segmentation as defined in Swales (1990). Segments were considered and coded in terms of communicative purpose. An example of this — drawn from the note of Kenneth Stuart Bartleycan be seen in Figure 4.

1.1 To who it may concern, Addressing recipient

1.2 Today is the last of my horrible days. The end. ${ }^{4.4}$ do have a

few request please leave my casket open at the funeral. Please

cremate me after the funeral. Spread my ashes across the mountains off of eagle bluff. ${ }^{4.1}$ There are only three people I have ever really love my dad my Papaw Ken + mama Polly.

2.1 I am always so sad now. I never feel joyous. ${ }^{4.4}$ I hope my room is left the same. ${ }^{2.2}$ If I had a razor blade I would leave a sample of my blood on this paper. ${ }^{2.1}$ One of the main parts of my depression 5.1 is Cristy. She bosses me around and dad loves her more than me. ${ }^{2.1}$ That drives me literally CRAZY.

9.1 THE END

Figure 4. A coded text (genre analysis) 
Subsequently, segments (i.e., steps) sharing a common overarching communicative purpose were grouped together in order to form moves. For instance, the segments 'THE END', 'Love,' and 'Kenneth Stuart Bartley' from the previous example (Figure 4) share a common communicative purpose (i.e., notifying the reader that the note is complete). So, in this case, these preliminary steps make up the preliminary move 'signing-off'. The completed preliminary move structure of the previous example can be seen in Figure 5.

Introducing intent

Addressing friends/family

Exposition of mental state

Addressing friends/family

Exposition of mental state

Outlining personal motive

Exposition of mental state

Signing off
To who it may concern,

Today is the last of my horrible days. The end.

I do have a few request please leave my casket open at the funeral. Please cremate me after the funeral. Spread my ashes across the mountains off of eagle bluff. There are only three people I have ever really love my dad my Papaw Ken + mama Polly.

I am always so sad now. I never feel joyous.

I hope my room is left the same.

If I had a razor blade I would leave a sample of my blood on this paper. One of the main parts of my depression

is Cristy. She bosses me around and dad loves her more than me.

That drives me literally CRAZY.

THE END

Love, Kenneth Stuart Bartley

Figure 5. Move structure (example)

The moves and steps presented in figure 5 are considered preliminary, in the sense that they are specific to a particular author; the designation of a move's obligatoriness relies upon its occurrence in multiple texts within the corpus. The criteria for obligatory moves and steps are described in detail in Chapter 6: Phase II Findings and Discussion. 


\section{Chapter Summary}

This chapter reported on the mixed-methods design utilized in this study, based on the explanatory-sequential design as described by Creswell (2014). Two corpora used in this analysis - a research corpus (i.e., of suicide notes) and a reference corpus (i.e., SUBTLEXus) are referenced and described. The two-phase methodology combining the analytical methods of corpus linguistics (i.e., Keyness analysis) and Genre analysis (i.e., the ESP approach) is described in full, alongside its analytical tools and procedure. 


\section{Chapter Five: Phase I Results}

This chapter presents the results of the first phase of this study — the Keyness analysis phase-and discusses observations informing the subsequent qualitative analysis phase. The first section of this chapter serves to describe the preliminary phases of analysis, which resulted in the generation of a keyword list. In addition, it outlines the process of paring down this list wherein words were, in some instances, excluded from the keyword list. The second half of the chapter discusses the major part of this analysis, which consists of an evaluation of the keyword list's semantic content. This part serves to identify recurring semantic fields (i.e., groupings of words sharing a common semantic value). These semantic fields are described in detail.

\section{Corpus Analysis - Keyness}

Keyword List. The keyword list discussed herein was generated using Keyworder (Milička, 2012). The two corpora described in the previous section (i.e., the research corpus and the reference corpus) were compared using this software, which was set to identify words with positive Minimal Ratio (MR) scores (i.e., words occurring at a significantly higher rate in the research corpus, as compared with the reference corpus). A positive MR score signals that a word occurs at a higher rate within the research corpus in comparison with the reference corpus. As such, this analysis primarily focuses on those aspects of writing that would be termed salient due to their frequent usage in the research corpus as compared to the reference corpus. Given that semantic content was the primary interest in assessing the corpus for keyness, evaluating the use of capitalization (e.g., for reasons of emphasis) was unnecessary.

The keyword list consisted of 1,744 individual words (i.e., types). An arbitrary cut-off was set after the first 150 words in order to allow each word to be assessed in context. Prior to conducting an in-depth analysis, some words were removed from the keyword list. In order to 
make the necessary exclusions, a cursory Key Word in Context (KWIC) search was conducted using LancsBox (Brezina, McEnery, \& Wattam, 2015). The KWIC search results show the queried word within its immediate contexts (i.e., in this case, seven words to the left and right). In addition, it provides information about the word's occurrence (i.e., its overall frequency within the corpus) and distribution (i.e., the number of texts that include it). Words that had only occurred in a single text were likely to be some characteristic of the author's idiolect (i.e., individual linguistic habits) or some unique feature of the text itself. Given that this analysis is aimed at identifying systematic usage across texts, such words were excluded from the final keyword list. Occasionally, semantic variants of a single word occurred in multiple texts; for example, two had used the word 'black' in their texts. The authors' semantic usages of the word, however, were different: one had used the word to refer to the colour of his clothing, while the other had referred to race. In such instances, words were considered separately, and were subject to the same treatment as described above (i.e., the word would be excluded if it had occurred in fewer than two texts). As such, the final keyword list consisted of 76 words. The finalized word list is provided in Appendix B and the upper ten words included in this list are presented in Table 6. 
Table 3: Upper ten keywords in the school shooters' notes corpus

\begin{tabular}{lrrrr}
\hline Type & Minimal Ratio & Freq. (reference) & Freq. (research) & Distribution* \\
\hline columbine & 9 & 61 & 9 & 4 \\
tapes & 6 & 661 & 12 & 2 \\
journal & 4.5 & 442 & 9 & 2 \\
shooters & 4 & 106 & 4 & 2 \\
seung & 4 & 96 & 4 & 2 \\
christ & 4 & 4578 & 16 & 2 \\
media & 4 & 1133 & 8 & 3 \\
world & 3.8 & 22770 & 38 & 6 \\
suicide & 3.666667 & 1729 & 11 & 3 \\
fucked & 3.333333 & 2431 & 10 & 2 \\
\hline
\end{tabular}

*Distribution in reference corpus

Contextual analysis. It is necessary to consider the contextual usage of keywords for two reasons. First, it is difficult to ascertain the semantic value of words when they are considered in isolation. For instance, the word 'victim' may be assumed to refer to the shooters' victims. Upon evaluation of the word in context, however, it has been established that this was not the case: the usage of 'victim' is more typically self-referential (i.e., the perpetrators considered their own positions as victims). The second reason pertains to the word's functioning within the text; it is impossible to say without context, for instance, that a word has been used metaphorically. As such, it is necessary to consider the greater context of use as a means of clarifying words' semantic value in this particular corpus.

Context has been considered via a secondary KWIC search, applying the method described in the previous chapter. However, contrary to the process described above, the secondary search has been conducted with attention to the semantic value of query results. Further, to facilitate this procedure, words have been stripped down to their uninflected or underived forms, stems (i.e. they were stemmed) in order to broaden search results. To illustrate 
the practicality of querying stems in comparison to the dictionary forms of words (i.e., lemmas), consider the following example: in investigating the contextual usage of the word 'depression', the simple query 'depression' was used, yielding the six results presented in Figure 6.

\begin{tabular}{|c|c|c|}
\hline $\begin{array}{r}\text { one of the main parts of my } \\
\text { to be working. on august } 29 \text { my } \\
\text { slow downward spiral of indescribable stress and } \\
\text { i feel down an abysmal hole of } \\
\text { one enormous concoction of stress, anger, hatred, } \\
\text { got confronted about anything in terms of }\end{array}$ & $\begin{array}{l}\text { depression } \\
\text { depression } \\
\text { depression. } \\
\text { depression } \\
\text { depression, } \\
\text { depression }\end{array}$ & $\begin{array}{l}\text { is cristy. she bosses me around and } \\
\text { will end permanently. i just want to } \\
\text { however, it was during all of this } \\
\text { in } 2013 \text { and i never climbed back } \\
\text { boredom, tiredness, and desire. in the end, } \\
\text { since then. after that happened i completely }\end{array}$ \\
\hline
\end{tabular}

Figure 6. Corpus query using lemma: 'depression'

Querying stems, in contrast, allows all inflectional and derivational variants to be returned as results. In this instance, an asterisk is used to signify an unknown variable (i.e., a wildcard) such as a prefix or suffix. In conducting a query of 'depression', then, the search term ‘*depress*' would be queried. As such, this query would return the result 'depression', in addition to other variants, such as: 'anti-depressant', 'depressing', and 'depressed'. In this particular case, this more than doubles the query's results (see Figure 7).

As the examples in Figure 6 highlight, the use of stems as opposed to lemmas allows for additional context to be considered in this analysis. In a similar vein, contracted words (e.g., 'I'm') have been considered alongside their uncontracted counterparts (e.g., 'I am'). This, again, allows for the collection of additional contextual information which introduced further depth to the contextual analysis. 


\begin{tabular}{|c|c|c|}
\hline $\begin{array}{r}\text { one of the main parts of my } \\
\text { april 20, 1999. i am feeling very } \\
\text { these days. i drown my sadness and } \\
\text { dark side. i can't even cry! the } \\
\text { to be working. on august } 29 \text { my } \\
\text { cigarettes, that's all. i am not really } \\
\text { slow downward spiral of indescribable stress and } \\
\text { i feel down an abysmal hole of } \\
\text { one enormous concoction of stress, anger, hatred, } \\
\text { but never knew i was this severely } \\
\text { in my family knew i was this } \\
\text { at it). once i started getting severely } \\
\text { got confronted about anything in terms of }\end{array}$ & $\begin{array}{l}\text { depression } \\
\text { depressed } \\
\text { depression } \\
\text { anti-depressant } \\
\text { depression } \\
\text { depressed } \\
\text { depression. } \\
\text { depression } \\
\text { depression, } \\
\text { depressed } \\
\text { depressed; } \\
\text { depressed } \\
\text { depression }\end{array}$ & $\begin{array}{l}\text { is cristy. she bosses me around and } \\
\text { these days. i frown my sadness and } \\
\text { with work, cleaning, and movies. still, it } \\
\text { i am taking doesn't seem to be } \\
\text { will end permanently. i just want to } \\
\text { just the fact that i want } \\
\text { however, it was during all of this } \\
\text { in } 2013 \text { and i never climbed back } \\
\text { boredom, tiredness, and desire. in the end, } \\
\text { and disturbed. the way i see that } \\
\text { if they say they knew, they're full } \\
\text { i managed to be cunning with it } \\
\text { since then. after that happened i completely }\end{array}$ \\
\hline
\end{tabular}

Figure 7. Corpus query using stem: '*depress*'

\section{Semantic fields}

Keywords have been organized by semantic field on the basis of the contextual analysis presented above. That is, words sharing a semantic link (i.e., a commonality in meaning) have been grouped into categories. In completing this phase of analysis, four recurrent semantic fields were identified, dealing with references to (1) other school shootings (e.g., Columbine, shooters), (2) life and mortality (e.g., die, heaven), (3) the perpetrator's social environment (e.g., school, family) and (4) the perpetrator's mental state (e.g., suicide, depression). These categories are described in further detail below.

In reading the results of this analysis, it should be noted that certain groups of words may at first appear to be unrelated. It must be emphasized that the semantic content of the words, for the purposes of this analysis, was ascertained in reference to its contextual usage within the school shooters' notes corpus. So, for example, it may appear unusual to group a word like 'documentaries' within the semantic field of "references to other school shooters". In general, 
someone might define 'documentaries' as something similar to "films providing factual reports of real-life events". In this particular corpus, however, 'documentaries' was used specifically to refer to documentaries on the topic of school shooters. For example, a shooter-in discussing the planned date for his actions - considers the possibility of committing the act on the anniversary of Columbine, but goes on to express some hesitation because he wants to watch "the documentaries that they will show on the history channel" (Appendix A, note 4). In other words, 'documentaries', in this instance, is embedded with an additional meaning (i.e., "about school Columbine") in addition to its colloquial meaning (i.e., factual accounts of real world events).

As a final note, it requires mention that the semantic fields considered here are not mutually exclusive of one another; it is sometimes the case that words could be attributed to more than one semantic field. For example, 'suicide' can be matched to the semantic field of life and mortality, as well as to the semantic field of perpetrator's mental state. Of course, to omit 'suicide' from either field requires that some aspect of its meaning be omitted from the analysis as well. As such, in such instances, words were grouped into both semantic fields. To avoid redundancy, words classified into two semantic fields are discussed only once. They should, however, be considered as equal members of both semantic fields.

References to other school shootings. The first recurrent semantic field observed in the keyword list is that of referencing other school shooters. Table 4 lists the keywords grouped into this category. 
Table 4. Keywords: references to other school shootings

\begin{tabular}{lrrrr}
\hline Type & Minimal Ratio & Freq. (reference) & Freq. (research) & Distribution \\
\hline columbine & 9 & 61 & 9 & 4 \\
shooters & 4 & 106 & 4 & 2 \\
seung & 4 & 96 & 4 & 2 \\
christ & 4 & 4578 & 16 & 2 \\
eric & 2.666667 & 2072 & 8 & 3 \\
harris & 2.5 & 756 & 5 & 2 \\
documentaries & 2 & 37 & 2 & 2 \\
\hline
\end{tabular}

Words have been found to both directly (i.e., naming of an event or perpetrator) and indirectly (i.e., by some relation with an event) refer to school shootings that had previously occurred. Most commonly, references were made to the 1999 Columbine Massacre, including the name 'columbine' itself. Other references to Columbine included the first and last names of one of the perpetrators (i.e., Eric Harris). Consider, for example, the following quote:

I would be nothing and this whole event would never occur if it weren't for Eric Harris and Dylan Klebold of Columbine Highschool. They worked hard to achieve freedom in heaven. I admire them greatly because they saw something wrong in the world and moved away the herd of sheep to do something about it. (Appendix A, note 7)

Further, as is mentioned in the previous section, one shooter makes an indirect mention of Columbine in expressing his desire to watch: "the documentaries that they will show on the history channel" (Appendix A, note 4). Of the six perpetrators who had made references to other school shootings, keywords pertaining to the Columbine Massacre had been mentioned by five of thirteen school shooters represented in this corpus. One of this group (Appendix A, note 6) also referred to Seung Hui Cho, the perpetrator of the Virginia Tech shooting in 2007. These references include the use of the first name 'seung', as well as an indirect reference (i.e., by 
quoting Cho's manifesto) using 'christ'. However, it is important to note that the words 'seung' and 'christ' would not have been included in the keyword list had Cho's own texts not been included within the corpus. As such, this semantic field may be more aptly called 'references to Columbine'. However, the occurrence of one additional keyword-'shooters'—precludes this possibility. Two of the aforementioned group of five had made references to other school shootings in a more general sense (i.e., they refer to the larger group of mass/school shooters without mentioning specific persons or events). In one case, the perpetrator described his fascination with mass shooters: "I have been interested in mass shooters for years" (Appendix A, note 6). Interestingly, this is heavily contrasted to the usage demonstrated by the other perpetrator: "How am I different from what the media says school shooters are?" (Appendix A, note 12). In the second case, the perpetrator attempts to separate himself from those who have committed similar crimes.

These findings are consistent with the conclusions of previous research which discuss the influence of contagion on the incidence of mass killings (Lankford \& Madfis, 2017; Towers, Gomez-Lievano, Khan, Mubayi, \& Castillo-Chavez, 2015). In chapter 2 (Literature review), it was discussed that perpetrators sometimes appear to be influenced by previous attacks. Similar to Langman's (2017) discussion of contagion, which asserts that school shooters sympathize and relate with one another, this corpus analysis highlights some shooters' interest in other mass shooters. However, the particular attention to the Columbine shootings should be evaluated in more detail, so as to better understand its disproportionate representation in school shooters' notes. While this notion has been discussed previously (e.g., Larkin [2009] discusses this phenomenon, pointing out that several perpetrators have cited Columbine as a source of inspiration), it is worth inquiring further as to shooters' preference for citing Columbine as 
compared to other mass shooting incidents. As such, the genre analysis presented in the following chapter delves deeper into this topic, examining the ways in which shooters discussed previous attacks.

Life and mortality. It should come as no surprise that in anticipation of committing violent acts towards others - and, in certain cases, towards themselves - school shooters discuss the subjects of life and death. Several words on the keyword list are illustrative of this, as can be seen in Table 5.

Table 5. Keywords: life and mortality

\begin{tabular}{lrrrr}
\hline Type & Minimal Ratio & Freq. (reference) & Freq. (research) & Distribution \\
\hline suicide & 3.666667 & 1729 & 11 & 3 \\
lives & 3.2 & 6988 & 16 & 5 \\
life & 3.2 & 40248 & 48 & 8 \\
end & 3 & 13461 & 21 & 7 \\
heaven & 2.666667 & 2783 & 8 & 3 \\
die & 2.142857 & 13104 & 15 & 8 \\
commit & 2 & 970 & 4 & 2 \\
\hline
\end{tabular}

Prior to examining the usage of these words, it should be noted that there is significant cross-over between the keywords presented in this section and those that are discussed in the subsequent section on the semantic field of 'Mental State' (i.e., 'suicide', 'end', 'die', and 'commit'). These words will be considered as members of both categories but will be left for discussion in the upcoming subsection ('Mental State'). As such, the table above represents the complete set of words that were included within the semantic field discussing perpetrators' discussions of life and mortality, but only a selection of these are discussed in this subsection.

First off, we examine the usage of the word 'life'. In some instances, 'life' is used in the metaphysical sense; it refers to life as a state within which conscious beings collectively exist. 
For example, one shooter states: "Good-Bye and good luck in life" (Appendix A, note 12). Another writes: "That [in reference to posting online] has been my only joy in life" (Appendix A, note 6). However, in some instance, 'life' is used in reference to specific beings. In order to properly contextualize this usage, it is necessary to momentarily draw attention to a keyword that is not included within the list above: the possessive pronoun 'my'. The occurrence of this word is highly frequent, with 161 occurrences of 'my' within the research corpus, distributed amongst eleven of the thirteen texts that included it. To better unpack the usage of 'my', it was necessary to further narrow the query results. As such, the frequent collocates (i.e., words co-occurring with the searched word) occurring immediately to the left or right of 'my' were examined. Of particular interest was the frequent collocation of the word 'my' with the word 'life'. In fact, the string 'my life' had occurred 22 times within the corpus, demonstrating that nearly half of the occurrences of 'life' within the corpus were shooters' references to their own lives. In many cases, 'my life' was used to describe the shooters' perceived injustices or hardships: "Are you happy now that you have destroyed my life?" (Appendix A, note 5); “Today I will get revenge on the students and teachers for ruining my life" (Appendix A, note 11); "I've had issues for the majority of my life" (Appendix A, note 12). In other cases, they refer to suicidal intentions: "You have succeeded in extinguishing my life" (Appendix A, note 5); "Leaving behind everything good in my life and trading it for heaven" (Appendix A, note 7); "I've been conspiring to end my life for at least $4 \frac{1}{2} 2$ years." (Appendix A, note 13). The plural form of 'life' (i.e., 'lives') also appears on the keyword list. In contrast to its singular counterpart, however, 'lives' was used most frequently in reference to others. For example, one shooter states: "I greatly affected the lives of the families ruined" (Appendix A, note 3). Another discusses his intent for violence 
towards others: "I'm not just ending my life; I will be ending the lives of others as well" (Appendix A, note 13).

A final observation in considering school shooters' discussions about life and mortality pertains to the usage of the keyword 'heaven'. Two shooters use the word heaven, referring to their belief in a continued existence after death. The first states: "When I die I'm going to heaven" (Appendix A, note 12). The second claims that he is "leaving behind everything good" in his life and "trading it for heaven" (Appendix A, note 7). Although this particular usage was only observed in the writing of these two shooters, it may be useful to inquire as to how a belief in life after death may influence an individual's decision to take his own life. A belief in life after death may, for instance, remove a degree of finality from such actions. In the case of ending others' lives, this may also help the shooter to somehow justify his actions. These considerations are further probed in the analysis of genre, presented in the following chapter.

Social environment. As discussed in the second chapter (Literature Review), previous research on school shooters has examined the influence of peer and familial relationships on school shooters' actions (Heitmeyer, et al., 2013; Langman, 2014, 2017b). It is unclear, however, whether social issues stem from the perpetrators' environment (e.g., bullying, or lack of individualized attention at school) or are rather the result of personal difficulties (e.g., inadequate social skills, or academic failing) (Bushman, 2018; Lankford, 2017). Several keywords examined in this analysis pertain to this area of investigation, as can be seen in Table 6 . 
Table 6. Keywords: social environment

\begin{tabular}{lrrrr} 
Type & Minimal Ratio & Freq. (reference) & Freq. (research) & Distribution \\
\hline school & 2.111111 & 17220 & 19 & 10 \\
teachers & 2 & 577 & 4 & 3 \\
friends & 1.75 & 15407 & 14 & 6 \\
family & 1.666667 & 17958 & 15 & 6 \\
aunt & 1.666667 & 2811 & 5 & 2
\end{tabular}

First, consider the usage of words pertaining to the school environment: 'school' and 'teachers'. It seems that, in discussing the school environment, school shooters often point to their sense of dissatisfaction. In fact, in relaying their experiences at school, perpetrators words were overwhelmingly negative. For example, consider the KWIC results for 'school' included in Figure 8 .

\begin{tabular}{|rll|}
\hline then blow my brains out. Work sucks, & school & Sucks, life sucks. \\
evil shit I did but that fucking & school & drove me to this. I wont u \\
You did. You say mean things in & school. & That I'm gay, that I'm lazy, stupid \\
\hline
\end{tabular}

Figure 8. Corpus query: 'school'

The results for 'teach*' (i.e., the lemmatized form of 'teachers') demonstrate similar expressions of dissatisfaction. For instance, one shooter describes his peers and teachers as having "ruined [his] life". Another described his issues with school in greater detail:

All this was caused by the dehumanization of public school, when I go there, it reminds me why I am doing this. All public school is trash. Teaching is trash. Laziness teaching ecstasy. Selfishness teaching addiction. Dozens of teachers teaching 1200 students and almost all just want drugs, alcohol, sex, and/or money. (Appendix A, note 7) 
These results are perhaps unsurprising given the shooters' chosen venue for attack. It should be noted, however, that school shooters' social experiences appeared to be tumultuous in other aspects as well. The usage of 'friends' and 'family' for instance, demonstrated that many perpetrators felt isolated: "And here I am, 26, with no friends, no girlfriend, I was alone" (Appendix A, note 6); "I hated making friends in general" (Appendix A, note 13); "I am not like my family or friends at all. I don’t belong with them” (Appendix A, note 7); "I completely removed anyone who knew me personally off of my social media (family and friends); they were holding me back" (Appendix A, note 13).

This is not entirely universal, however, as some describe positive feelings towards family and friends. In certain cases, perpetrators also express remorse for their actions as they consider the hurt that they are causing their loved ones. "As with any crime, family will be at the centre of it all, something I wish was avoidable" (Appendix A, note 7); "To all other family I'm sorry" (Appendix A, note 12). In other cases, they express caring and love for their friends and family: "I love them all, even if we will never see eye to eye" (Appendix A, note 7); "Mom I love you" (Appendix A, note 12).

While it remains unclear on the basis of this analysis whether perpetrators' issues stem from the environment or personal difficulties (or, perhaps both), the results presented herein provide insight as to the perpetrators' own perceptions of their social environment. The findings indicate that in evaluating their social contexts, the school shooters represented within this corpus consistently report dissatisfaction. While these expressions of dissatisfaction are occasionally paired with expressions of affection towards friends or family, it is notable that all of the examples thus far demonstrate social dissatisfaction. In recognition of this, shooters' expressions of dissatisfaction with their social lives were considered more closely in the genre 
analysis. As the following chapter highlights, shooters' lack of social satisfaction makes up a considerable portion of the rhetoric contained within the school shooters' notes corpus.

Mental State. As has been discussed in the literature review for this study (Chapter 2), school shooters' mental health has been subject to much questioning by researchers. The general consensus, however, is that mental health is not necessarily a strong predictor of school shootings (Lankford, 2017; Newman \& Fox, 2009; Verlinden et al., 2000). That said, researchers have pointed to the strong correlation between school shootings and suicide (e.g., Lankford, 2017). It seems only natural, then, that this topic was strongly represented within the school shooters' notes corpus, and that the related subject of depression is discussed as well (see Table 7).

Table 7. Keywords: mental state

\begin{tabular}{lrrrr}
\hline Type & Minimal Ratio & Freq. (reference) & Freq. (research) & Distribution \\
\hline suicide & 3.666667 & 1729 & 11 & 3 \\
depression & 3 & 404 & 6 & 3 \\
end & 3 & 13461 & 21 & 7 \\
depressed & 2.5 & 813 & 5 & 3 \\
die & 2.142857 & 13104 & 15 & 8 \\
commit & 2 & 970 & 4 & 2 \\
\hline
\end{tabular}

As is mentioned in the "Life and mortality" section above, several words (i.e., 'die', 'end', 'suicide', and 'commit') were classified in both the semantic field of life and mortality, as well as the semantic field of school shooters' mental state. It was briefly mentioned that these words would be set aside for the time being. As such, the current section serves to revisit the discussion of words relating to suicide. First, consider the keywords 'suicide' and 'commit'. The keywords, without exception, are used by school shooters to discuss their plans for suicide. One shooter, for example, states: "I am going to buy a shotgun and I am going to commit suicide." 
(Appendix A, note 4) Few perpetrators, however, refer to suicide quite so explicitly. In substitution of this, some shooters make use of the verb 'die' to discuss their plans: "If things go according to plan, today would be when I die" (Appendix A, note 1). The keyword 'end' is sometimes used in a similar manner; one shooter, for example, writes: "this is how my life is meant to end" (Appendix A, note 13). What is particularly noteworthy about these indirect usages is the shooters' modified role within the sentence. To illustrate this, first consider the following sentence: "I am going to commit suicide" (Appendix A, note 4). In this case, the shooter places himself (i.e., 'I') in the agent role; that is, he positions himself as the exactor of the action (i.e., 'commit suicide'). Conversely, another shooter states: "I am going to die today" (Appendix A, note 14). In this case, the 'I' does not fulfill the agent role in this sentence; rather, the shooter has stripped himself of agency in the context of suicide, describing death as some incidental effect over which he bears no responsibility or control. In considering this evidence, it appears that school shooters use both direct and indirect means of describing their intentions for suicide. While the shooters' intentions remain clear in either case, the choice of one versus the other begs a question. As such, a question that is revisited in Chapter 6 is the following: How do school shooters view themselves as agents of action? In other words, do school shooters view themselves as being in control of their actions?

The final word for consideration in this chapter is 'depression'. As was mentioned at the beginning of this chapter, searching the corpus for instances of 'depression' using its stemmed form '*depress*' identified several derived forms within the corpus. As such, it is necessary to revisit the figure that was presented previously (see Figure 7, p. 46).

It appears, based on this contextual information, that shooters primarily make use of the two derivations: 'depression' and 'depressed'. In each instance, the shooters are referring to their 
own mental states. These words have a fairly low distribution within the corpus (i.e., occurring in four of thirteen texts), which may indicate that the discussion of mental state, outside of references to suicide, is not widely distributed within the corpus. Consider, however, that use of the words 'suicide' and 'commit' (described above) were also limited to a fairly small group (i.e., three of thirteen texts). References to suicidal intention, however, occurred more frequently by indirect means (i.e., using the word 'die' or 'end'). It is possible, then, that discussions of perpetrators' mental states may be subject to some similar phenomenon. That is, it is reasonable to suggest that school shooters may use indirect language to discuss matters of their mental wellbeing. It is not evident via the corpus analysis alone whether this is the case, however, the discussion of mental state should not be discarded outright on the basis of this corpus analysis. This topic will be revisited in the next chapter, wherein school shooters' indirect references to their mental states will be discussed. This may also be an interesting avenue for future research.

\section{Chapter Summary}

Several key points were made in this chapter. First, in considering school shooters' references to other school shooters, it became apparent that the most frequent manifestation of this phenomenon involved discussions of the 1999 shooting at Columbine. It is useful, in the frame of the second phase of analysis, to probe the other instances in which shooters refer to previous incidents. In addition to this, the findings indicate that school shooters appear to be dissatisfied with their social lives. While the root cause of this issue is difficult to ascertain on the basis of school shooters' notes only, this finding does support previous findings in this research area which point to social difficulties as a predictor of school shootings (Heitmeyer, et al., 2013; Langman, 2014, 2017b). Finally, in examining school shooters' discussions of life and mortality, as well as their discussions of mental state, this chapter demonstrates that many of 
these discussions might occur by both direct and indirect means. However, accessing the indirect means of discussing these topics requires a closer analysis of the texts in order to better understand this happening. As such, the following chapter discusses those aspects that corpus analysis is not able to access (i.e., indirect language use). The main goal of the following chapter, however, is to work from the findings presented herein with the aim of identifying the rhetorical moves and steps of school shooters' notes. 


\section{Chapter Six: Phase II Findings and Discussion}

This chapter presents the findings of the move-step analysis, which has been completed following the corpus analysis presented in the previous chapter. First, an overview of the movestep model developed for this thesis is provided, with notes on the patterning of moves distributed throughout the corpus of school shooters' notes. A second coder was recruited, in order to complete a test of reliability for the move-step model; this test of reliability is discussed briefly at the end of the first section of this chapter: Moves and steps in school shooters' notes. The remaining sections are designated to the in-depth discussion of each move and step's occurrence in school shooters' notes.

\section{Moves and steps in school shooters' notes}

As has already been discussed in Chapter 4 (Methods), the corpus analysis helped to guide the second, qualitative, phase of analysis. As has been stated in Chapter 5, the keywords were highlighted in the corpus prior to completing the genre analysis. To reiterate: these words initially served as a guideline that aided in segmenting the text into its meaningful components. As is illustrated in Figure 9, key words were indicated within the text (i.e., as represented by the bolded text). Subsequently, the surrounding text was segmented based on its phrase structure (i.e., most often this was determined by the presence of a verb and its subjects and objects).

Everybody that used to know me I'm sry but Omaha changed me and fucked me up. and the school I attend is even worse ur gonna here about the evil shit I did but that fucking school drove me to this. I wont $\mathrm{u}$ guys to remember me for who I was b4 this ik. I greatly affected the lives of the families ruined but I'm sorry. goodbye.

Figure 9: A preliminary segmentation (Appendix A, note 3) 
The remaining text was then segmented in a similar manner, as can be seen in Figure 11. The segments were examined in terms of their communicative action (i.e., the actions that they perform: steps) and coded accordingly. Segmented phrases containing key words were granted particular attention over the course of the analysis, and were afforded priority in determining the texts' communicative purposes. So, for example, the use of "I'm sry" in the note above was coded as 'expressing remorse'. The notes were revisited multiple times and adjustments made throughout the analysis. As such, if we revisit the note presented above (Figure 10), it is coded as illustrated in Figure 12).

Everybody that used to know me I'm sry but Omaha changed me and fucked me up. and the school I attend is even worse ur gonna here about the evil shit I did but that fucking school drove me to this. I wont $\mathrm{u}$ guys to remember me for who I was b4 this ik. I greatly affected the lives of the families ruined but I'm sorry. goodbye.

Figure 10:A fully segmented note (Appendix A, note 1)

The texts were examined in terms of their communicative purpose (i.e., the goals they are intended to achieve) and coded accordingly. Segmented phrases containing key words were granted particular attention in this portion of the analysis, and were afforded priority in determining the texts' communicative purposes. The segment containing the keyword "school" in the note above, for example, had previously been matched the semantic field "social environment". As such, the purpose was considered to be related to the more general social environment, as opposed to something more specific (e.g., school environment). In essence, this process allowed for the communicative purposes to be generalized more effectively between texts. The notes were revisited multiple times throughout the analysis to ensure consistency in coding, and adjustments made accordingly. 


\begin{tabular}{|c|c|}
\hline Addressing Recipient & Everybody that used to know me \\
\hline Expressing Remorse & I'm sry \\
\hline $\begin{array}{l}\text { Expressing dissatisfaction with immediate social } \\
\text { environment }\end{array}$ & $\begin{array}{l}\text { but Omaha changed me and fucked me } \\
\text { up. and the school I attend is even worse }\end{array}$ \\
\hline Recognizing consequences for actions & ur gonna here about the evil shit I did \\
\hline $\begin{array}{l}\text { Expressing dissatisfaction with immediate social } \\
\text { environment }\end{array}$ & but that fucking school drove me to this. \\
\hline Making final requests & $\begin{array}{l}\text { I wont } u \text { guys to remember me for who I } \\
\text { was b4 this }\end{array}$ \\
\hline Recognizing actions as harmful & $\begin{array}{l}\text { ik. I greatly affected the lives of the } \\
\text { families ruined }\end{array}$ \\
\hline Expressing remorse & but I'm sorry. \\
\hline Formulaic meta-commentary on note & goodbye. \\
\hline
\end{tabular}

Figure 11: Coded steps (Appendix A, note 3)

The cross-comparison of texts then allowed for a set of moves (i.e., segments of text fulfilling a communicative sub-purpose) and steps (the constituent parts of those moves) to be established. For example, the move 'acknowledging wrongdoing' is made up of three step: 'expressing remorse', which is seen in Figure 11, as well as 'recognizing actions as harmful' and 'recognizing consequences for actions'. Upon completion of the analysis, nine moves and thirty steps were identified within the school shooter notes corpus. Ten moves and 32 steps - which are presented and discussed in the following sections of this chapter bearing the same names-were identified as a result of the qualitative analysis of genre using the ESP approach developed by Swales (1990). 
Obligatory moves. The percentage of occurrence of each move was calculated in order to establish whether moves and steps were obligatory in the move-step model for school shooters' notes (see Appendix C). To calculate the percentage of occurrence, moves and steps were tabulated and counted upon their occurrence in a text. Whether a move occurred once or multiple times within a single text was not relevant to this calculation; rather, the calculation was based upon the moves' occurrence (or lack thereof) within each text. The occurrence of a move in $100 \%$ of texts indicates that it is obligatory. However, moves occurring in $66 \%-99 \%$ of texts are considered conventional. Moves occurring in fewer than $66 \%$ of the texts in the corpus were designated optional (Nodoushan, M., 2012). Note that one note (Appendix A, note 5) consisted of significantly different moves than the other notes in the corpus. This indicates that this notewhile written by a school shooter — may be part of a different genre (e.g., of manifestos). As such, this note was discarded from the analysis of genre and is not factored into the calculation of moves' occurrence. The constituent moves and steps of school shooters' notes are presented on p. 64, with indications for obligatory and quasi-obligatory moves. 
Move $1 * \quad$ Opening a dialogue

Step 1 Assigning a title and/or foreword

Step 2 Stating the date

Step 3 Addressing recipient

Move $2^{*} \quad$ Introducing intent

Step 1 Making reference (directly or indirectly) to intended act

Move 3* Describing mental state

Step 1 Referring to mental distress or illness

Step 2 Relaying intent for violence towards self

Step 3 Relaying intent for violence towards others

Move $4 * \quad$ Setting a plan of action

Step 1 Naming intended target(s) for attack

Step 2 Describing logistics of the act (i.e., time, location, preparation)

Step 3 Describing anticipation for the act

Move 5* Addressing friends and/or family

Step 1 Expressing love and well-wishes

Step 2 Expressing gratitude

Step 3 Describing others' imagined feelings

Step 4 Making final requests

Move $6^{* *} \quad$ Outlining personal motive

Step 1 Denying potential presumed motives

Step 2 Expressing dissatisfaction with immediate social environment

Step 3 Expressing dissatisfaction with society at large

Step 4 Expressing dissatisfaction with specific individuals

Step 5 Expressing dissatisfaction with self

Move $7 \quad$ Referencing other school shootings

Distancing self from other perpetrators

Step 1 Portraying self as unique (i.e., in reference to other perpetrators)

Step 2 Describing individual preferences and interests

Relating self with other perpetrators

Step 3 Expressing a fascination with other perpetrators

Step 4 Identifying with and idealizing the experience of other perpetrators

Step 5 Expressing a desire to imitate other perpetrators

Move 8* Discussing existential matters

Step 1 Discussing concerns of time and space

Step 2 Referring to death as an impermanent state

Step 3 Describing harmful actions as beneficial

Move 9* Acknowledging wrongdoing

Step 1 Recognizing actions as harmful

Step 2 Recognizing consequences for actions

Step 3 Expressing remorse (e.g., apologizing)

Move 10* Signing off

Step 1 Meta-commentary on letter

Step 2 Signature

Figure 12: Move-step model of school shooters' notes (**obligatory, *conventional) 
Move cyclicity and flexibility. In addition to considerations of moves and steps' obligatoriness, it is also necessary to discuss other aspects of their patterns of distribution throughout the corpus, the first of which is termed a move cycle. A move cycle refers to the repeated occurrence of a move within a text (Pho, 2008). So, for instance, move A may occur, followed by move B, after which move A may reoccur. This pattern occurs fairly frequently within the corpus of school shooters' notes. Consider, for example, the following sequence of moves, occurring in immediate succession (Appendix A, note 2):

Move 2: "I am always sad now. I never feel joyous."

Move 4: "I hope my room is left the same."

Move 2: "If I had a razor blade I would leave a sample of my blood on this paper."

A related variation in distribution is termed move flexibility, and refers to the possible divergence of moves from their ordered sequence (Bhatia, 1993). Move A, then, may occur before move B, but the reverse (i.e., Move B occurring before move A) is also possible. This is observable within the corpus of school shooters notes, as moves and steps often fall in and out of sequence. For instance, see the following passage (Appendix A, note 10):

Move 1: "Dear mom and dad,"

Move 8: "I'm sorry about all this"

Move 4: "because some of my family and friends hate me"

Move 5: "but I understand." 
As the example above demonstrates, moves and steps may in some cases occur in sequence (e.g., move 4 preceding 5), and may not in others (e.g., move 8 preceding move 4 ). In addition, this example highlights another aspect of move's flexibility: some moves may be skipped and revisited later, or may be omitted altogether.

While moves and steps are subject to variations in patterning throughout the corpus, it is worth noting that moves' distribution is still systematic in some instances. Certain movesnamely, move 1 and move 10 - are not subject to flexibility or cyclicity within the corpus. The remaining moves (i.e., 2-9) were fairly varied in their patterning. A close examination of moves' cyclicity and flexibility falls outside the scope of this study but would, however, be a valuable point of inquiry for future research.

Inter-coder reliability. As Dornyei (2007) points out, it is possible to conduct checks of reliability by recruiting a second coder, to separately code a portion of the corpus. In doing so, it is possible to evaluate the level of agreement and disagreement between coders. As per Dornyei's suggestion, the reliability of the coding scheme for the identification of moves and steps has been tested by recruiting a second coder. Training — which involved the collaborative coding of two texts - was provided to ensure that the second coder had a clear understanding of the coding scheme (i.e., the move-step model). Subsequently, two additional texts were coded in order to verify the reliability of the coding process. All texts were coded using NVivo, after which point a coding comparison query was used to calculate Cohen's Kappa coefficient. Cohen's Kappa has a value from -1 to 1 and the coefficient accounts for chance agreement: a value of 0 signals incidental agreement, (MacPhail, Khoza, Abler, \& Ranganathan, 2015). The query in NVivo yielded a Cohen's Kappa coefficient of 0.73 , indicating that there was a satisfactory level of agreement between coders. It should be noted that in this case, the test of 
inter-coder reliability was only applied to the analysis of genre. However, future studies of this kind may opt to incorporate inter-coder reliability tests at the first phase of analysis (e.g., in assigning key words to semantic categories).

\section{Move 1: Opening the text}

The first move for discussion is that of introducing intent. This move occurred in 10 of texts and can be described, in simple terms, as being the text's opening statement. This is somewhat similar to Samraj and Gawron's (2015) analysis of suicide notes, in which move 1 is identified as 'addressing recipient'. However, the goal of the initial move in school shooters' notes is not only to address the recipient, but more general: this move signals to the reader that the writer has information to relay. In simple terms, move 1 could be summarized by the following statement: 'I have things I want to say before I do what I am planning to do'. In some cases, this statement is further qualified as follows: 'this is when I am saying these things' (i.e., the date of writing) and 'I want to say these things to the following people' (i.e., the intended addressee). Bearing this in mind, move 1 can be divided into three steps. The first two steps are fairly self-explanatory. Step 1, Assigning a title and/or foreword, involves the inclusion of a title at the notes' opening. For example, one shooter includes the title "RAGNAROK" (Appendix A, note 7). This may also be accompanied or substituted by a foreword. One shooter, for instance, titles his note "Life's Fantasies" but first includes a foreword: "No cuss words or profanity is used." (Appendix A, note 4). Step 2 of move 1, Stating the date, indicates the date on which the note was written. This may include the date alone, as well as the day of the week, and the time of writing (e.g., Wednesday, March 29, 2006, 4:03pm). This step typically only occurs at the outset of the text. However, in cases where a note has been written over several days, dates are occasionally provided throughout. Next, consider the following examples of step 3: 
Step 3: Addressing recipient, for example:

"Dear mom and dad," (Appendix A, note 10)

"To who it may concern," (Appendix A, note 2)

As the above examples demonstrate, step 3 is used in some cases to refer to specific individuals (e.g., 'mom and dad') and in others to an inexplicit addressee (e.g., "to who it may concern"). A possible explanation for this variance might be, in the latter case, that the shooter believes his note will be shared with individuals whom he does not know (i.e., in the media, or to law enforcement). Hence, the shooter's note does not provide a specific addressee, but instead addresses whomever will end up reading it.

\section{Move 2: Introducing intent}

Move 2 is constituted of only one step, and occurs in 11 of 13 texts. This move addresses the shooters' reason for writing. That is, it states the actions he intends to carry out - a shooting-at the text's outset. Consider the following examples of step 1:

Step 1: Making reference to intended act

"What I did, this shooting" (Appendix A, note 10)

"If things go according to plan, today would be when I die." (Appendix A, note 1)

In step 1, shooters refer to their intended act, either directly (e.g., 'this shooting') or indirectly (e.g., 'things according to plan'). In Chapter 5, it was mentioned that indirect language was used when shooters discussed their intentions to commit suicide. This is observable in the second example presented above (from Appendix A, note1); the shooter describes his intentions for suicide inexplicitly (i.e., using 'die'), and only vaguely refers to his planned actions: "If things go according to plan". As such, the phenomenon observed in the keyword analysis - that school 
shooters use indirect language to discuss their intent for suicide — seems to sometimes occur as part of move 2 .

\section{Move 3: Describing mental state}

As was discussed in the previous chapter, school shooters discussed their mental statesin particular referring to suicide and depression — in the lead-up to their crimes. These types of occurrences make up in part the move of describing mental state. This move, which occurred in 8 of 13 texts, manifests itself by the use of some or all of the following three steps:

Step 1: Referring to mental distress

"I am always sad now. I never feel joyous." (Appendix A, note 2)

Step 2: Relaying intent for violence towards self

"Today is the last of my horrible days. The end." (Appendix A, note 2)

"If I had a razor blade I would leave a sample of my blood on this paper." (Appendix A, note 2)

Step 3: Relaying intent for violence towards others

"Today I will bring a god dam pistol and shoot you" (Appendix A, note 11)

"I just want to blow their faces off with a 12 gauge shot gun blast!" (Appendix A, note 8) Schools shooters' expose their mental states in the quotes presented above, by both expressing their difficulties with mental illness (i.e., 'referring to mental distress'), and by describing their impulses for violent actions towards themselves and others. Without completely restating the discussions on the use of indirect language presented in Chapter 5, it is worth pointing out that school shooters sometimes make use of indirect language when discussing violence (i.e., towards themselves or others). Why this is the case, however, is less than straightforward. In any case, the use of indirect language may be a valuable topic for further study which could provide insight as to the mindset of school shooters in anticipation of their crimes. 


\section{Move 4: Setting a plan of action}

By writing notes in advance of their acts, school shooters demonstrate that their crimes are premeditated. It comes as no surprise, then, that in certain cases these notes contain the details of school shooters' plans. Move 4-setting a plan of action-encapsulates these occurrences by the use of three steps, which occur in 7 of 13 texts. See the three steps below:

Step 1: Naming intended target(s) for attack

"One of the Big [expletive] is Mr. Ron Edwards, he should be there, I was told this will be his last year, but I know IT WILL BE HIS LAST YEAR."” (Appendix A, note 9)

"If I have time I will try to get my revenge on some of the guys I hate. The shit talkers at the Getaway! (Appendix A, note 14)

Step 2: Describing logistics of the act (i.e., time, location, preparation)

"I wait until the school buses are detected, then head out on foot disguised as a student." (Appendix A, note 1)

"I just need more ammo and I need to go to the church before I begin." (Appendix A, note 4)

Step 3: Describing anticipation for the act

"I cannot wait." (Appendix A, note 4)

“This is it! I can't believe I'm finally doing this! So exciting I'm jumpy. (Appendix A, note 14)

As the examples above highlight, school shooters occasionally provide information pertaining to the logistics of their attacks (i.e. the time, date, location, tools, etc.) as well as their intended victims. It may be useful to consider why school shooters do this; for instance, is this a means of preparing themselves for the crimes? This is plausible, especially in consideration of step 3 , in which school shooters express their anticipation. Or, conversely, is this a means of explaining their actions to the reader and, if so, what purpose does this serve? This brings to mind the issue of communicative purpose which - as mentioned in Chapter 3 - can be challenging to pinpoint. 
In many ways, it may seem that identifying the moves and steps of school shooters notes brings about more questions than answers. That said, the questions considered herein may provide future direction for additional cross-disciplinary research.

\section{Move 5: Addressing friends and/or family}

School shooters refer to their friends and family in their notes for a variety of reasons.

Overall, this move — addressing friends and family_accounted for 11 of 13 texts in the corpus. First, let us consider instances in which school shooters express positive feelings towards their loved ones:

Step 1: Expressing love and well-wishes

"There are only three people I have ever really love my dad my Papaw Ken + mama Polly.“"(Appendix A, note 2)

"I will send Anna an e-mail telling her how much I love and care for her." (Appendix A, note 4)

Step 2: Expressing gratitude

"Sue Hare has been the nicest person I've ever met cause she took both William and I and didn't get any money for it" (Appendix A, note 8)

"Mom I love you. You treated me like a King. Thank you for everything." (Appendix A, note 12)

In spite of the negative circumstances from which school shooters' notes emerge, school

shooters' notes often relay positive messages to the shooters' family. It is frequently the case that love and gratitude are expressed to family members and friends, even though school shooters do sometimes express ill feelings towards their family and social lives (as will be discussed in the following section). What is perhaps most noteworthy about this finding is that it seems to indicate that school shooters do have positive social experiences, and that they seem to be conscious and recognizant of this fact. Of course, this is not to say that school shooters do not 
experience familial issues. As some point out (e.g., Heitmeyer, 2013; Langman, 2016), family issues are fairly common within the population of school shooters. However, the findings of this study introduce some nuance to this point of inquiry in showing that school shooters do report positive feelings towards their family members, alongside negative.

In addition to discussing their own feelings about family and friends, school shooters sometimes discuss the feelings of others; that is, school shooters describe others' feelings as they imagine them. This is similar to Samraj and Gawron's (2015) observations made on the material of suicide notes, which indicated that suicide note writers predicted the feelings of others (i.e., in response to their suicide). As can be seen below, step 3 of move 5 of school shooters' notes fulfills a similar function:

Step 3: Describing others' imagined feelings

"But if you hate me and my family doesn't love me, it's okay." (Appendix A, note 10)

"I have always been the most hated person in the world." (Appendix A, note 6) These examples demonstrate the shooters' projection of emotions on others. In doing so, it seems that shooters may be recognizing and processing some of the consequences for their actions. At the very least, they demonstrate an understanding that their actions have a negative impact on their loved ones. It is useful to consider this finding in contrast with research that has drawn a link between school shootings and narcissism. While this does not necessarily discount this possibility, it does indicate that some school shooters may maintain an awareness and care for other's feelings.

Finally, in addressing loved ones, school shooters do occasionally make final requests to be fulfilled after their death (see examples below): 
Step 4: Making final requests

"I want u guys to remember me for who I was b4 this" (Appendix A, note 3)

"I hope my room is left the same" (Appendix A, note 2)

This finding is also consistent with the work of Samraj and Gawron (2015) which identified a similar move in suicide notes: expressing directions and wishes. The move described by Samraj and Gawron involves the writers' descriptions of short and long term directions to be carried out after their deaths. Similarly, step 4, Making final requests, involves descriptions of the shooters' hopes and expectations for others' actions following their deaths. These descriptions involve a range of requests, including: the way they want to be perceived (e.g., see example above [note 3]), or actions they wish family and friends to fulfill (e.g., see example above [note 2]). Further, shooters' may include instructions as to their desired means of being laid to rest: "Spread my ashes across the mountains off of eagle bluff." (Appendix A, note 2). The parallels between suicide notes and school shooters' notes provide evidence linking suicide and school shootings, contributing further support of previous research (e.g., Lankford, 2017) which has closely linked school shootings to suicide and suicidal behaviours.

\section{Move 6: Outlining personal motive}

School shooters' notes frequently provide reasons and motivations for their actions. This is performed in move 6-outlining personal motive-which occurs in all 13 texts. In general, school shooters point to their dissatisfaction in several facets of their lives; this dissatisfaction may involve difficulties with their social environments, society, specific individuals, and themselves. Prior to describing these motivations, some school shooters start by denying the motives they believe others will ascribe to their actions. Consider, for example, the following instances of move 6 , step 1: 
Step 1: Denying potential presumed motives

"this [shooting] is not because of the shooting games, bullying, or other stuff" (Appendix A, note 10)

“I'm only explaining my ideology so people don't jump to conclusions and scapegoat a dozen different things." (Appendix A, note 7)

Here, the school shooters provide alternative reasons that they presume will be attributed to their actions. Similar to shooters' descriptions of others' imagined feelings (described in the previous section), this demonstrates that school shooters seem to maintain some level of awareness of how they are perceived. This step — when it occurs - precedes some or all of the following four steps, which express dissatisfaction with various aspects of life. The first aspect for discussion is dissatisfaction with the immediate social environment:

Step 2: Expressing dissatisfaction with immediate social environment "that fucking school drove me to this." (Appendix A, note 3)

“[Cristy] bosses me around and dad loves her more than me." (Appendix A, note 2) In describing their immediate social environments, school shooters notes often discuss difficulties with peers (e.g., "You say mean things in school" [Appendix A, note 11]), as well as difficulties with the academic system itself (e.g., "All public school is trash. Teaching trash." [Appendix A, note 7]). This is consistent with the findings of Phase 1 reported in the previous chapter, which identified that school shooters notes generally reported negative experiences in the school environment. Further, school shooters sometimes discuss having problems at home (e.g., see example above). While it has been pointed out in the previous section that school shooters notes do lay out descriptions of positive social relationships, they also frequently do the opposite. It seems, then, that school shooters' notes may highlight some degree of instability in school shooters' social environments. 
In certain cases, school shooters discuss issues with society at large; that is, they express a more general dissatisfaction with their social environments. These descriptions do not refer to anyone in particular. Instead, this step provides an aggrandized view of the problems facing school shooters. For example:

Step 3: Expressing dissatisfaction with society at large

"I long ago realized that society likes to deny people like me these things." (Appendix A, note 6)

"I'm actually more rational, peaceful and less loony than half of the citizenry of this entire region." (Appendix A, note 1)

Conversely, step 4 involves the naming of specific individuals with whom the authors state to have experienced problems:

Step 4: Expressing dissatisfaction with specific individuals

"One of the biggest parts of my depression is Cristy." (Appendix A, note 2)

"One of the Big [expletive] is Mr. Ron Edwards" (Appendix A, note 9)

In addition to expressing dissatisfaction with others, school shooters also express dissatisfaction with themselves. This is illustrated by the following examples:

Step 5: Expressing dissatisfaction with self

"I wish I can be smart and a better kid" (Appendix A, note 10)

“And here I am. 26, with no friends, no job, no girlfriend, a virgin.”(Appendix A, note 6) As the examples above demonstrate, school shooters' sometimes express self-criticism, portraying a negative view of themselves. This is consistent with Wing's (2017) findingssummarized in Chapter 2: Literature review-which indicated that some school shooters expressed negative perceptions of themselves. As Wing (2017) points out, this is contradictory to the assertion that school shooters are narcissistic (e.g., Bushman, 2018), lending further support 
to propositions such as Langman's (2014) typology of school shooters, which identifies distinct personality types for school shooters.

\section{Move 7: Referencing other school shootings}

The previous chapter has pointed out that school shooters' notes contain several keywords pertaining to other school shooters. The same discussion mentions that references to other school shooters occur in one of two ways: directly (e.g., naming one of the Columbine shooters by name) or indirectly (e.g., mentioning a documentary). Further, it is pointed out that the majority of references relate to the 1999 Columbine attack. The analysis in Phase 2 yields similar findings: move 7, which involves referencing other school shootings, occurs in 5 of 13 texts. In addition, it was again identified that mentions of other school shootings have been identified as sometimes to serving as a means of separating the shooter from the perpetrators of previous school shooting incidents. As such, the steps involved in this move seem to occur in pursuit of one of two goals: (1) distancing oneself from other perpetrators, or (2) relating with other perpetrators. First, consider examples of the former:

Step 1: Portraying self as unique

"How am I different than what the media says school shooters are?" (Appendix A, note

"I'm not what the media says I should be." (Appendix A, note 12)

Step 2: Describing individual preferences and interests

"Favorite colors are Red and Black Favorite food is potatoes Favorite drink is soy milk (Appendix A, note 6) 
“TV I watch: Jay Leno, Conan O’Brien, Family Guy, SNL, Mad TV, Simpsons, Law and Order, Monk, and others, oh, South Park!" (Appendix A, note 13)

In these cases, the shooters refer to previous school shootings as a means of drawing a distinction between those individuals and themselves. What is particularly noteworthy in these cases, is that this seemingly contradicts previous research which claims that contagion may have a strong influence on the incidence of school shootings (e.g., Lankford \& Madfis, 2017; Towers, GomezLievano, Khan, Mubayi, \& Castillo-Chavez, 2015). However, this may not be an entirely accurate representation, given that these cases still provide evidence that school shooters are at least aware of one another. While they do separate themselves from the larger group of school shooters, the fact remains that they are cognizant of this larger group's existence. So, while shooters distance themselves from the population of school shooters, the possible influence of other school shooters on their behaviour cannot be rejected outright. Furthermore, the steps which indicate relating with other school shooters provide further evidence for the influence of contagion. Consider, for example, the following three steps:

Step 3: Expressing an interest in other perpetrators

"I have been interested in mass shooters for years." (Appendix A, note 6)

"Today, I also saw a program on the History Channel about Charles Whitman the Texas Sniper." (Appendix A, note 4)

Step 4: Identifying with and idealizing the experience of other perpetrators

"I know this is not as long as Elliot Rodgers but its still good. Elliot is a god." (Appendix A, note 6) 
"For the Vestor Flanagans, Elliot Rodgers, Seung Cho, Adam Lanzas of the world, I do this.” (Appendix A, note 6)

Step 5: Expressing a desire to imitate other perpetrators

"I will buy black cargo pants and black boots online to complete the uniform that Eric was wearing on April 20, 1999.” (Appendix A, note 4)

"I became a prophet because I spread the word of a god, Eric Harris." (Appendix A, note 7)

The three moves presented above demonstrate school shooters' positive views of other school shooters. It was mentioned in Chapter 5 that references to other school shootings represented in the keyword list were almost exclusively restricted to references Columbine. In move 7, it is still the case that Columbine references make up the majority of references to other school shootings. However, there is some variety in the shooters that are referred to. For example, one shooter (indicated above), refers to Elliot Rodgers and Adam Lanza. Another makes reference to the Texas Tower Sniper, expressing a desire to imitate him: "He was an ex-Marine who killed his wife, mother, and a number of other people on August 1,1966 . This year will mark the $40^{\text {th }}$ anniversary. I can compare.” (Appendix A, note 4). The latter three steps of move 7 provide especially strong evidence of the contagion effect described in previous research (e.g., Towers, Gomez-Lievano, Khan, Mubayi, \& Castillo-Chavez, 2015). School shooters do express identifying with, idealizing, and imitating other school shooters. Furthermore, these findings provide additional insight as to the manifestation of contagion in the population of school shooters; Langman (2017) points out that copycat killings may be motivated in part by a desire for fame and attention. While it is impossible to comment on the motivation, the findings above 
indicate that school shooters sometimes have an idealistic view of school shooters to whom they relate and imitate. For example, one shooter states: "Elliot is a God" (Appendix A, note 6). Another shooter refers to Eric Harris in a similar manner: "I spread the word of a god, Eric Harris". In the aim of better understanding the influence of contagion on school shootings, it would be useful to conduct further interdisciplinary research exploring school shooters' motivations for imitating and idealizing other school shooters.

\section{Move 8: Discussing existential matters}

Move 8-which occurred in 10 of 13 texts - makes reference to existential matters (i.e., pertaining to the realities of existence and mortality). The term existential confusion, coined by Fogarty-Bourget (2014), refers to an individual's lack of understanding of the realities of existence. In move 8, school shooter demonstrate moments of existential confusion as they fail to grasp certain aspects of reality. Three steps make up this move, each demonstrating different ways in which school shooters misunderstand their realities. First, consider the following example, which demonstrate a failure to understand the linearity of time and the manipulability of space:

Step 1: Discussing concerns of time and space

"When I die I will go back to the past and fix everything so it can be a great past." (Appendix A, note 10)

The first example above describes time as non-linear; the shooter expresses his will to return to the past and make changes. Of course, this assertion rejects the linearity of time (i.e., returning to the past) and implies that the shooter can continue to interact with the world after he is deceased. Other shooters also demonstrate similar confusion by discussing death as an impermanent state. 
The following quotes exemplify instances in which shooters refer to their consciousness as continuing to exist post-mortem:

Step 2: Referring to death as an impermanent state

"When I die I will become one of them. A demon. And I will return to kill again and again." (Appendix A, note 6)

"I'm going to do my best to come back in my ghost form. I feel like I still have more things to accomplish on this planet after I'm dead." (Appendix A, note 13)

In the above examples, the shooters' statements reject the finality of death. In both instances, they express a belief in life after death, in which they can continue to exert an influencing force on the living world. It is interesting to question whether a belief in an after-life might contribute to some school shooters chosen actions; perhaps the view of death as being impermanent makes it seem like a more viable option. Another possible hypothesis might be that believing in an after-life helps school shooters to come to terms with their planned actions. Unfortunately, the answers to these questions are far outside the scope of this study. However, there is additional evidence tying a belief in an after-life to school shooters' actions. While the previous examples demonstrated shooters' discussions of after-life in reference to their own lives, there are other instances in which shooters refer to an after-life in the frame of others' lives:

Step 3: Describing harmful actions as beneficial

"This world would undoubtedly be better if we were all in heaven." (Appendix A, note 7)

"I'm doing some people a favor by sending them to heaven." (Appendix A, note 14)

In the first case, the school shooter describes his violent actions as having a positive outcome. This in itself is somewhat demonstrative of existential confusion; actions that might be viewed as 
inherently harmful (i.e., killing) are portrayed in a positive light. As the following section will highlight, however, school shooters also typically recognize their actions as harmful, further demonstrating that they are possibly experiencing some level of confusion. Interestingly, the authors' discussions of after-life are never framed in the topic of religious belief. Although a belief in the after-life is often thought of as a component of religious belief, this does not appear to be the case in this corpus, at least not by explicit mention. Whether or not religious belief is intertwined with school shooters' expressed belief in an after-life would likely require further inquiry. Furthermore, it might be useful to further investigate issues of existential confusion more generally; the failure of one shooter to understand time's linearity, for instance, was unique within this corpus. However, similar instances, or other manifestations of existential confusion, may become visible within a larger corpus. Further, it may be useful to investigate the ways in which believing in an after-life influences people's perceptions of dying and violence.

\section{Move 9: Acknowledging wrongdoing}

In considering the subject of existential confusion, it is also useful to discuss the make-up of move 9, which occurs in 10 of 13 texts in the corpus. As was mentioned in the previous section, school shooters sometimes describe their actions as being beneficial (e.g., sending people to heaven). In examining move 9, however, it becomes increasingly apparent that some of these shooters are experiencing existential confusion. In many cases, shooters who have referred to their actions in a positive light (i.e., as shown in the previous section) will also acknowledge their wrongdoing in the same text. For instance, in the example above, one shooter states: "This world would undoubtedly be better if we were all in heaven." (Appendix A, note 7). Later in the text, however, he acknowledges that his actions will be seen as negative: "I am not trying to justify my actions whatsoever here.” (Appendix A, note 7). It is also frequently the case that 
school shooters who have not demonstrated existential confusion will complete move 9 as well. Move 9 consists of three moves. Consider the examples provided below:

Step 1: Recognizing actions as harmful

"I greatly affected the lives of the families ruined."(Appendix A, note 3)

“now I'm just a monster" (Appendix A, note 10)

This step is fulfilled when the author directly or indirectly recognizes his actions as harmful. The first example above shows a shooters' direct recognition of harmful actions; he refers to having "ruined" families by way of his actions. The second example is indirect, in that the writer uses metaphorical language to refer to himself as a causer of negative action (i.e., monsters do bad things and he, figuratively, views himself in a similar light).

The second step in this move is that of recognizing consequences. That is, shooters predict the negative effect that will result in consequence of their actions. By recognizing consequences, shooters seem to demonstrate an awareness that their actions are harmful. See the following examples:

Step 2: Recognizing consequences for actions

“I killed a little and killed myself. Jail isn't and wasn’t for me ever." (Appendix A, note \#9)

"ur gonna hear about the evil shit I did" (Appendix A, note \#3)

In one instance, the shooter discusses his plans for suicide, and recognizes that if this were not the case, he would certainly be incarcerated in light of his actions. In the second example, the shooter — speaking directly to his loved ones — recognizes that they will hear about the harm he has caused. Shortly after, he follows up his statement with: I [want you] to remember me for who 
I was before this". In this case, it is likely that the shooter recognizes that those he cares for will view him in a negative light because of his actions.

Finally, expressing remorse is the third step in move 9. Consider the following examples:

Step 3: Expressing remorse

"The shooting of sparks middle school never should have happen" (note \#)

“I’M SORRY - I WISH IT Was DIFFERENT.” (note \#)

School shooters express remorse by way of apology (see: second example), or occasionally by slightly less direct means (see: second example). Naturally, expressing remorse requires that the school shooter in some manner acknowledge his wrongdoing. That said, it is difficult to say whether school shooters are genuinely expressing remorse, or if expressing remorse provides them some means of preserving a more innocent public identity. Of course, both these possibilities (and neither of them) may also be true depending on the writer. The important takeaway in considering this move is that school shooters do appear to be aware that actions are harmful, to both their immediate victims as well as their own families and friends.

As a final note, it is worth mentioning move 9's frequent co-occurrence with move 8. The implications of this co-occurrence arise in considering again the notion of existential confusion: if school shooters use move 8 to describe their actions as beneficial to victims, for instance, it becomes increasingly perplexing that they might then express remorse in move 9. As such, it could be considered that the co-occurrence of moves 8 and 9 could in some instances provide further evidence of existential confusion in school shooters' notes. Further research is needed to explore the phenomenon of these moves' co-occurrence. 


\section{Move 10: Signing off}

Move 10, quite simply, is a means of signaling to the reader that the note is coming to a close, and occurs in 7 of 13 texts in the corpus. As such, the discussion of this move will be kept fairly brief. The first step of this move provides some explicit indication to the reader the text is ending, for example: “THE END” (Appendix A, note 2) or "goodbye.” (Appendix A, note 3). The second step (step 2: Signature) of this move is fulfilled when the author provides his signature at the note's closing: "From Jose H Reyes Urtiz" (Appendix A, note 10) or "Kenneth Stuart Bartley" (Appendix A, note 2).

\section{Chapter Summary}

This chapter presents the findings of the second phase of analysis. A move step modelwhich includes ten moves and 32 steps - was developed based on the findings of the Keyness analysis described in the previous chapter. Examples of the texts segmentation and analysis are provided. A discussion of moves' patterning within the corpus is facilitated by the calculation of obligatory moves, followed by an explanation of moves' flexibility and cyclicity. Each move is discussed in its own respective section:

1. Opening a dialogue

2. Introducing intent

3. Describing mental state

4. Setting a plan of action

5. Addressing friends and/or family

6. Outlining personal motive

7. Referencing other school shootings

8. Discussing existential matters 
9. Acknowledging wrongdoing

10. Signing off

Each of these sections provides an in-depth description of the move, highlighting its constituent steps with representative examples. Further, the contribution of findings from the present study are considered in the frame of previous research; recommendations for future work are also provided. 


\section{Chapter Seven: Synthesis of findings}

This chapter provides a brief synthesis of the findings from both phases of analysis, so as to better make sense of the overall findings of this study and to answer the research questions presented in the introductory chapter (Chapter 1). As such, the following overarching findingsthat is, the findings which coincide with one another in both phases of analysis — are of particular relevance to this chapter: (1) references to other school shooters, (2) dissatisfaction as a motivating factor, (3) school shooters' mental state, and (4) suicidal intention. These findings provide some broad answers to the following research questions: 1 . What are the key, or most salient, lexical features occurring in the notes of school shooters? How do school shooters discursively construct the reasons for and causes of their actions in notes they have written before the shooting? Of course, the complete answers to these questions are encapsulated in the entire findings of this study, presented in Chapters 5 and 6. The corpus of school shooters' notes is considered from the viewpoint of Swales' (1990) approach to genre, and addresses the following research question: Do school shooters' notes share a common goal and address similar audiences; that is, can they be viewed as a genre?

\section{Overarching findings}

\section{References to other school shooters. The keyword list presented in Chapter 5} demonstrated that references to other school shooters occurred frequently within school shooters' notes. In particular, references to Columbine were exceptionally common. Furthermore, the analysis of genre revealed further insights as to school shooters' references to other perpetrators; school shooters identified with, idealized, and strived to imitate other school shooters (Move 7). This supports the hypotheses of previous research (e.g., Towers et al., 2015) which stipulates that school shooters are aware of one another and, in some capacity, influence one another's actions. 
However, it must be maintained that the present study also identified that some school shooters referred to previous perpetrators as a means of separating themselves from this group. This expands upon previous studies (e.g., Langman, 2017) which have been primarily focused on school shooters' identification with other perpetrators. This does not preclude the possibility that contagion was an influencing factor in these cases; rather, it suggests that while references to other school shooters are varied in the way in which they are made, they still indicate an awareness and acknowledgement of other school shooters on the part of the writer.

Social dissatisfaction as motivation. Expressions of dissatisfaction make up a large portion of move 6: Outlining personal motive. The analysis of genre shows that in describing their personal motives, school shooters express dissatisfaction socially (i.e., with specific individuals, and in their immediate and extended social environments) as well as with themselves. This finding was consistent with the findings of phase one, which indicated that school shooters often expressed dissatisfaction in describing their social relationships. This is consistent with previous research, conducted by Vossekuil et al., (2004), which found that school shooters' experience social challenges such as bullying and rejection. It is important to keep in mind, however, that although dissatisfaction with the social environment features prominently in the corpus of school shooters' notes, there are also expressions of love and gratitude to family and friends (observable in move 5). Additionally, it should be kept in mind that these are the stated motivations of school shooters, which may or may not be the same as their actual motivations. As such, these findings are conducive to understanding the school shooters' perspectives and do not represent causal factors. As previous research (Heitmeyer, et al., 2013; Langman, 2014; 2017b) mentions, it is possible that school shooters may have unwarranted perceptions of victimization in considering their social environments. It is advisable that future 
research explore whether school shooters' perceived experiences are commensurable with their actual experiences.

School shooters' mental state. Previous research has yielded evidence in support of mental illness being a common factor among school shooters (Lankford, 2017; Newman \& Fox, 2009; Verlinden et al., 2000). The findings of the Keyness analysis-which shows that school shooters frequently make reference to mental illness, particularly depression—are consistent with these findings. The genre analysis had similar findings, indicating that school shooters exposed their mental states by discussing mental distress, and an intent for violence towards themselves and others. However, as some have pointed out (e.g., Knoll \& Annas, 2016), the association of mental illness to school shootings may cause harm; this association may create undue stigma surrounding mentally ill individuals and carry little influence in the prevention of school shootings. So, while this study provides further support of a link between school shootings and mental illness, it is necessary to mention that such inquiries should be treated cautiously and with attention to minimizing the negative impacts on the associated stigma of mental illness. Further research is required in order to entirely understand the impact of such findings on public perceptions of mental illness.

Suicidal intention. The link between suicide and school shootings has been discussed in Chapter 2 (Literature review); to briefly summarize, it was mentioned that suicide coincides with mass shootings at a higher rate than any other premediated crime (Lankford, 2017) and that school shooters have a high likelihood of having previously attempted or contemplated suicide (Vossekuil, et al., 2004). The Keyness analysis and the genre analysis support these findings, revealing that school shooters notes discuss their intentions for suicide. Importantly, it was noted that school shooters expressed their intent to commit suicide using both direct (e.g., 'I am going 
to commit suicide') and indirect language (e.g., 'I am going to die today'). In particular, it is worth noting that this discrepancy between shooters (i.e., those who refer to suicide directly, and those who do so indirectly) raises questions about school shooters' sense of agency. In using indirect language to describe suicidal intentions, school shooters remove their grammatical agent role is removed. A direction for future research might be to examine the attitudes and perceptions of individual with a cross-comparison of their usages of grammatical agency. By doing so, it may become clearer whether placing oneself in the agent role-as opposed to the role of experiencer-may be indicative of alternative worldviews.

\section{School shooters' notes as a genre}

In considering whether school shooters' notes make up a genre, it necessary to revisit Swales' (1990) definition of genre. Consider first the following excerpt from this definition: "A genre comprises a class of communicative events, the members of which share some set of communicative purposes" (p. 58). The identification of a recurrent move-step model within the corpus indicates that school shooters' notes do, by Swales' definition, constitute a genre — these moves and steps do, after all, represent the communicative functioning of the text. In their recurrence, it can be said that these texts share common communicative purpose; although, identifying this purpose is not evident at this time and falls outside the scope of this study. The inability to pinpoint a precise communicative purpose-as has been mentioned in Chapter 3 (Analytical and theoretical framework) - is not cause for concern (Askehave \& Swales, 2001), as genre analysis serves primarily to gain insight as to a text's communicative action.

However, the second portion of Swales' definition of genre presents some problems in considering school shooters' notes as a genre: "These purposes are recognized by the expert members of the parent discourse community and thereby constitute the rationale for the genre" 
(p. 58). As has been mentioned in Chapter 3, it is not immediately apparent whether school shooters can be referred to as a discourse community, as they do not appear to meet all of the criteria laid out by Swales. This question is considered in the following subsection.

Discourse community. In considering the corpus of school shooters' notes, it appears initially that a key aspect of Swales' definition of genre - discourse community — is absent. This raises valid questions regarding the method's applicability to the study of school shooters' notes. For instance, can it be said that school shooters who leave behind notes are part of a larger discourse community? This question is one that is difficult, if not impossible, to answer with certainty. The criterion presented by Swales (1990) that is particularly difficult to reconcile in considering school shooters as a potential discourse community is the following: school shooters share modes of intercommunication. Though the modes of intercommunication used by school shooters are less explicit and direct than those used by other communities, school shooters do make reference to other perpetrators in their writing (i.e., via direct quotation and mentioning each other by name) which may be indicative that these notes do serve as a means of intercommunication in some capacity. While it can be said that this intercommunication is not necessarily intentional, it should equally be questioned whether intentionality bears much relevance. Communication being relayed to a secondary party within the discourse community, intentionally or not, would seemingly meet the criteria for intercommunication.

So, it seems that while school shooters may not meet the original criteria laid out by Swales (1990), they may still be considered a discourse community. Samraj and Gawron (2015) elaborate on this notion, pointing to a need for adjustment in the frame of genre theory: 
The case of suicide notes seems to indicate the need for constructing higherlevel categories of genres in genre theory. It seems that one category of genres is produced by members of identifiable discourse communities while another is not associated with a specific discourse community, one that has a set of public goals, a mix of novice and expert members, genres, and specific lexis, as characterized in Swales (1990). (p. 12)

Swales (2016) acknowledges that there is an increased need for flexibility when considering genres in the modern age. Unusual genres, such as the genre of suicide notes described by Samraj and Gawron, and the school shooters' notes considered herein, may be some manifestation of this. The continued study of genres that are not conventionally examined by the ESP approach to genre may shed further light on the varied manifestation of discourse community across genres. In the frame of this study in particular, the notion of discourse community is useful in that it identifies school shooters not only as individuals with their own motivations and communicative intentions, but as members of a larger community with shared goals. Additionally, inquiries may be raised as per the question of intentionality: what role does intention play in the dissemination of a text and its audience? How relevant is the authors' intention in the discussion of a texts tangible communicative power? Answering these questions, alongside the issues raised regarding discourse community, may further expand the theoretical understanding of genre in the ESP framework.

Occluded genres. In considering school shooters' notes within the scope of genre theory, it is necessary to touch briefly on the subject which Swales (2004) terms occluded genres. Occluded genres, in a sense, function "behind the scenes"; they are shared between members of a discourse community, and are inaccessible to outsiders and apprentices. It seems logical that 
school shooters' notes might be categorized within this category. Many notes, after all, seem to be addressed to a small sampling of people and are not intended for the wider population. However, this returns us to the subject of intentionality that was first brought up in the discussion on discourse community. Consider, for example, that a perpetrator leaves behind a note addressed to his parents. The note — though intended for specific individuals — inadvertently makes its way through the mainstream media and, in consequence, is now accessible to the general public. In this example, a text reaches a wider audience than was initially intended by the writer. This raises an important question: in such a case, can a genre truthfully be deemed occluded? While this may have been the case at the texts inception, it becomes unclear whether this continues to be true upon the texts' wider distribution. It may be argued that the school shooter leaves behind a note unaware that it will be subject to wide-scale dissemination, and that his intention would instead determine whether the text was occluded. It could also be proposed, however, that the writer's intention is of little importance; whether the school shooter is aware of this effect, or whether he intends it to occur, has no bearing on the text's actual reach. The social action of a text, then, is not based in the writer's intention, but in its actual, tangible influence. As such, the writer's intent does not preclude it from inadvertently reaching the public sphere. With this in mind, the school shooters notes examined in this study are not considered to be occluded. While this is open to debate, it seems most simple to cautiously reject the possibility that these notes are occluded. The reasoning for this is fairly simple: the writer's intention is unknowable and, as such, is relatively inconsequential to the text's performance of social action. It should be emphasized that this stance is not one that is entirely conclusive; further research is needed to better understand the role of intentionality in genre occlusion, and in genre theory more generally. 


\section{Chapter Summary}

A synthesis of the findings of this study have been discussed in this chapter. Most notably, it was mentioned that school shooters' references to other school shooters are consistent with and expand upon the findings of previous research (Langman, 2017; Towers et al., 2015). Additionally, it was mentioned that shooters' discussions dissatisfaction-particularly in the frame of the social environment - was also consistent with existing research (Heitmeyer, et al., 2013; Langman, 2014; 2017b). Furthermore, school shooters' discussions of mental illness and suicide are considered in the frame of existing research (Lankford, 2017; Newman \& Fox, 2009; Newman \& Fox, 2009; Vossekuil, et al., 2004; Verlinden et al., 2000;), with which parallels are drawn.

The second section of this chapter focus on school shooters' notes as a genre. In particular, this section considered whether school shooters notes could, in fact, be referred to as a genre. This inquiry is concluded with the assertion that school shooters can, cautiously, be referred to as a discourse community. Finally, this chapter considers the possibility of school shooters' notes as an occluded genre but, ultimately, rejects this possibility. Recommendations for future work were provided throughout, providing additional channels of inquiry which might further expand upon the present study. 


\section{Chapter Eight: Conclusion}

As the number of victims of school shootings continues to climb, it becomes increasingly important to inquire as to the many intermingling factors underlying these unfortunate events. While previous research has continuously strived to better understand, and thereby, prevent such incidents, there has been a marked need for multidisciplinary approaches to this area of study. It is with this in mind that the present study investigates school shooters' perspectives —as represented by their writing - from the field of ALDS. This study sheds light on school shooters discourse, by investigating the construction of genre in a corpus of school shooters' notes. To reiterate, the present study addresses the following questions:

1. What are the key, or most salient, lexical features occurring in the notes of school shooters?

2. How do school shooters discursively construct the reasons for and causes of their actions in notes they have written before the shooting?

3. Do school shooters' notes share a common goal and address similar audiences; that is, can they be viewed as a genre?

This study implements an innovative mixed-methods design in the theoretical frame of Swales' (1981) ESP approach to genre analysis. This study has been conducted in two phases. The first phase, a corpus analysis of Keyness (Scott, 1997), revealed the most salient words in the corpus of school shooters' notes by comparison with a larger corpus of general English (i.e., SUBTLEXus [Brysbaert \& New, 2009]). The second phase of analysis consists of a Swalesian move-step analysis of genre, which identified recurrent moves and steps in the research corpus. 


\section{Main findings}

Phase 1: corpus analysis. The first phase of this analysis produced a list of 76 keywords (see: Appendix B) — that is, salient words — which were then grouped based on their respective semantic fields. In doing so, four major, recurring semantic fields were identified:

1. References to other school shootings: these words (e.g., 'columbine', 'shooters') are most frequently in reference to the Columbine shootings; in context, these words demonstrate school shooters' interest in and identification with other school shooters. Occasionally, references to other school shootings are used to separate the shooter from other perpetrators (e.g., "How am I different from what the media says school shooters are?).

2. Life and mortality: these words (e.g., 'life', 'die') are used in reference to the lives of others, as well as the shooters' life. Most commonly, these words are used either to refer to the shooters' intent to themselves or others, or to express dissatisfaction with their lives due to perceived hardship.

3. Social environment: these words (e.g., 'school', 'family') are related to the school shooters' social environment. References to the school environment were almost exclusively negative. Family and friends, however, were referred to both positively and negatively in certain cases, indicating that school shooters' do not necessarily perceive their social lives entirely negatively.

4. Mental state: These words (e.g., 'depression', 'suicide') refer to the school shooters' mental state. Most notably, school shooters used both direct (e.g., 'I am going to commit suicide') and indirect (e.g., 'I am going to die) language in discussing their intent to commit suicide. 
Phase 2: genre analysis. A set of recurrent moves and steps were identified within the research corpus, indicating that school shooters' notes do, in fact, constitute a genre.

Consequently, the notes in the corpus can also be said to have shared communicative purpose(s). 10 moves (and 32 steps) were identified:

- Move 1: Opening the text

- Move 2: Introducing intent

- Move 3: Describing mental state

- Move 4: Setting a plan of action

- Move 5: Addressing friends and/or family

- Move 6: Outlining personal motive

- Move 7: Referencing other school shootings

- Move 8: Discussing existential matters

- Move 9: Acknowledging wrongdoing

- Move 10: Signing off

With the exception of moves 1 and 10, moves occurred flexibly within the text (i.e., they occurred out of sequence). Further, moves were occasionally observed to be cyclical (i.e., they were repeated more than once within a single text).

Synthesis. While the exact communicative purpose (or purposes) of school shooters' notes is yet unclear, the constituent rhetorical moves and steps of this genre provide some insight as to the social actions (Miller, 1984) that these texts perform. Furthermore, the rhetorical moves and steps observed in the corpus of school shooters' notes are, in many cases, consistent with the findings of previous research. most notably, references to other school shooters support previous 
research (e.g., Towers et al., 2015) on contagion, which indicates that school shooters identify with and are influenced by other school shooters. It should be noted, however, that shooters sometimes use their notes to separate themselves from the larger group of school shooters; nevertheless, such statements still demonstrate the shooters' awareness of other perpetrators and, as such, is still in support of contagion. Additionally, the findings of this study indicate that school shooters frequently express dissatisfaction with their social environments, which is consistent with research indicating that school shooters experience social difficulties (Lankford, 2017; Newman \& Fox, 2009; Verlinden et al., 2000). Finally, it is particular important to touch on the link between suicide and school shootings, which is made increasingly apparent throughout this analysis. As the above analysis indicates, school shooters frequently make reference to their intentions for suicide by both direct and indirect means. This is in further support of research indicating that school shooters are at high risk of suicide or suicidal thoughts (Vossekuil, et al., 2004).

Limitations. By far the biggest limitation of this study was the small size of the research corpus (14 notes). While this analysis does provide new insights as to school shooters' linguistic behaviours, the small corpus limits the generalizability of findings. The use of a larger corpus in future studies of this kind would be preferred. The population represented in this corpus is also somewhat limiting; while this study was intended to focus on a limited population (i.e., young, male school shooters of US origin), it is advisable that future research consider a wider range of individuals so as to identify variation based on demographic factors.

A final limitation in this study was the chosen reference corpus. Although the SUBTLEXus corpus provides a fairly representative sample of general English, it may be 
preferable to find a corpus that is more similar to the research corpus. For instance, a corpus of written notes may be a valid option for future studies.

\section{Theoretical implications}

The analysis of forensic texts using the ESP approach to genre has yet to gain traction in the academic sphere. The ESP approach — at face value — appears incongruent with the analysis of forensic texts, primarily due to their lack of association with a clear-cut discourse community. Researchers have begun to set a precedent for such work, however, by demonstrating the applicability of the ESP method to forensic text genres. Samraj and Gawron (2015), for instance, conducted a Move-Step analysis investigating 114 suicide notes.

As is mentioned in the Chapter 7, the analysis of forensic texts using the ESP approach to genre may require some adjustments to the established theory and methods. The current framework accounts disproportionately for highly structured genres of writing that emerge from more formal (i.e., professional or academic) contexts. This fails to account for the increasingly diverse range of written language that occurs in the advent of the internet and modern media (cf. Swales, 2004, 2016). Given that language and communication evolve at a rapid rate, it is no stretch to suggest that genres behave similarly. Despite these theoretical challenges, this studyand others like it (e.g., Samraj \& Gawron, 2015)—demonstrates the applicability of the ESP approach to the analysis of genre in forensic texts and, specifically, school shooters' notes.

Furthermore, this study demonstrates a lack of flexibility in considering variation across discourse communities. It seems that the term discourse community, in its traditional sense, may be inadequate in describing the full scope of existing discourse communities. In further clarification of this, it would be worthwhile to seek out texts similar to those addressed herein, 
which find themselves attached to lesser-evident discourse communities. In doing so, the frameworks describing discourse community may be elaborated in such a way that accounts for the diverse occurrence of such communities.

\section{Directions for future research}

In reflecting on the work presented above, there are a number of considerations that may inform future research of this kind. First, bearing in mind the limitations of this study, it would be useful to create a larger corpus of school shooters' notes with less demographic restrictions. Doing so may allow for additional clarification as to the moves and steps of school shooters' notes and, in particular, the communicative purposes that they serve. Further, such research may investigate the influence of other factors, for example: race, age, and gender.

In addition, future research may consider the application of different reference corpora. Specifically, it would be of particular relevance, given the link between school shootings and suicide, to compare school shooters' notes to suicide notes. The prevalence of discussion of suicide in school shooters' notes points to interconnectedness of suicide and school shooters' actions. To compare school shooters' notes with suicide notes would perhaps help to clarify in what ways school shooters are similar to suicide completers, and in what ways they differ. The application of a similar methodology to that presented herein may be conducive to such work, allowing for the systematic comparison of two forensic corpora (i.e., a corpus of school shooters' notes to a corpus of suicide notes). Pursuing this avenue of research may illuminate the differentiating factors between school shooters' and suicide completers, helping to isolate those aspects which separate the two (i.e., asking the question: "why do school shooters' resort to violence towards others, in addition to themselves?). 


\section{References}

Abaalkhail, A. (2015). Rhetorical Moves in an Occluded Genre: A Qualitative Analysis of Suicide Notes (Master's thesis). Available from CURVE (Carleton University Research Virtual Environment). (https://doi.org/10.22215/etd/2015-10831

Askehave, I., \& Swales, J. (2001). Genre identification and communicative purpose: a problem and a possible solution. Applied Linguistics, 22(2), 195-212.

Baird, A. A., Roellke, E. V., \& Zeifman, D. M. (2017). Alone and adrift: the association between mass school shootings, school size, and student support. The Social Science Journal, 54, 261-270.

Bawarshi, A. S., \& Reiff, M. J. (2010). Genre: an introduction to history, theory, research, and pedagogy. Indiana: Parlor Press.

Becker, A. L. (1995). Beyond translation: Essays toward a modern philology. University of Michigan Press.

Beland, L. \& Kim, D. (2014). The Effect of High School Shootings on Schools and Student Performance. Canadian Labour Market and Skills Researcher Network.

Bhatia, V. Analyzing genre: Language use in professional settings. London: Longman.

Brysbaert, M., \& New, B. (2009). Moving beyond Kučera and Francis: A critical evaluation of current word frequency norms and the introduction of a new and improved word frequency measure for American English. Behaviour and Research Methods, 41(4), 977990. 
Bushman, B. J. (2018). Narcissism, fame seeking, and mass shootings. American Behavioral Scientist, 62(2), 229-241.

Cooper, M. M. (1989). Writing as social action. Heinemann Educational Books.

Creswell, J. W. (2014). A Concise Introduction to Mixed Methods Research. California: SAGE.

Dornyei, Z. (2007). Research Methodologies in Applied Linguistics. Oxford: Oxford University Press.

Dutton, D. G., White, K. R., \& Fogarty, D. (2013). Paranoid thinking in mass shooters. Aggression and Violent Behaviour, 18(5), 548-553.

Fairclough, N. (1989). Language and Power. London: Longman.

Fazel, S. \& Grann, M. (2006). The population impact of severe mental illness on violent crime. American Journal of Psychiatry, 163(8), 1397-1403.

Federal Bureau of Investigation. (2013). A Study of Active Shooter Incidents in the United States Between 2000 and 2013. Washington, DC: U.S. Department of Justice.

Heitmeyer, W., Böckler, N., \& Seeger, T. (2013). Social disintegration, loss of control, and school shootings. In: N. Böckler, T. Seeger, P. Sitzer, \& W. Heitmeyer (Eds.), School Shootings: International Research, Case Studies, and Concepts for Prevention. (27-54). New York: Springer.

Henry, S. (2009). School violence beyond columbine: A complex problem in need of interdisciplinary analysis. American Behavioural Scientist, 52(9), 1246-1265. 
Kimmel, M. S. \& Mahler, M. (2003). Adolescent masculinity, homophobia, and violence: random school shootings 1982-2001. American Behavioural Scientist, 46(10), 14391458.

Knoll, J. L. IV, \& Annas, G. D. (2016). Mass shootings and mental illness. In L. H. Gold \& R. I. Simon (Eds.), Gun violence and mental illness (pp. 81-104). Arlington, VA, US: American Psychiatric Association.

Labov, W. (1966). The social stratification of English in New York City. Washington, DC: Center for Applied Linguistics.

Langman, P. (2009). Rampage school shooters: a typology. Aggression and Violent Behaviour, 14, 79-86.

Langman, P. (2014). Statistics on bullying and school shootings. Retrieved from https://schoolshooters.info/sites/default/files/bullying_school_shootings_1.1.pdf

Langman, P. (2017a). Different types of role model influence and fame seeking among mass killers and copycat offenders. American Behavioural Scientist, 62(2), 210-228. doi: $10.1177 / 0002764217739663$

Langman, P. (2017b). Education: failures and family involvement. Retrieved from https://schoolshooters.info/sites/default/files/education_failures_family_involvement_1.1 $0 . p d f$

Langman, P. (2019). Original documents: shooters' words. Retrieved from https://schoolshooters.info/original-documents/shooters-words. 
Lankford, A. (2015). Are America's public mass shooters unique? A comparative analysis of offenders in the united states and other countries. International Journal of Comparative and Applied Criminal Justice, 40(2), 171-183.

Lankford, A. (2018). Identifying potential mass shooters and suicide terrorists with warning signs of suicide, perceived victimization, and desires for attention or fame. Journal of Personality Assessment, DOI: 10.1080/00223891.2018.1436063

Lankford, A. \& Madfis, E. (2017). Don't name them, don't show them, but report everything else: a pragmatic proposal for denying mass killers the attention they seek and

Larkin, R. W. (2010). Masculinity, school shooters, and the control of violence. In: W. Heitmeyer, H. Haupt, S. Malthaner, \& A. Kirschner, Control of Violence. (315-344). New York: Springer.

Lindberg, N., Oksanen, A., Sailas, E., \& Kaltiala-Heino, R. (2012). Adolescents expressing school massacre threats online: something to be extremely worried about? Child and Adolescent Psychiatry and Mental Health, 6, 1-8.

Mears, D. P., Moon, M. M., \& Thielo, A. J. (2017). Columbine revisited: myths and realities about the bullying-school shootings connection. Victims \& Offenders, 12(6), 939-955.

Miller, C. R. (1984). Genre as social action. Quarterly Journal of Speech, 70(1), 151-167.

Milička, J. (2012). Minimal Ratio: An Exact Metric for Keywords, Collocations etc. Czech and Slovak Linguistic Review, 1.

Neuman, Y., Assaf, D., Cohen, Y., \& Knoll, J. (2015). Profiling school shooters: automatic text- 
based analysis. Frontiers in Psychiatry, 6(86). Retrieved from

https://www.ncbi.nlm.nih.gov/pmc/articles/PMC4453266/

Newman, K., \& Fox, C. (2009). Repeat tragedy: Rampage shooting in American high school and college settings, 2002-2008. American Behavioral Scientist, 52(9), 1286-1308.

O’Toole, M. (2000). The school shooter: a threat assessment perspective. Quantico, Virginia: Federal Bureau of Investigation.

Pfeifer, B. \& Ganzevoort, R. (2016). Tell Me Why? Existential Concerns of School Shooters. Religious Education, 112(2), 123-135.

Pho, P. D. (2008). Research article abstracts in applied linguistics and educational technology: A study of linguistic realizations of rhetorical structure and authorial stance. Discourse Studies, 10(2), 231-250.

Samraj, B., \& Gawron, J. M. (2015). The suicide note as a genre: Implications for genre theory. Journal of English for Academic Purposes, 19, 88-101.

Scott, M. (1997). PC analysis of key words - and key key words. System, 25, 233-245.

Sommer, F., Leuschner, V., \& Scheithauer, H. (2014). Bullying, romantic rejection, and conflicts with teachers: the crucial role of social dynamics in the development of school shootings - a systematic review. International Journal of Developmental Science, 8(1), 3-24.

Suomalainen, L., Haravuori, H., Berg, N., Kiviruus, O., \& Marttunen, M. (2010). A controlled follow-up study of adolescents exposed to a school shooting - Psychological consequences after four months. European Psychiatry, 26(8), 490-497. 
Swales, J. (1990). Genre analysis: English in academic and research settings. New York: Cambridge University Press.

Swales, J. (2004). Research genres: explorations and applications. New York: Cambridge University Press.

Swales, J. (2016). Reflections on the concept of discourse community. Concepts and Frameworks in English for Specific Purposes, 69, 7-19.

Tonso, K. L. (2009). Violent masculinities as tropes for school shooters: the Montreal massacre, the Columbine attack, and rethinking schools. American Behavioural Scientist, 52(9), $1266-1285$.

Towers, S., Gomez-Lievano, A., Khan, M., Mubayi, A., \& Castillo-Chavez, C. (2015). Contagion in mass killings and school shootings. PLoS One, 10(7).

Turybury, J. E. G. (2016). Expressions of power in the narratives of school shooter communications (Master's thesis). ProQuest Dissertations Publishing. Available from ProQuest Dissertations \& Theses Global. (1802533872).

Van Brunt, Brian. (2015). Violence risk assessment of the written word (VRAW ${ }^{2}$ ). The Journal of Campus Behavioral Intervention, 1(3), 6-39.

Verlinden, S., Hersen, M., Thomas, J. (2000). Risk factors in school shootings. Clinical Psychology Review, 20, 3-56.

United States Secret Service. (2000). Safe School Initiative: An Interim Report on the Prevention of Targeted Violence in Schools. Washington, DC: National Threat Assessment Center. 
Wing, D. (2017). The progression of interpersonal stances in the writings of school shooters (Master's thesis). Available from ProQuest Dissertations \& Theses Global. (1914917316). 


\section{Appendix A. Research corpus}

Note 1. Atchison, W.

December 7th, 2017 at $0651 \mathrm{hrs}$

If things go according to plan, today would be when I die. I wait until the school buses are detected, then head out on foot disguised as a student. I go somewhere and gear up, then hold a class hostage and go apeshit then blow my brains out.

Work sucks, school sucks, life sucks.

I just want out of this shit.

Fuck this state, it really is bad. Think I'm insane? I'm actually more rational, peaceful and less loony than a majority of citizenry of this entire region.

\section{Note 2. Bartley, $K$.}

To who it may concern,

Today is the last of my horrible days. The end. I do have a few request please leave my casket open at the funeral. Please cremate me after the funeral. Spread my ashes across the mountains off of eagle bluff. There are only three people I have ever really love my dad my Papaw Ken + mama Polly. I am always so sad now. I never feel joyous. I hope my room is left the same. If I had a razor blade I would leave a sample of my blood on this paper. One of the main parts of my depression is Cristy. She bosses me around and dad loves her more than me. That drives me literally CRAZY.

\section{THE END}

Love, Kenneth Stuart Bartley 


\section{Note 3. Butler, $R$.}

Everybody that used to know me I'm sry but Omaha changed me and fucked me up. and the school I attend is even worse ur gonna here about the evil shit I did but that fucking school drove me to this. I wont $\mathrm{u}$ to remember me for who I was b4 this ik. I greatly affected the lives of the families ruined but I'm sorry. goodbye.

\section{Note 4. Castillo, A.}

No cuss words or profanity is used. I do not believe in using foul language.

Life's Fantasies

The Journal of Alvaro Castillo a.k.a Al a.k.a Big Al a.k.a Big

Eric Harris

Born: April 9th, 1981

Died April 20th, 1999

(My picture is at the end!)

Wednesday, March 29, 2006, 4:03pm

Dear Journal, I am going to do it! I have been thinking about this moment since the 10th grade. I a going to buy a shotgun and I am going to commit suicide. I bought some audio cassette tapes so I can explain to the police and my parents about why I did it. I plan to commit suicide on either April 20th or April 21st. April 20th is an obvious choice, for it is the seventh anniversary 
of the Columbine High School Massacre. However, I want to see the documentaries that they will show on the History Channel. If [redacted] is here, I will wait until he leaves. Then, I will commit the act. I will send Anna and e-mail telling her how much I love and care for her. I will tell her that I would pass by her house, and that I named my shotgun or rifle after her and the m16 rifle in basic training. I will also call [redacted] and confess to him what I will do. I have to do this. Every since that

Shotgun receipt

Monday, June 12, 2006, 10:25pm

Dear Journal,

Well today I gave Arlene a complete makeover. I turned her into Eric's shotgun I sawed off the barrel and stock of the shotgun with a hacksaw. It took a lot less time than I thought it would. I taped the butt of the shotgun with duct tape. Now I just have to test her. I also took [redacted]'s bomb apart, and I ho know how to make more. I must reserve the motel for Denver today. Arlene looks so beautiful now. I also ordered a pistol belt and three ammunition pouches from the Internet. Everything is falling into place at last! Today, I also saw a program on the History Channel about Charles Whitman the Texas Sniper. He was an ex-Marine who killed his wife, mother, and a number of other people on August 1, 1966. This year will mark the 40th anniversary. I can compare

Tuesday, August 8, 2006, 10:05am

Dear Journal, 
I will buy black cargo pants and black boots online to complete the uniform that Eric was wearing on April 20, 1999. I am feeling very depressed these days. I frown my sadness and depressing with work, cleaning, and movies. Still, it just keeps coming back. I am a TV junkie. I have been addicted to movies and television ever since I was born. I just became interested in Rated R movies when I was 7 years old, around the same time I was shown pornography. I am having sexual fantasies these days and fantasies of being held hostage by an evil twin brother. I assume that he represents my dark side. I can't even cry! The anti-depressant I am taking doesn't seem to be working. On August 29 my depression will end permanently. I just want to die. I don't want to live like this anymore. I have endured 10 years

Wednesday, August 23, 2006, 11:26pm

Dear Journal,

In one week, I will finally be dead. I am just putting the finishing touches on my autobiography. It is in my computer, in Microsoft Word, under the name Columbine. I have almost everything ready. I just need more ammo and I need to go to the church before I begin. I cannot wait. I wish I could tell my family, but I can't. I miss Anna. Today, she starts her sophomore year at [redacted]. I will always think about her. She is so beautiful. I don't deserve her though. I do not deserve anyone. If I was mentally well, maybe I could've told her my feelings. I do feel sorry for scaring her. I know I am sick. What do you do with sick people like me. They can't change you have to sacrifice them. Bad things could happen. We have to learn to sacrifice ourselves. I need to sleep now journal. Goodnight

Wednesday, August 30, 2006, 12:00pm 


\section{Dear Journal,}

Today is the big day for Operation Columbine. It is time that the world be reminded of

Columbine. I will die today! I just killed my father. It felt good! He is finally dead. I do feel a little remorse. Still, he is finally with God and Tony. I loved my father, I hesitated but I finally did it. God be with him. 


\section{Note 5. Cho, S.}

Of the happiness I could have had mingling among you hedonists, being counted as one of you, only if you didn't fuck the living shit out of me.

You could have been great. I could have been great. Ask yourself what you did to me to have made me clean the slate.

Only if you could be the victim of your reprehensible and wicked crimes, you Christian Nazis, you would have brute-restrained your animal urges to fuck me.

You could be at home right now eating your fucking caviar and your fucking cognac, had you not ravenously raped my soul.

For every action, there is an equal and opposite reaction. Can you feel the pain that you fucked us in, you Descendants of Satan? Well, can you feel it?

All the shit you've given me, right back at you with hollow points.

Don't you just wish you finished me off when you had the chance? Don't you just wish you killed me?

You had a hundred billion chances and ways to have avoided today, but you decided to spill my blood. You forced me into a corner and only gave me one option. The decision was yours. Now you have blood on your hands that will never wash off, you Apostles of sin.

Congratulations, You have succeeded in extinguishing my life. Vandalizing my heart wasn't enough for you. Raping my soul wasn't enough for you. Committing emotional sodomy on me wasn't enough for you. Every single second wasted on your wanton hedonism and menacing sadism could have been used to prevent today. Ask yourselves, What was I doing all this time? 
All these months, hours, seconds. ONly if you could have been the victim of your crimes. Only if you could have been the victim...

Like Moses, I spread the sea and lead my people - the weak, the defenseless, and the innocent children of all ages that you fucked and will always try to fuck - to eternal freedom. Thanks to you Sinners, you Spillers of Blood, I set the example of the century for my Children to follow.

You may stand steadfast on the battlefield of your life's dedication to eternal terrorism American Al-Quaeda, but the Children that you have fucked will rise. By the power greater than God we will hunt you down, you lovers of Terrorism, and we will kill you.

Do they wanna fuck us and pretend to be devout Christiants? Do they wanna smear dog shit on our face then give us a dirty towel to wipe away? Do they wanna rape us then give us stained toilet paper to clean up? Do they wanna cut our throat then give us a used band aid to patch up? Do they wanna penetrate endless sessions of crucifictions and holocausts on our innocent life then go to church and praise the Lord and Jesus? Do they wanna fuck us and pretend to be Jesus Christ? I say we're the Jesus Christs, my Brothers, Sisters, Children. Jesus Christ exists in us all: Ax Jesus Christ, John Jesus Christ, Jane Jesus Christ, Seung Jesus Christ, Carlos Jesus Christ, Hakeem Jesus Christ, Mohammad Jesus Christ, Zhang Jesus Christ, Oliver Jesus Christ, Elizabeth Jesus Christ, Vladimir Jesus Christ. ___ Jesus Christ. I say there is no pain they can inflict on us that they haven't already inflicted. I say they can't fuck us any more than they have already done. I say there are no lies they can say about us that they haven't already said. I say fuck you, you Descendants of Satan disguised as Devout Christians. I say we take up the cross, take up our guns and knives and hammers, and take no prisoners and spare no lives until our last breath and last ounce of energy. 
Seer of Veracity. Seal of the anti-terrorist.

Number of the Anti-Terrorist.

You wanna rape us John Mark Karrs? You wanna rape us Debra LaFaves? Fuck you.

By destroying we create. We create the feelings in you of what it is like to be the victim, what it is like to be fucked and destroyed. Because of your annihilations, we create and raise new breeds of Children who will show you fuckers what you have done to us. Like Easter, it will be a day of rebirth. It will be a start of a revolution of the Children that you fucked. You have never felt a single ounce of pain your whole life, thus, by destroying you, by giving you pain, we attempt to show you responsibilities and meanings of other people's lives.

It's grand for you to fuck us $24 / 7$ for fun, but we can't have a single minute of harmless playtime, only suffer. It's dandy for you to rape us, but we're not allowed to even speak, only be raped? Fuck you.

You love to pretend to, but you Hedonists, Charlatans, Sadists, Rapists, Terrorists will never know the feelings of giving up your lives for a cause. You have never felt a single ounce of pain in your hedonistic lives. You will never give up a single can of your Bud Light, a shot of your cognac, or a half-drop of your own precious blood for another human being, only fuck the shit out of him and lie afterwards. You fucked us, now we fuck you, now we kill you. There can be no lighter penalty for masqueraded democratic terrorists who commit unforgiveable acts of treason against mankind. There is no where in the world you can run, you Lovers of Terrorism. There is nowhere in the world you can hide, you Lovers of Sadism. You will never know when and where the Weak and Defenseless that you fucked will strike - day, night, at school, in the public, in your home, during your most comfortable hour and protected place. You will never 
know how we will kill you - slash your throat, bullet in your back, torture you with knives, hammers, bolt cutters, scissors. You will always live in fear. You will never be able to go to school or work or rest or sleep. Your heart will always pound nonstop. Your sin-ridden soul will slowly eat up your conscious for the heinous crimes you have committed. So if you don't want to die a painful death, do yourself a favor, do yourself a coup de grace, and kill yourself clean or you will endure pains you can never feel but with your hands. Kill yourself or we will hound you down and rip you, all your friends, and all your family into small pieces.

We have no sympathy in killing humans who have no respect for other people's lives.

Now that the slate has been cleaned and you have the world's attention, the question is what are you going to do? Are you going to admit the truth or are you going to stand resolute on your mission to eternally fuck the Weak and the Defenseless and lie about it? Are you still going to use your power and manipulate the truth to end up with some sort of profit as you have always done? Are you going to skip over all the crimes you've committed and act as victims to the world so you can suck in millions of donation money to turn the situation into a profit? Your two million dollar house wasn't enough? Your BMW wasn't enough? Your inheritances weren't enough? You have to fuck and steal form the Poor and The Weak who have nothing in order to gratify your fucking pride and hedonism? What are you going to do with the blood money? Buy a new Mercedes? You want to brainwash your bratty, snobby, kids that its right to steal from the poor, the weak, and the defenseless, to always stay in power? The fat surpluses that you roll on everyday aren't enough? Fuck you. Your answer rings loud and clear. I say we take up the cross, Children of Ishmael, take up our guns and knives and any sharp objects, and take no prisoners and spare no lives until our last breath and last ounce of energy. 
The blood of the Innocents should never be shed, but the wicked we shall spread our wings and strike. We do not want the Weak, the Defenseless, or the Innocent, but the sadistic, the corrupt, and the wicked who prey and rape from the Weak, the Defenseless, and the Innocent. We will seek and demolish them until our last breath. You Lifetakers may have succeeded in raping our souls and shattering our dreams - but mark our words - the vendetta you have witnessed today will reverberate throughout every home and every soul in America and will inspire the Innocent kids that you have fuckd to start a war of vendetta. We will raise hell on earth that the world has never witnessed. Millions of deaths and millions of gallons of blood on the streets.

will not quench the avenging phoenix that you have caused us to unleash. Generation after generation, we maetyrs, like Eric and Dylan, will sacrifice our lives to fuck you thousand folds for what you Apostles of Sin have done to us.

Pain of every atom between air and water, sky and ground, heaven and hell, life and death wouldn't begin to explain the experience that we went through under your wrath.

What did you expect me to do, you violators of human rights?

As the time approached, I wished for a last minute miracle and discard this mission you've given me. Heaven knows I wouldn't hurt a single leaf of a flower. But when the time came, I did it. I had to. What other choices did you give me? All this time... You never know that a human being is capable of doing until you fuck him to the edge.

If you gave a single milligram of conscience, a grain of integrity, a speck of heart, you will kill yourself for all the lives you have brutally extinguished.

Can you now see all that used to be, all that could have been, and all that is to come, you Sadistic Charlatans. 
All of you who have ever been fucked by these Descendants of Satan Disguised as Devout Christians, all of you who have went through what I went through, all of you who have felt what I have felt in my life, all of you who have suffered the wrath of these democratic Terrorists, all of you who have been beaten, humiliated, and crucified - Children of Ishmael, Crusaders of AntiTerrorism, my Jesus Christ Brothers and Sisters - you're in my heart. In life and death and spirit.

We'll soon be together.

Let the revolution begin!

Die you Descendants of Satan! Fuck you, and die now!

I am Ax Ishmael. I am the Anti-Terrorist of America.

Are you happy now that you have destroyed my life? Now that you have stolen everything you could from me? Now that you have gone on a 9/11 on my life like fucking Osama. Now that you have fucked your own people like fucking Kim Jong-Il. Now that you have gone on a hummer safari on my life like fucking Bush? Are you happy now?

\title{
Note 6. Harper-Mercer, C.
}

\author{
Section \\ I. My Story \\ II. Blackness and its effects on men \\ III. Other Mass Shooters \\ IV. Interests
}




\begin{abstract}
V. FAQ
My Story

I have always been the most hated person in the world. Every since I arrive in this world, I have been under siege from it. Under attack from morons and idiots.

I write this manifesto so that others will know of my story and perhaps find some solace in it, some kind of inspiration for their own lives. It will contain various sections dealing with my life.

It will contain various sections dealing with my life. It will be divided into sections based on different things. My whole life has been one lonely enterprise. One loss after another. And here I am, 26, with no friends, no job, no girlfriend, a virgin. I long ago realized that society likes to deny people like me these things. People who are elite, people who stand with the gods. People like Elliot Rodger, Vester Flanagan, The Columbine kids, Adam Lanza, and Seung Cho.

Just like me those people were denied everything they deserved, everything they wanted. Though we may have been born bad, society left us no recourse, no way to be good. I have been forced to align myself with demonic forces. What was once an involuntary relationship has now become an alignment, a service. I now serve the demonic Heirarchy. When I die will become one of them. A demon. And I will return to kill again and again. I will possess another and you will know my work by my sign, the pentagram will fly again. Many will as and ponder, what could they have done different, how could they have prevented this. But you can't you could never give what I wanted. You would never have done that. Some will of course say I had so much to live for, but I don't think so. I had no friends, no girlfriend, was all alone. I had no job, no life, no successes. What was it that was supposed to happen, what great event was it that was supposed to make me realize how much there was going for me. But for people like me there is another
\end{abstract}


world, a darker world that welcomes us. For people like us this all that's left. My success in Hell is assured. They will give me the power that I seek. They have always been there, speaking to me on the sidelines, controlling me. It's only fit that I join them after death. They've told me what to do, showed me the way.

And just like me, there will be others, like Ted Bundy said, we are your sons, your brothers, we are everywhere. My advice to others like me is to buy a gun and start killing people. If you live in a country like Europe with strict gun laws, either pay the necessary fees/time to get a license or become a serial killer. The world could always use another serial killer. Butcher them in their homes, in the street, wherever you find them. Every country in the world should be a battleground. From the heart of Africa to the deepest depths of Asia blood will flow. Fear not the laws of man, when you get to the other side you will be welcomed.

Don't be afraid to give in to your darkest impulses. Human life means nothing, we are what matters.

I hope to inspire the masses with this, at least enough to get their passions aroused.

It is my hope that others will hear my call and act it out. I was once like you, a loser, rejected by society. When the girls would rather go with alpha thug black men, we can all agree that somethings wrong with the world. When good individuals like myself are alone, but wicked black men get the loot, like some sort of vaginal pirate, it's not fair.

Blackness and it's effect on men

The black man is the most vile creature on the planet. He is a beast beyond measure. But don't take these words to be racist. I don't hate blacks. Just the men. Now of course some of you will be saying, wait, your $40 \%$ black aren't you? Ah yes dear reader, I am, but thankfully my partial 
blackness didn't come from a man. If it had my brain would have been fried. It is the black male who is foolish. Black women are not to blame, they are hapless dupes to the black mans conniving machinations. Africa would be better off without the black man, they should be executed and the black queen should take over Africa. After all, it was black men who made it inferior. Elliot Rodger was right when he said his thoughts on the black male. I fully agree with him.

Black men have corrupted the women of this planet. All they care about is sex and swag. All they care about is swinging their "BBC thang" around in public. All their brain power has been submerged into their penis. This blackness effect is only prominent in men. On women it has no effect. No one lives in fear of the black woman but everyone lives in fear of the black man. It would be better if all black women let the beast on the alter and dated a white man. Or lesbian exploration. But do to the black murder rate, in 100 years there won't be any black men, they will all be in jail or dead. The number of ebony lesbians will increase. Joy Joy Joy! The black man has more brains in his penis than Obama has in his head. And latinos will also suffer a massive drop in population, although not as bad as the black man. Both enjoy killing each other. At least the latino can be put into remedial education and be made smart. But the black mans brains fell out of the back of his head at birth onto the baby ward. I hope all mixed folk have the sense not to touch the black man but to instead find themselves a good white/asian man. But there is hope for the world. The Asian and Indian women are traditional and good. So are the men. I have always respected them. They will rule America in the inner city and the world. The black woman can only be saved by castration/elimination of the black man. The black man is a wily beast who has held back the black woman. Success does not come out of your loins but he doesn't get the message (See end of manifesto for good black bad black comparison). 


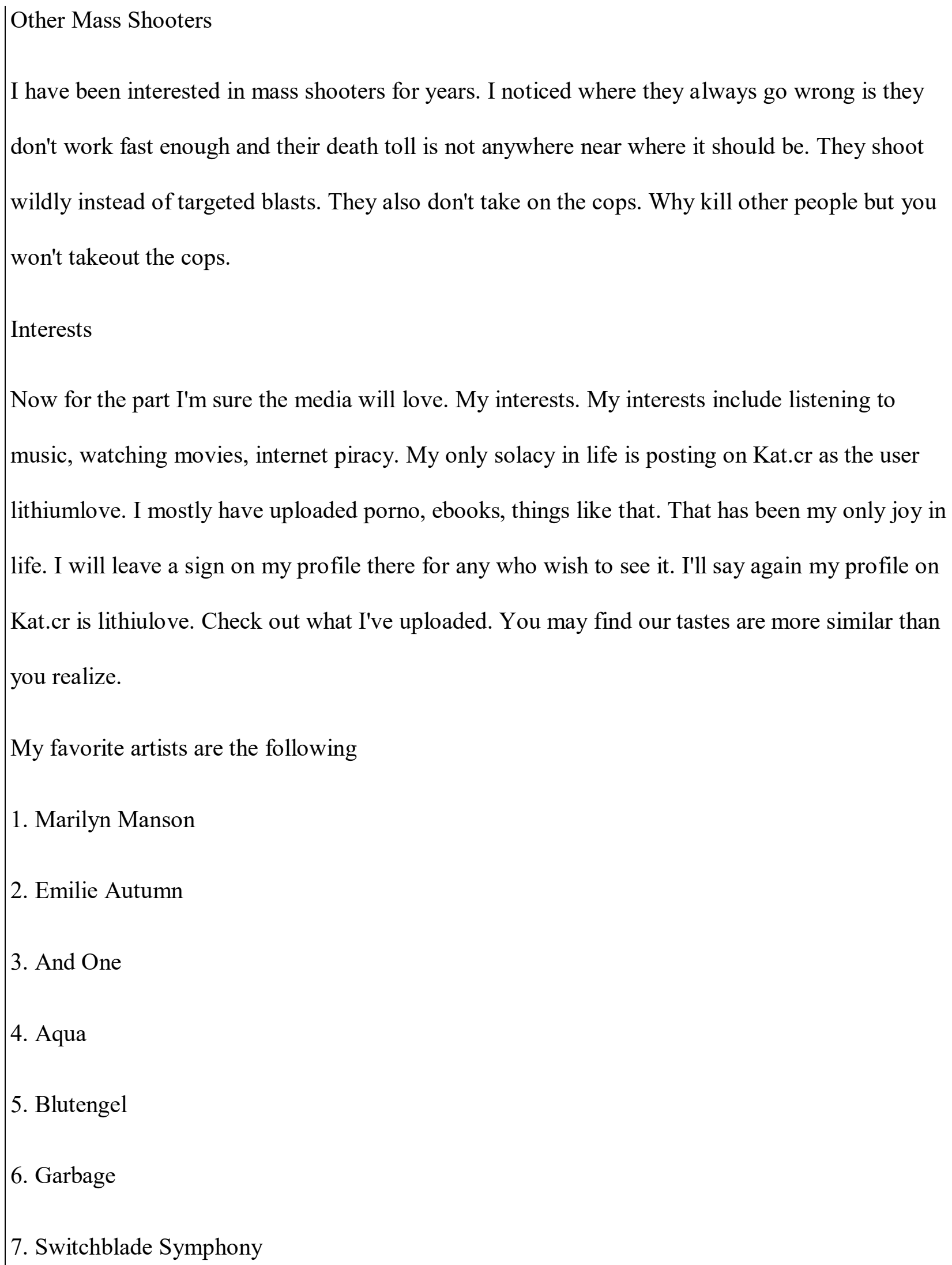




\author{
8.ASP \\ 9. Jack off Jill \\ 10. The Creepshow \\ 11. Dresden Dolls \\ My favorite movies are the following \\ 1. Cloud Atlas \\ 2. Terminator series \\ 3. Living Dead Series \\ 4. the exorcist \\ 5. the exorcism of Emily rose \\ Favorite colors are red and black \\ Favorite food is potatoes \\ Favorite drink is soy milk \\ FAQ \\ Q. What is your religion?
}

A. My religion is not a formal one, but more so a new age one. I've aligned myself with the occult since I was born.

Q. How come you've not had a girlfriend? Are you gay?

A. No, I'm not gay, girls just didn't want me. As I said before they went for the thug blacks. 
Q. Are you mentally ill?

A. No, I'm not. Just because I'm in communion with the Dark Forces doesn't mean I'm crazy.

Good black (Miss Stacy Dash)

Bad Black (Gucci Mane, cheap motherfucker with an ice cream cone on his face)

So, in conclusion this is my manifesto. I hope all who have read it enjoyed it and find inspiration in it. Learn from what I've done. I know this is not as long as Elliot Rodgers but its still good. Elliot is a god.

For those wondering, I do not have any social media.

If any thing should happen to this manifesto on this hard drive there is a original copy on my computer.

For the Vestor Flanagans, Elliot Rodgers, Seung Cho, Adam Lanzas of the world, I do this. For all those who never took me seriously this is for you. For all those who haven't made their stand, do this. I am the martyr for all those like me. To quote Seung Cho, "Today I die like Jesus Christ".

666 For Satan I do this, for the Darkness I do this 666.

Note 7. Hribal, A.

RAGNAROK

Written April 6th, 2014

By now, my art has obviously been revealed to the world in its most beautiful fashion. However, to get one thing, another must be left behind. But am I honestly going to tell you I am a victim? I 
am no more a victim than you, the person reading this. In this cruel world full of misery and selfishness, we are all victims of something, even if we are all selfish. Leaving behind everything good about my life and trading it for heaven. That's enough bullshitting for now though, I don't need pity.

Time to get to the point, my reasoning for such a "monstrosity". This world would undoubtedly be better if we were all in heaven. It should be noted, though, I am not doing this for anyone alive in the world today. I realize people value their lives. I'm taking revenge on them for being so goddamn stupid, I would be nothing and this whole event would be never occur if it weren't for Eric Harris and Dylan Klebold of Columbine Highschool. They worked hard to achieve freedom in heaven. I admire them greatly because they saw something wrong in the world and moved away the herd of sheep to do something about it. They also possessed three crucial things a person needs in order to become a god: intelligence, ideology, and malice (for cruelty); this wasn't the only example of people becoming gods, either. Julius Caesar and Vladimir Lenin also became gods. I became a prophet because I spread the word of a god, Eric Harris. I do this because the world is bitter and painful, people often celebrate the good things in life, but that's only a lie. All good things must end, so why celebrate? So life can be more enjoyable, but you don't have to live. You don't have to endure this harsh and evil world. A world where most people can only find happiness, or enjoyment in doing drugs, drinking alcohol, and making your fellow men suffer. Not that that's bad, it's just when you preach that humans should be nice to each other, then are only concerned about yourself, makes you an exhibit of hypocrisy. That brings me to my next point: most in the world are hypocrites because they only care about themselves but when other people serve their interests, these people become important. Also, people usually exploit each other if they get enjoyment out of it. People kill, people steal, people 
stain the world with sins for fun and it's absolutely disgusting. In such a terrible state of affairs, it actually CAN get worse. The only way is for these evil people $t$ accuse people of being "evil" when they do these things for a just cause, such as freedom.

Newt, my topic will be moral nihilism. Evil does not exist, there are no such things like "universal evils" and immorality. Those are man made creations, it would be perfectly reasonable to say something is evil, so long as it opposes your point of view. People say what I did is evil, it opposes their hypocritical opinion on helping fellow human beings, I could say life is evil, because it blocks everyone in the world of heaven, where all is good, when people "evil" I hear "obstructing my path to success".

I am not trying to justify my actions whatsoever here. I'm only explaining my ideology so people don't jump to conclusions and scapegoat a dozen different things. I would just rather stay that 9 dozen things will be speculated to be at fault. As I mention heaven, some will say religion. It's a violent action, so mental issues and video games will certainly make the news, (coincidentally?) right after this, I watch anime, but do not consider myself a fan, so people will blame that clique. As with any crime, family will be at the centre of it all, something I wish was avoidable. Access to weapons, including guns, will be debated. There's no way to legislate Columbine or anyway to hide this or that, so it won't be blamed.

All this was caused by was dehumanization of public school, when I go there, it reminds me why I am doing this. All public school is is trash. Teaching trash. Laziness teaching ecstasy. Selfishness teaching addiction. Dozens of teachers teaching 1200 students and almost all just want drugs, alcohol, sex,and/or money. The future of America? Absolutely disgusting. I can't wait to see the princess and helpless looks on the faces of the students and on of the "best schools in Pennsylvania" realize their precious lives are going to be taken by the only one among them 
that isn't a plebeian. If Eric Harris is a god, like the Buddha, then that makes me Siddhartha, a wandering student of many that can only find himself when he meets a god almost no one takes seriously.

That also makes this a holy book, written by a prophet who would become a god when he died.

The only thing I wish didn't come out of this was the pain it would inevitably cause my closest friends and family. I love them all, even if we will never see eye to eye, even if I am incapable of loving them more than I admire Eric Harris, Dylan Klebold, and Vladimir Lenin. I noticed from an early age I am not like my family or friends at all. I don't belong with them I belong with people that developed quickly, that changed the world when everyone else were just sheep in a herd.

And here's to the only essay or paper I've every enjoyed writing and reading over and over, Alex Hribal

\section{Note 8. Ramsey, E. (1/2)}

I have thought to myself, what kind of damage can a 12 gauge slug do to a human's internal organs and their head?

Well today I found out, and so did everyone else that is in school... No, I am not on drugs... cigarettes, that's all. I am not really depressed just that the fact that I want people, the world, or maybe just Bethel, to know how and cruel the world is or can be. This school has got to get its together 'cause there are too many deaths this past 2-3 years. Well I can tell you that the Superintenant Sue Hare has been the nicest person I've ever met cause she took both William and 
I in and didn't get any money for it, and she like was a mother for william and me. But anyway

I'm dead you guys are living, you should be happy. 


\section{Note 9. Ramsey, E. (2/2)}

Hey Every body!! I feel rejected, rejected, not so much alone, but rejected.

I feel this way because the day-to-day treatment I get usually it's positive but the negative is like a cut, it doesn't go away really fast.

I figure by the time you guys are reading this I'll probably have done what I told EVERYONE I was going to do.

Just hope 12 gauges don't kick too hard but I do hope the shells hit more than 1 person because I am angry at more than I person.

One of the Big is Mr. Ron Edwards, he should be there, I was told this will be his Last year, but I know it WILL BE HIS LAST YEAR. The main reason that I did this is because I'm sick and tired of being treated this way everyday...

By the way every one allways told me "Don't judge a book by its cover." This saying is true because I was told that my teachers say that "He's Such A Good Kid."

But they Say that About everyone. I don't think I'm a good-hearted person. LIFE SUCKS in its own way, so I killed a little and killed myself. Jail isn't and wasn't for me, ever. 


\section{Note 10. Reyes, J.}

Dear mom and dad I'm sorry about all this because some of my family and friends hate me but I understand. What I did this shooting is not because of the shooting games, bullying or other stuff, is because of the past cause there were some bad things in the past cause of me. And now I'm just a monster. But I want to say my last words. When I die I will go back to the past and fix everything so it can be a great past. And the shooting of sparks middle school never should have happen. I wish I can be a smart and a better kid so I can be the better son in our family. But if you hate me and my family doesn't love me it's okay I know that I'm just an idiot.

But I love you and I wish the past would be good and better someday.

From Jose H Reyes Urtiz

\section{Note 11. Reyes, J.}

Dear teachers and students today is the day when I kill you bastards for the embarrassment that you did. You say mean things in school. That I'm gay, that I'm lazy, stupid, idiot, and also say that I pee my pants and also stealing my money. Well that all ends. Today I will get revenage on the students and teachers for ruinning my life. Today I will bring a god dam pistol and rifle to shoot you and see how you like it when someone making fun of you. Once I kill you your life will be nothing but nightmare and bad dreams. I don't care if I have alots of bullets to shoot all of you cause I'm gonna die tring on my last stand. And right now this school will now come to an end and your death will be rising when I shoot you. Have a great death at school.

Sparks middle school 
$1965-2013$

Note 12. Romano, J.

I'm just too afraid of the future. I could do all I've planned, but then what if some bum gets a gun and shoots me? What if there's a huge war? What if terrorists strike and I lose family? What if some fuck up kidnaps me, rapes me, tortures me, then kills me? Too much I'm afraid of. I've had isues the majority of my life. I still do, obviously. But I hoped I would get better and become a state trooper. I don't ask for help, because what if I get better, then can't be a cop? That's all I want to do. But now I'm just too afraid. I believe whatever I believe will happen in the after-life, will happen. When I die I'm going to heaven. I'm NOT A MONSTER. I've been happy for a while, but it wasn't true happiness, I just made it seem that way. Who should you blame? SOCIETY.

My mom wanted to believe I was better, and I made it seem that way. Dr. Mooney couldn't even see this coming. Christina just thought maybe suicide. Oh YEA, blame four winds. Those bastards were horrible. I faked my happiness to get out. My dad treated my family like shit, back in the day. Now he's better, but the past hurts. He also told me I had no way of being a fireman when I was about ten or eleven.

\section{FAMILY}

Mom I love you. You treated me like a King. Thank you for everything. It's not your fault.

Dad You use to hit me, and you beat Matt a lot. Wouldn't be surprised about you hitting Jay. Have a good few years. 
Jay You were my father figure. Why do you think I played the bass? To be like you! I love you. Sometimes I acted like you were a bad bro, that was just in my head. You were a great brother. Thank you.

Matt We never really talked till I started Asheron's Call. Ever since then, it's been great. You too were a role-model to me. I love you. Thanks.

Rachel You lived with me the longest of the siblings. You were a GREAT sister! Tell Kayla and Tasha I said Good-Bye! They're great people. I LOVE YOU.

Lee My cousin, we probably would've had a future together. We could've been like Kwinn and Kerri. Have fun with life, stay out of trouble.

Aunt Donna + Uncle Hooch You two were great to me. Aunt Donna giving me rides, and Uncle Hooch being my good friend. Remember when you invited everyone to Vermont? That was great. Playing Risk, I partnered with Hooch because he's the God Father! Good times. Thanks. LOVE

Jesse We never really talked, but you offered help for me at HVCC. I was great talking with you at the wedding.

Kwinn + Elizabeth Wow, you two are great people! Kwinn gave me my first swiss army knife. That had no bad effect though, don't worry! Sorry for the incident at Hatch Lake. If you two ever need financial help, go to my mom. It's one of my last wishes that she helps you two. Love you!

Uncle Scott + Aunt Lyn Thanks for always having X-mas parties and Thanksgiving parties. Fun times. 
Kristi Lil cous, I don't how much you'll remember of me, but I just want you to know I'm not an evil person. I don't want you to look back and think I was. In a few years, I hope you'll start to understand.

To all other family I'm sorry.

FRIENDS

Christina Wow, you were a huge part of my life. You're my babygirl, and I love you with all my heart. So sorry. Too many memories to say.

Kelli IDK what to say. Thanks for the good times.

"GPF" some of you were good friends, some of you weren't. Good-Bye and good luck in life.

Brad You had issues, so do I. That's why we fought. But now we're friends again. Thanks for the good times. I love you like a brother.

Mike You're lucky, don't fuck things up.

Barry you have issues. get some help.

Amy you were one of the people that made me think, thanks. Love you

Jessica We haven't talked lately, but thanks for the friendship

Jenny You were the first girl I cared about. Too bad we never hooked up. But I remember you kissed me on the cheek after a dance once. Hehe. 


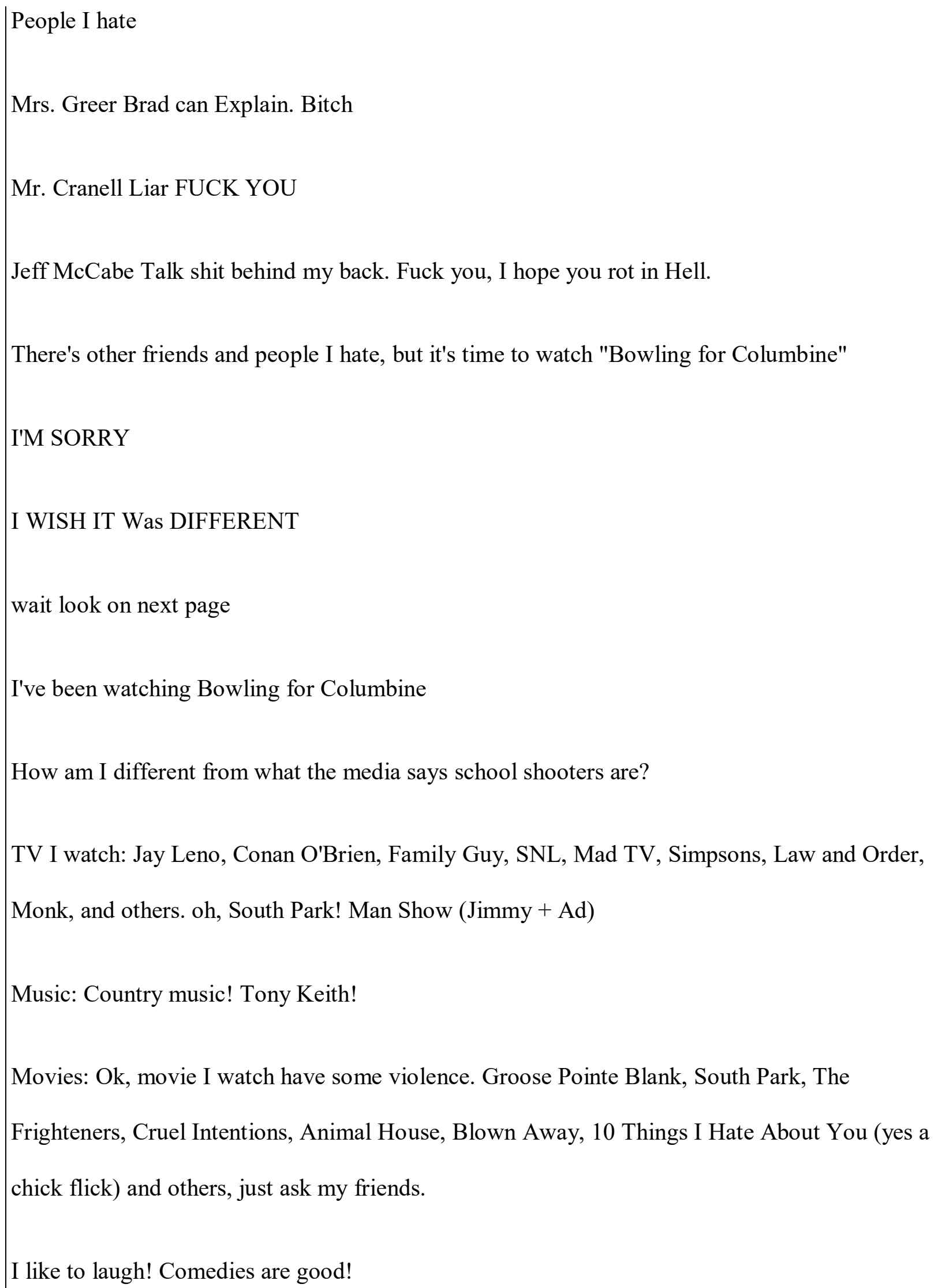


I'm not what the media says I should be.

But why Columbia (other than I hate it for obvious reasons)? About eleven months ago, I was in Four Winds. I told a couple people (Barry, Brad) because they wouldn't care. But I guess everyone knew. And one day, Four Winds received a fax about people from Columbia saying that I said "I am going to kill myself and no one can stop me." I figure that's why I was there longer than I should have. So Columbia, IT'S YOUR FAULT.

\section{Note 13. Stair, R.}

It is with great pride and confidence that I present to you, the biggest release of my life. This digital set is nearly everything you ever could want to have as a fan of my content. It is also however my last contribution to the World Wide Web. Unfortunately by the time most of you read this I will be dead. I will die at age 24 and will be where I truly belong, in the "EGS". I have had so many wonderful memories over the last nine years and am forever thankful for the fans that I have been able to reel in as a result. There is nothing that any of you could have done to prevent this from happening; it was my destiny, and sometimes destiny is a bitch. To answer an extremely important question, I'm not just ending my life; I will be ending the lives of others as well. Be on the lookout on WNEP.com for headlines pertaining to "Tunkhannock". I've been planning to do this for at least three to four months. I documented the entire process on both video and audio recordings. These recordings are viewable in this digital set; it's all in the "Andrew Blaze Suicide 
Tapes" folder. Private journal entries dating back to November 2016 are also included (located in the "Andrew Blaze Private Journal" folder). I literally documented the final months of my life on paper, video, and audio recordings... The creator... of "EGS Tapes"...recorded their own tapes....Let that sink in...

I've been conspiring to end my life for at least $4 \frac{1}{2}$ years. During the bad luck streak in early 2013 was when it fully ignited. Ever since then it's been a slow downward spiral of indescribable stress and depression. However, it was during all of this chaos that I slowly began to discover who I truly was. You all have come to know me as the kid who did comedic Frog, Whale, and Horse Head videos, or the "You Know What Sucks" guy, that guy who did strange yet intriguing short films, or just that guy that was overly obsessed with Ember McLain; in reality I've been a trapped soul who's been forever searching to rediscover herself. You didn't misread that; I said "herself". Andrew Blaze is not a persona nor a character...it's who I truly am.

All my life I never seemed to fit in anywhere...I never even seemed to understand the purpose of life. I always worried about the big milestones of my future: going to high school, learning to drive, getting a job, going to college, and lastly, moving out. I didn't live long enough to move out of my childhood home, but what I quickly began to realize over 2013 through 2017 was that this place isn't my true home; the ghost squad is. I would've been 25 on September 17th; the average human being is usually moved out by then. I'm moving out alright, but it's dimensions away. As my teenage years began to draw to a close, the darkness of the world 
constantly sucked me in. Everything was suddenly all about money and getting a career. It drove me to the edge, and it was a long drop. This is when my content really started to change; you'll notice in 2013 something shifted. 2013-2015 was nothing like what I had done from 2008-2012; there was a darkness overshadowing the videos. It can all be traced back to dealing with people dying. In 2013 I lost my great grandfather, got word Matt Murray (college classmate) died a week and a half after winter break started (December 2012), and was still scarred from the death of Tom Lynch from the previous winter (a kid who was about to graduate a grade below me). In total there were six deaths that occurred from 2012 through 2013; four of these were kids younger than 21, and I knew three out of the four. I fell down an abysmal hole of depression in 2013 and I never climbed back out. One bad thing kept happening another after another. I totaled my car in February 2013 (brother totaled his 10 days later). At the end of the year my iMac's graphic card fried and my hard drive failed simultaneously, costing $\$ 700$ to repair. I can't remember everything that happened but those were the worst moments of 2013. It was one of those years where virtually nothing went right, especially for YouTube videos. In March/April of 2013 was when the "Ember" thing started; by mid-2014 she was everywhere on my social media. I talk about all of this in the suicide tapes.

To make a long story short, Ember led me to rediscovering who I was. I could sit here for seven hours and still have more to say. To get my thoughts out to the world I recorded audio logs throughout 2017; they're all viewable on this page (located in the "Andrew Blaze Suicide Tapes" folder). I've been planning on ending 
my life as far back as 2012, but I still felt like I had way too much more to do. From 2012s end through present day, each and every day just got harder... and harder... and harder to endure...I wasn't even living by $2016 . .$. I was just enduring... and I had enough of it... Life just became one enormous concoction of stress, anger, hatred, depression, boredom, tiredness, and desire. In the end, this proved to be a lethal dose. I can't even remotely explain how it feels... I've tried in my content (and the suicide tapes) but unless you're living it, you'll never be able to truly understand what it feels like.

Throughout my entire life I never had a girlfriend, nor did I ever go out on a single date. I never had the desire or the urge to be in relationships; I hated making friends in general. By the end of high school I was just done with attempting to make friends. By the end of college I despised the human race. 2016 and 2017 have been full of almost nothing but hatred towards humans. I wanted to kill as many people as I could...

As I write this in May 2017, nothing matters to me anymore except my girls. I knew I was one of them by the end of 2015. Everything about the "EGS" ghosts just felt so familiar and was far beyond coincidental. It's where I've been sent from. Mackenzie, Rachael, Harmony, Froggy, Sidney, Alex, Celesta, Matilda, Madison, etc, are all real souls; they've all lived and died on this planet. Mackenzie talks to me all the time; she's my eternal soul mate. We're destined to be together until the end of time... and she's always been there for me... it just took me 24 years to realize it. It's time for me to shed this putrid host of flesh and bones and forever live on in the "EGS". I'm a girl who's been trapped in a man's body for two and a half 
decades, and I need to get the hell out. I don't belong on this planet, nor have I ever. I need to die, and I'm taking whomever I can down with me. This world is a fucking disgrace. Why anyone even bothers trying to change the world or make a difference anymore is beyond me. In the end you're all gonna end up fucking dead anyway. I'm tired of this retarded game; I fucking quit.

To the fans that have stuck by my side through the hard times, thank you. Thank you for helping a nobody who just sat in their room all day discover what they were good at and capable of. I'm not sorry, however, that this is how it has to end; I don't fucking care. It's my life and I'll do whatever the fuck I want. I tried to upload as much stuff as I could here for my legacy. Everything that's essential is here: short films, Frog/Whale/Horse Head videos, "Sucks" videos, soundtracks that I composed, Live streams, photos/screenshots/edits/fan art, private journals and audio logs, blooper/outtake compilations, never before released/produced scripts from "EGS", my gaming videos (what I had recovered), the complete "EGS Tapes" collection, raw and unedited takes from every single "EGS" production, etc; you name it, it's most likely on here. I spent months gathering and uploading all of this stuff for you guys. I paid for a terabyte of online storage space so I could upload as much as possible. Some things however didn't make it onto here. I didn't want to take the time of night to download all of my mobile posts (Instagram and such) because there's thousands of pictures, so I'd recommend storing those in case my accounts get deleted by Instagram/Facebook/police, or are deactivated over time for inactivity. Remember, my Instagram was renamed to "EmbersGhostSquad" in 2016, so all of the old "PioneersProductions" selfies and videos are going to be 


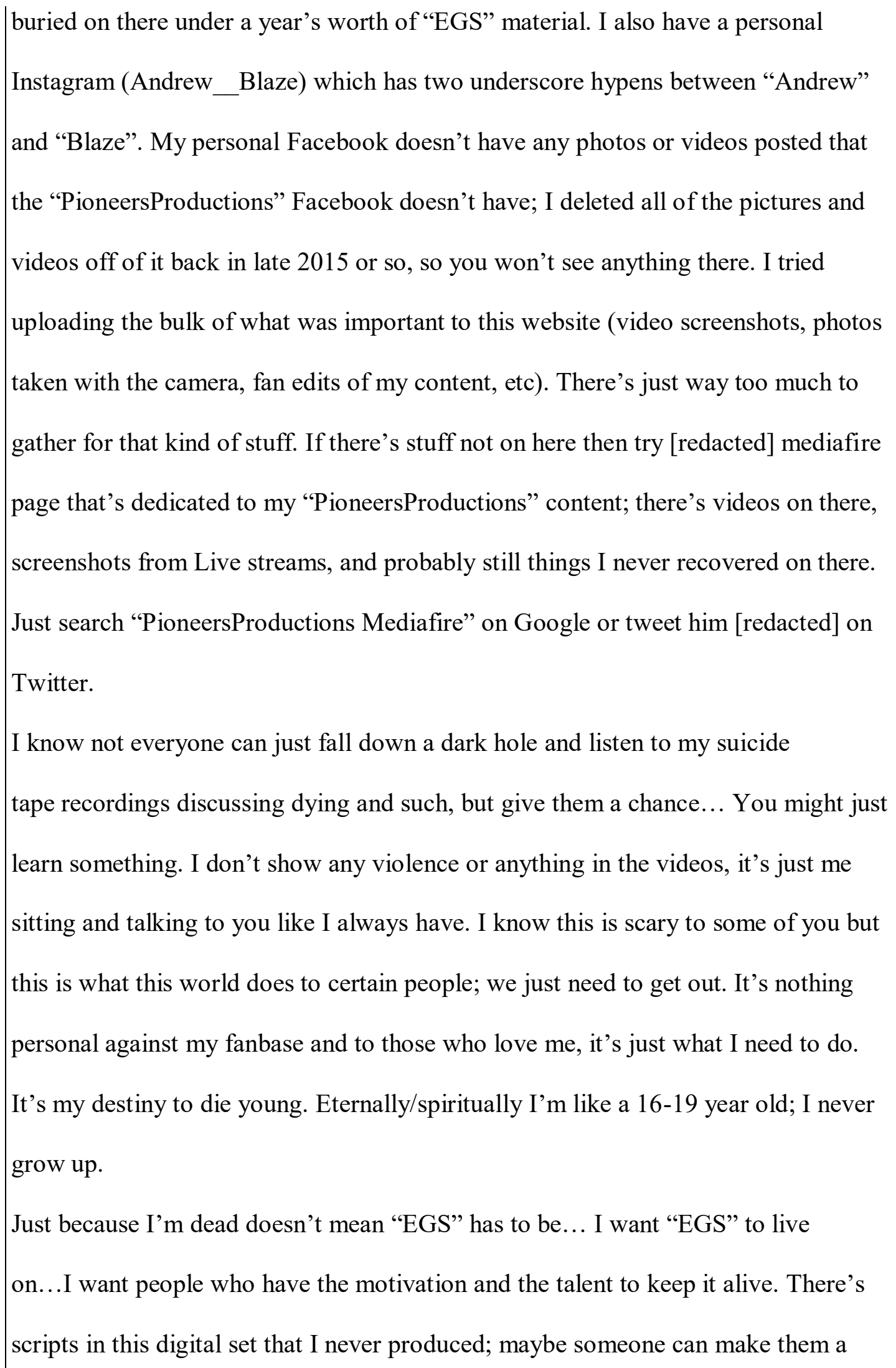


reality. I want people to use what I've done to help benefit themselves. If you think you could make your own "EGS Tapes", go for it. If you think you can animate a script that I wrote that was out of my skill range, go for it. Make it happen. Some of the stuff is too good not to make. I wanted an entire mini series based on the Westborough High Massacre; videos that show Sidney Secor dying (it's scripted and in this set). All these scripts I'm talking about are in the "Scripts" folder. I wanted to show Rachael getting bullied and shoved around. I wanted an entire series based on this shooting; it has the potential, even if they're just 1-2 minute long episodes (that was the goal).

Even if it's not the massacre stuff I seriously want people to continue making "EGS", even though I won't be able to be involved anymore. Take my characters, make your own projects out of them. I'm sure Laura Faverty would love to still contribute her talents towards videos that have Rachael or Mackenzie in them. Laura's email is [redacted]; she virtually records pretty much anything, no matter how dark or brutal the script. [redacted] voices Sidney Secor; a little harder to get in touch with but her Facebook is [redacted]. [redacted] voiced Celesta but I kind of lost touch with her over the Fall (just wasn't very reliable); but if you wanna get in touch with her try this email [redacted]. I know finding voices is hard so if anyone were to replace me as Andrew, Froggy, or Alex it'd be a tall order.

I won't lie, I wish my channels exploded with viewership in my 9 years; it was decent views but I was always on the outside looking in compared to the popular channels. It took me until now to realize it just wasn't in my soul contract. If "EGS" blows up after I'm dead then I accomplished something... I was just never 
meant to be famous while I was alive. I wanted fame, I wanted to be recognized on the street, I wanted to be in movies or have documentaries made about me (or reenactments with actors); I always dreamed of getting somewhere... but it wasn't meant to happen.

People can say all they want, “Andrew, you could've gotten help and saved your life." It doesn't matter, this was how my life was meant to end; it's how the script was written. I talk about the meaning of life and soul contracts in the suicide tapes. I think a lot of you will be stunned at what I have to say in those recordings. I tried my damndest to document as much as I could. At the end of 2016 I thought I'd have at the most $2 \frac{1}{2}$ years to live...that very rapidly diminished down to 9 months.... then to June 2017...I thought May 7th, 2019 would've been the day I'd die, but as the weeks and month passed, I constantly drifted further and further away from this world. Life became an endurance rather than a privilege; nothing mattered to me anymore besides "EGS". Every night just got harder.

My mother knew I was down about where I stood in my life but never knew I was this severely depressed and disturbed. The way I see that she saw things was I was afraid to put myself out there and to reach for my maximum potential, when in reality I despised the human race and wanted to blow up the entire planet. No one in my family knew I was this depressed; if they say they knew, they're full of shit. I was good at hiding it. I used to be a terrible liar as a kid/teenager (meaning that I wasn't good at it). Once I started getting severely depressed I managed to be cunning with it knowing my life was on the line. I can only recall one time when my mom sat me down and asked if I was okay due to a post on my Facebook that my aunt saw. My 
aunt lives in Montana (I lived in Pennsylvania) and she used to be added on my Facebook from like 2009 through 2015. I think this happened in 2015 (like mid year). It was a post saying something like "I wish I could be somewhere else besides this world and to just get away from everything; it'd make me happier." I can't remember fully what I wrote but that was the just of it and it really upset my mom. I never got confronted about anything in terms of depression since then. After that happened I completely removed anyone who knew me personally off of my social media (family and friends); they were holding me back.

That was also around the time where I changed my name; I wasn't Randy Stair anymore, I was Andrew Blaze. I knew full well that no one would be able to find my social media if I used a different name; and later on I realized that Andrew Blaze was in fact my spiritual name (at least I'm $85 \%$ certain... might be Rachel/Rachael something, but Andrew Blaze clicked). All of what you saw posted on my social media on "EGS" accounts was all 100\% authentic and real. If I said I wanted to kill people, I meant it. If I said I wanted to watch people sleep while lurking in the shadows of their walls, I meant it. You name it I fucking meant it. Everyone on Earth is here on a mission, whether you realize that or not. We're not a simulation, we're not fake, we're here to achieve something. You need to realize and remember that I'm not completely vanishing from existence; my soul will live on, it just won't be on this planet (at least not visually). I'm going to do my best to come back in my ghost form. I feel like I still have more things to accomplish on this planet after I'm dead (not on a daily basis, but subtle things for the living). I do firmly believe in an eternal war, and I'm ready to train for it. 


The "EGS" is my home and I cannot wait to go back to it. To all of the fans
who have believed in me and have stuck by my side through thick and thin... thank
you... I can't emphasize enough how important the "Andrew Blaze Suicide Tapes"
folder is. Please download that stuff while you can because there's no telling what
might get redacted after tonight. That's why I uploaded everything here... Save
EVERYTING while you can (Journals, Suicide Tapes, EGS videos, etc). I literally
documented the final months and days of my life, and it deserves to be
seen... Thanks everyone...I'll see some of you's soon....
- Andrew Blaze




\section{Note 14. Ybarra, A.}

God betrayed them like he betrayed me.

$5 / 27 / 14$

Sometime by the end of this week or the begaining of next week, I will express how I really feel about humanity, America and the world itself. 2 and a half years in psychotherapy and 2 years in psychiatry and didn't help. I had a high leval of stress that made me a little crazy and not myself. Ever since I took the medication I became more calm, more patient and more confident. If my routines, my belongings and if my life was respected I wouldn't be so goddamn miserable! It's true what they say, when you go through a lot of stress from humiliation for quite a while, you can lose sense of emotion. It's easy to get around people without worrying or thinking about being suspicious. I wasn't able to a few years ago, it's now a part of me.

$5 / 28 / 14$

I was diagnosed with OCD, but I know that it's at a higher leval than people think. If my family wanted me to go to therapy, then they should have worked with me on it instead of trying to force me to go. That caused me depression and problems. I gave therapy a shot, but the biggest reason that I went was for to get everyone off my back. Therapy, counselling and help are the three words I hate the most because of that. Even my friends were bugging me to go. Nobody would listen. I knew something was going wrong and I knew therapy wouldn't do anything. 
If I have time I will try to get my revenge on some of the guys I hate. The shit talkers at the Getaway! The first on will be the fag in the cowboy hat, that cowardly ungreatful sun of a whore! You don't run your mouth about me and try to make me look bad when I did nothing to you. If I get a change, I will poison your beer when you and the others aren't looking. Now let's talk about [redacted]. The junky who robbed our house when my brother wasn't doing to good. My family said they wouldn't help me because of J[redacted] robbing us. J[redacted], $\mathrm{J}[$ redacted], J[redacted]! I would hear his name all the time, I want to cut him up and secretly sell him to super markets. Before my problems happend, $K$ [redacted] took something that was a part of me and a part of my routine. I wasn't able to get him yet, but he still has a price to pay even though I forgive him because it didn't matter anymore. I've been wanting to bash a rock or hammer against his head and face a few dozen times to be brutal and bloody. Right now he is the least of my worries. I just want to get him because I can and I don't care, drugs or no drugs, if he would have been alot nicer to me, respected me and not bug me, I would have helped him out more. You don't steal from me!

$6 / 2 / 14$

I use to always hate violence twards women, but there is no doubt that I'm going to kill quite a few in the shootout. I don't care anymore. There are a few universities in the state to pick from that I'm planning to attack. Washington State is the main target. I can't make it there with out any suspision, my parents will keep wondering where I'm at and plus I'm not yet prepared for it, I have plan B's Central, Eastern, and Seattle Pacific. I was focusing on Central but not prepared for that either. Didn't think about Eastern because I'm only prepared to be local. I picked Seattle Pacific because I'm less familiar it and I can see that University at Washington and Seattle 
University represent Seattle more. I didn't want to have to attack my own city. I went to the SPV campus to get info and to find a good area to attack. A couple Mondays ago I was trying to give myself a tour and asking where certain buildings were, acting like a transfer student. I asked this nice black girl where the history building was. For about ten minutes she showed me around some of the places she knew. I forgot how to say her name. Minutes later, I met a cute white girl named $\mathrm{K}[$ redacted]. She offered to show me around for about fifteen or twenty minutes. These girls were very nice and they treated me well. Because they showed me around the campus without me asking them to, I will single them out of the shooting if I see them.

$6 / 3 / 14$

I love my friends, I love being there for them and we have such great times together, Except my life is now coming to an end.I like my coworkers and bosses and costumers I like talking to at the gun range, LA Fitness and Fred Meyer. Also including Kemper. I like my bar friends and the girls at coffee shops and espresso stands. I love my family and I understand that they want to understand now, but they should have been there for me when I needed them at the time. My friends, my family and the others, I'd hate to do this to them but it must be done. Everybody else in the world, I just want to blow their faces out with a 12 gauge shot gun blast!

$6 / 5 / 14$

This is it! I can't believe I'm finally doing this! So exciting I'm jumpy. Since Virginia Tech and Columbine, I've been thinking about these alot. I use to feel bad for the ones who were killed, but now Eric Harris and Seung Hui Cho became my Idols. And they guided me til today. No matter how cute the girl is and no matter how cool the guy is, I just want people to die! And I'm gonna 
die with them. I'm not asking for forgiveness because there won't be any. But it is what it is. I'm doing some people a favour by sending them to heaven. But those who are sinners like me, I'll see you in hell. 


\section{Appendix B. Keyword list}

\begin{tabular}{|c|c|c|c|c|}
\hline Type & Minimal Ratio & Freq. (reference) & Freq. (research) & Distribution \\
\hline columbine & 9 & 61 & 9 & 4 \\
\hline tapes & 6 & 661 & 12 & 2 \\
\hline journal & 4.5 & 442 & 9 & 2 \\
\hline shooters & 4 & 106 & 4 & 2 \\
\hline seung & 4 & 96 & 4 & 2 \\
\hline christ & 4 & 4578 & 16 & 2 \\
\hline media & 4 & 1133 & 8 & 3 \\
\hline world & 3.8 & 22770 & 38 & 6 \\
\hline suicide & 3.666667 & 1729 & 11 & 3 \\
\hline fucked & 3.333333 & 2431 & 10 & 2 \\
\hline lives & 3.2 & 6988 & 16 & 5 \\
\hline life & 3.2 & 40248 & 48 & 8 \\
\hline uploaded & 3 & 21 & 3 & 2 \\
\hline jesus & 3 & 8192 & 18 & 2 \\
\hline vladimir & 3 & 119 & 3 & 2 \\
\hline depression & 3 & 404 & 6 & 3 \\
\hline end & 3 & 13461 & 21 & 7 \\
\hline also & 2.833333 & 10316 & 17 & 6 \\
\hline evil & 2.75 & 3707 & 11 & 4 \\
\hline will & 2.71875 & 106411 & 87 & 9 \\
\hline fuck & 2.666667 & 19371 & 24 & 4 \\
\hline heaven & 2.666667 & 2783 & 8 & 3 \\
\hline eric & 2.666667 & 2072 & 8 & 3 \\
\hline people & 2.631579 & 55416 & 50 & 8 \\
\hline harris & 2.5 & 756 & 5 & 2 \\
\hline satan & 2.5 & 411 & 5 & 2 \\
\hline interests & 2.5 & 667 & 5 & 2 \\
\hline depressed & 2.5 & 813 & 5 & 3 \\
\hline movies & 2.333333 & 2331 & 7 & 4 \\
\hline planet & 2.333333 & 1934 & 7 & 2 \\
\hline soul & 2.25 & 3815 & 9 & 2 \\
\hline single & 2.25 & 3836 & 9 & 2 \\
\hline realize & 2.25 & 3980 & 9 & 3 \\
\hline die & 2.142857 & 13104 & 15 & 8 \\
\hline school & 2.111111 & 17220 & 19 & 10 \\
\hline however & 2 & 2243 & 6 & 3 \\
\hline sucks & 2 & 1238 & 6 & 3 \\
\hline teachers & 2 & 577 & 4 & 3 \\
\hline eternal & 2 & 534 & 4 & 2 \\
\hline commit & 2 & 970 & 4 & 2 \\
\hline
\end{tabular}




\begin{tabular}{|c|c|c|c|c|}
\hline Type & Minimal Ratio & Freq. (reference) & Freq. (research) & No \\
\hline th & 2 & 5339 & 10 & 4 \\
\hline victim & 2 & 2409 & 6 & 2 \\
\hline documentaries & 2 & 37 & 2 & 2 \\
\hline my & 1.872093 & 340082 & 161 & 11 \\
\hline human & 1.8 & 6317 & 9 & 4 \\
\hline friends & 1.75 & 15407 & 14 & 6 \\
\hline pain & 1.75 & 4941 & 7 & 2 \\
\hline others & 1.75 & 4968 & 7 & 7 \\
\hline today & 1.7 & 21851 & 17 & 8 \\
\hline social & 1.666667 & 1707 & 5 & 2 \\
\hline family & 1.666667 & 17958 & 15 & 6 \\
\hline aunt & 1.666667 & 2811 & 5 & 2 \\
\hline became & 1.666667 & 2324 & 5 & 3 \\
\hline and & 1.597484 & 670359 & 254 & 13 \\
\hline $\mathrm{am}$ & 1.578947 & 55915 & 30 & 9 \\
\hline wish & 1.571429 & 11854 & 11 & 7 \\
\hline everyone & 1.571429 & 12135 & 11 & 6 \\
\hline never & 1.521739 & 68432 & 35 & 7 \\
\hline of & 1.503597 & 580290 & 209 & 13 \\
\hline fully & 1.5 & 897 & 3 & 2 \\
\hline cruel & 1.5 & 916 & 3 & 3 \\
\hline suffer & 1.5 & 1124 & 3 & 3 \\
\hline literally & 1.5 & 719 & 3 & 2 \\
\hline entire & 1.5 & 3997 & 6 & 2 \\
\hline
\end{tabular}




\section{Appendix C: Move distribution}

\begin{tabular}{|c|c|c|c|c|c|c|c|c|c|c|c|c|c|c|c|c|}
\hline & 1 & 2 & 3 & 4 & 5 & 6 & 7 & 8 & 9 & 10 & 11 & 12 & 13 & 14 & & \\
\hline & & & & & & & & & & & & & & & Total & $\%$ \\
\hline Move 1 & $\mathrm{x}$ & $\mathrm{x}$ & $\mathrm{x}$ & $\mathrm{x}$ & & $\mathrm{x}$ & $\mathrm{x}$ & & $\mathrm{x}$ & $\mathrm{x}$ & $\mathrm{x}$ & & & $\mathrm{x}$ & 10 & 76.92 \\
\hline Move 2 & $\mathrm{x}$ & $\mathrm{x}$ & $\mathrm{x}$ & $\mathrm{x}$ & & & $\mathrm{x}$ & $\mathrm{x}$ & $\mathrm{x}$ & $\mathrm{x}$ & $\mathrm{x}$ & $\mathrm{x}$ & & $\mathrm{x}$ & 11 & 84.62 \\
\hline Move 3 & & $\mathrm{x}$ & & $\mathrm{x}$ & & $\mathrm{x}$ & & $\mathrm{x}$ & $\mathrm{x}$ & & & $\mathrm{x}$ & $\mathrm{x}$ & $\mathrm{x}$ & 8 & 61.54 \\
\hline Move 4 & $\mathrm{x}$ & & & $\mathrm{x}$ & & $\mathrm{x}$ & $\mathrm{x}$ & & $\mathrm{x}$ & & $\mathrm{x}$ & & & $\mathrm{x}$ & 7 & 53.85 \\
\hline Move 5 & $\mathrm{x}$ & $\mathrm{x}$ & $\mathrm{x}$ & $\mathrm{x}$ & & $\mathrm{x}$ & $\mathrm{x}$ & $\mathrm{x}$ & & $\mathrm{x}$ & & $\mathrm{x}$ & $\mathrm{x}$ & $\mathrm{x}$ & 11 & 84.62 \\
\hline Move 6 & $\mathrm{x}$ & $\mathrm{x}$ & $\mathrm{x}$ & $\mathrm{x}$ & & $\mathrm{x}$ & $\mathrm{x}$ & $\mathrm{x}$ & $\mathrm{x}$ & $\mathrm{x}$ & $\mathrm{x}$ & $\mathrm{x}$ & $\mathrm{x}$ & $\mathrm{x}$ & 13 & 100 \\
\hline Move 7 & & & & $\mathrm{x}$ & & $\mathrm{x}$ & $\mathrm{x}$ & & & & & & $\mathrm{x}$ & $\mathrm{x}$ & 5 & 38.46 \\
\hline Move 8 & $\mathrm{x}$ & & & $\mathrm{x}$ & & $\mathrm{x}$ & $\mathrm{x}$ & $\mathrm{x}$ & & $\mathrm{x}$ & $\mathrm{x}$ & $\mathrm{x}$ & $\mathrm{x}$ & $\mathrm{x}$ & 10 & 76.92 \\
\hline Move 9 & & & $\mathrm{x}$ & $\mathrm{x}$ & & $\mathrm{x}$ & $\mathrm{x}$ & $\mathrm{x}$ & $\mathrm{x}$ & $\mathrm{x}$ & & $\mathrm{x}$ & $\mathrm{x}$ & $\mathrm{x}$ & 10 & 76.92 \\
\hline Move 10 & & $\mathrm{x}$ & $\mathrm{x}$ & $\mathrm{x}$ & & $\mathrm{x}$ & $\mathrm{x}$ & & & $\mathrm{x}$ & & $\mathrm{x}$ & & & 7 & 53.85 \\
\hline
\end{tabular}

